\title{
Application of Inorganic Membrane Technology To Hydrogen-hydrocarbon Separations
}

June 2003

Prepared by

L. D. Trowbridge 


\title{
DOCUMENT AVAILABILITY
}

Reports produced after January 1, 1996, are generally available free via the U.S. Department of Energy (DOE) Information Bridge:

Web site: http://www.osti.gov/bridge

Reports produced before January 1, 1996, may be purchased by members of the public from the following source:

\author{
National Technical Information Service \\ 5285 Port Royal Road \\ Springfield, VA 22161 \\ Telephone: 703-605-6000 (1-800-553-6847) \\ TDD: 703-487-4639 \\ Fax: 703-605-6900 \\ E-mail: info@ntis.fedworld.gov \\ Web site: http://www.ntis.gov/support/ordernowabout.htm
}

Reports are available to DOE employees, DOE contractors, Energy Technology Data Exchange (ETDE) representatives, and International Nuclear Information System (INIS) representatives from the following source:

Office of Scientific and Technical Information

P.O. Box 62

Oak Ridge, TN 37831

Telephone: 865-576-8401

Fax: 865-576-5728

E-mail: reports@adonis.osti.gov

Web site: http://www.osti.gov/contact.html

\begin{abstract}
This report was prepared as an account of work sponsored by an agency of the United States Government. Neither the United States government nor any agency thereof, nor any of their employees, makes any warranty, express or implied, or assumes any legal liability or responsibility for the accuracy, completeness, or usefulness of any information, apparatus, product, or process disclosed, or represents that its use would not infringe privately owned rights. Reference herein to any specific commercial product, process, or service by trade name, trademark, manufacturer, or otherwise, does not necessarily constitute or imply its endorsement, recommendation, or favoring by the United States Government or any agency thereof. The views and opinions of authors expressed herein do not necessarily state or reflect those of the United States Government or any agency thereof.
\end{abstract}




\title{
APPLICATION OF INORGANIC MEMBRANE TECHNOLOGY TO HYDROGEN-HYDROCARBON SEPARATIONS
}

\author{
L. D. Trowbridge
}

Date Published: June 2003

Prepared by

OAK RIDGE NATIONAL LABORATORY

P.O. Box 2008

Oak Ridge, Tennessee 37831-6285

managed by

UT-Battelle, LLC

for the

U.S. DEPARTMENT OF ENERGY

under contract DE-AC05-00OR22725 



\section{CONTENTS}

Page

LIST OF FIGURES $\ldots \ldots \ldots \ldots \ldots \ldots \ldots \ldots \ldots \ldots \ldots \ldots \ldots \ldots \ldots \ldots \ldots \ldots$

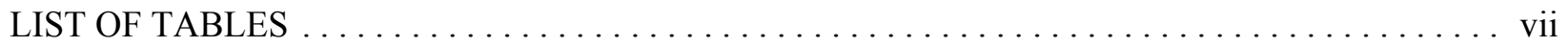

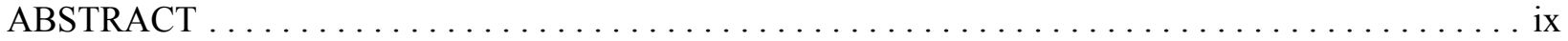

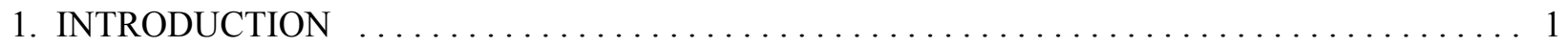

2. EXPERIMENTAL APPARATUS AND METHOD $\ldots \ldots \ldots \ldots \ldots \ldots \ldots \ldots \ldots \ldots \ldots$

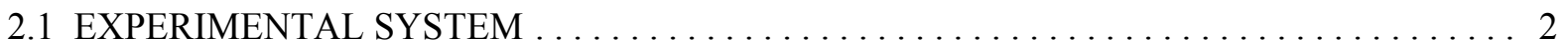

2.2 EXPERIMENTAL METHOD $\ldots \ldots \ldots \ldots \ldots \ldots \ldots \ldots \ldots \ldots \ldots \ldots \ldots \ldots \ldots$

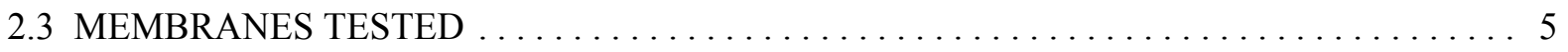

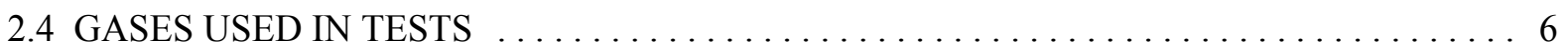

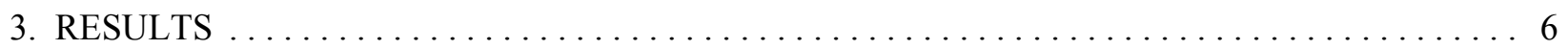

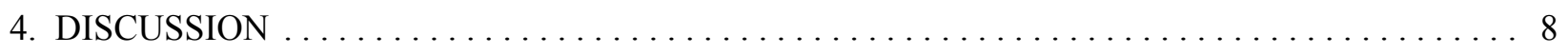

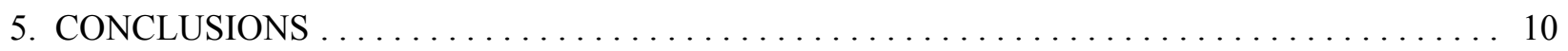

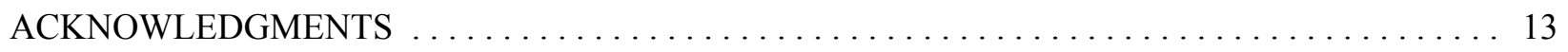

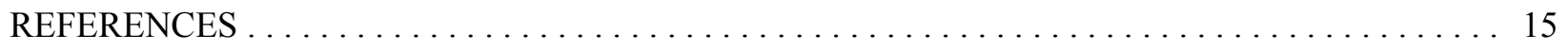

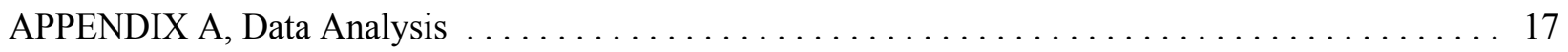

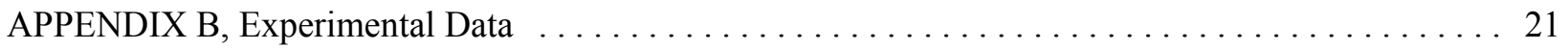





\section{LIST OF FIGURES}

Page

1 Schematic of membrane test apparatus, showing major operation elements only. ....... 3

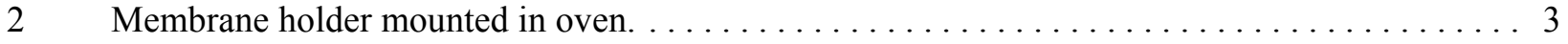

B.1 Membrane efficiency vs average pressure: Membrane 1226678-1-1, 25\% $\mathrm{CH}_{4}$ in $\mathrm{H}_{2} \ldots \ldots \ldots 46$

B.2 Membrane efficiency vs average pressure: Membrane 1226678-1-1, 25.02\% $\mathrm{C}_{2} \mathrm{H}_{6}$ in $\mathrm{H}_{2}$. . . . 46

B.3 Membrane efficiency vs average pressure: Membrane 1226678-1-1, 24.97\% $\mathrm{C}_{3} \mathrm{H}_{8}$ in $\mathrm{H}_{2} \ldots$. . . 47

B.4 Membrane efficiency vs average pressure: Membrane 1226678-1-1, 25\% $\mathrm{CO}_{2}$ in $\mathrm{He} . \ldots . .47$

B.5 Membrane efficiency vs average pressure: Membrane 1226678-1-1, 25\% Ar in He. . . . . . . 48

B.6 Membrane efficiency vs average pressure: Membrane $1230530-89,25 \% \mathrm{CH}_{4}$ in $\mathrm{H}_{2} \ldots \ldots$. . . 48

B.7 Membrane efficiency vs average pressure: Membrane 1230530-89, 25.02\% $\mathrm{C}_{2} \mathrm{H}_{6}$ in $\mathrm{H}_{2}$. . . . 49

B.8 Membrane efficiency vs average pressure: Membrane 1230530-89, 24.97\% $\mathrm{C}_{3} \mathrm{H}_{8}$ in $\mathrm{H}_{2}$. . . . 49

B.9 Membrane efficiency vs average pressure: Membrane $1230530-89,25 \% \mathrm{CO}_{2}$ in $\mathrm{He} . \ldots \ldots 50$

B.10 Membrane efficiency vs average pressure: Membrane 1230530-89, 25\% Ar in He. . . . . 50

B.11 Membrane efficiency vs average pressure: Membrane 1230530-108, 25\% $\mathrm{CH}_{4}$ in $\mathrm{H}_{2}$. . . . 51

B.12 Membrane efficiency vs average pressure: Membrane 1230530-108, 25.02\% $\mathrm{C}_{2} \mathrm{H}_{6}$ in $\mathrm{H}_{2}$. . . 51

B.13 Membrane efficiency vs average pressure: Membrane 1230530-108, 24.97\% $\mathrm{C}_{3} \mathrm{H}_{8}$ in $\mathrm{H}_{2}$. . . . 52

B.14 Membrane efficiency vs average pressure: Membrane 1230530-108, 25\% $\mathrm{CO}_{2}$ in $\mathrm{He} . \ldots \ldots 52$

B.15 Membrane efficiency vs average pressure: Membrane 1230530-108, 25\% Ar in He. . . . . . 53 



\section{LIST OF TABLES}

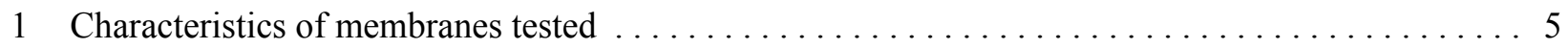

2 Experimental average membrane separation efficiency, $E_{B}$, expressed in percent $\ldots \ldots \ldots \ldots 8$

3 Parameters relevant to molecular screening and surface effects $\ldots \ldots \ldots \ldots \ldots \ldots \ldots \ldots \ldots$

A.1 Gas correction factors $\mathrm{C}$ for Hastings HFM/C-200 series units $\ldots \ldots \ldots \ldots \ldots \ldots \ldots \ldots$

B.1 Separation results for IMTL membrane 1226678-1-1: 25.00\% $\mathrm{CH}_{4}$ in $\mathrm{H}_{2} \ldots \ldots \ldots \ldots \ldots 22$

B.2 Separation results for IMTL membrane 1226678-1-1: 25.02\% $\mathrm{C}_{2} \mathrm{H}_{6}$ in $\mathrm{H}_{2} \ldots \ldots \ldots \ldots \ldots$

B.3 Separation results for IMTL membrane 1226678-1-1: 24.97\% $\mathrm{C}_{3} \mathrm{H}_{8}$ in $\mathrm{H}_{2} \ldots \ldots \ldots \ldots \ldots$

B.4 Separation results for IMTL membrane 1226678-1-1: $25 \% \mathrm{CO}_{2}$ in $\mathrm{He} \ldots \ldots \ldots \ldots \ldots \ldots$

B.5 Separation results for IMTL membrane 1226678-1-1: 25\% $\mathrm{Ar}$ in $\mathrm{He} \ldots \ldots \ldots \ldots \ldots \ldots$

B.6 Separation results for IMTL membrane 1230530-89: $25.00 \% \mathrm{CH}_{4}$ in $\mathrm{H}_{2} \ldots \ldots \ldots \ldots \ldots$

B.7 Separation results for IMTL membrane 1230530-89: 25.02\% $\mathrm{C}_{2} \mathrm{H}_{6}$ in $\mathrm{H}_{2} \ldots \ldots \ldots \ldots \ldots$

B.8 Separation results for IMTL membrane 1230530-89: 24.97\% $\mathrm{C}_{3} \mathrm{H}_{8}$ in $\mathrm{H}_{2} \ldots \ldots \ldots \ldots \ldots$

B.9 Separation results for IMTL membrane 1230530-89: $25 \% \mathrm{CO}_{2}$ in $\mathrm{He} \ldots \ldots \ldots \ldots \ldots$

B.10 Separation results for IMTL membrane 1230530-89: 25\% $\mathrm{Ar}$ in $\mathrm{He} \ldots \ldots \ldots \ldots \ldots \ldots . .42$

B.11 Separation results for IMTL membrane 1230530-108: 25.00\% $\mathrm{CH}_{4}$ in $\mathrm{H}_{2} \ldots \ldots \ldots \ldots \ldots 4$

B.12 Separation results for IMTL membrane 1230530-108: $25.02 \% \mathrm{C}_{2} \mathrm{H}_{6}$ in $\mathrm{H}_{2} \ldots \ldots \ldots \ldots$

B.13 Separation results for IMTL membrane 1230530-108: 24.97\% $\mathrm{C}_{3} \mathrm{H}_{8}$ in $\mathrm{H}_{2} \ldots \ldots \ldots \ldots \ldots$

B.14 Separation results for IMTL membrane 1230530-108: $25 \% \mathrm{CO}_{2}$ in $\mathrm{He} \ldots \ldots \ldots \ldots \ldots \ldots$

B.15 Separation results for IMTL membrane 1230530-108: 25\% $\mathrm{Ar}$ in $\mathrm{He} \ldots \ldots \ldots \ldots \ldots \ldots$ 



\begin{abstract}
Separation efficiency for hydrogen/light hydrocarbon mixtures was examined for three inorganic membranes. Five binary gas mixtures were used in this study: $\mathrm{H}_{2} / \mathrm{CH}_{4}, \mathrm{H}_{2} / \mathrm{C}_{2} \mathrm{H}_{6}, \mathrm{H}_{2} / \mathrm{C}_{3} \mathrm{H}_{8}, \mathrm{He} / \mathrm{CO}_{2}$, and $\mathrm{He} / \mathrm{Ar}$. The membranes examined were produced during a development program at the Inorganic Membrane Technology Laboratory in Oak Ridge and provided to us for this testing. One membrane was a (relatively) large-pore-diameter Knudsen membrane, and the other two had much smaller pore sizes. Observed separation efficiencies were generally lower than Knudsen separation but, for the small-pore membranes, were strongly dependent on temperature, pressure, and gas mixture, with the most condensable gases showing the strongest effect. This finding suggests that the separation is strongly influenced by surface effects (i.e., adsorption and diffusion), which enhance the transport of the heavier and more adsorption-prone component and may also physically impede flow of the other component. In one series of experiments, separation reversal was observed (the heavier component preferentially separating to the low-pressure side of the membrane). Trends showing increased separation factors at higher temperatures as well as observations of some separation efficiencies in excess of that expected for Knudsen flow suggest that at higher temperatures, molecular screening effects were observed. For most of the experiments, surface effects were stronger and thus apparently overshadow molecular sieving effects.
\end{abstract}





\section{INTRODUCTION}

In FY 2000, the Chemical Technology Division at Oak Ridge National Laboratory (ORNL) constructed a test bed for laboratory-scale evaluation of inorganic membranes designed to separate hydrogen from hydrogen/hydrocarbon gas streams. In FY 2001, a 6-month extension of this activity was funded under the Ultra-Clean Fuels Program. Then, in FY 2002, further funding was received from the U.S. Department of Energy's (DOE) National Petroleum Technology Office to continue this work. The inorganic membranes tested were prototypes developed under a different portion of the Fossil Energy Program by the Inorganic Membrane Technology Laboratory (IMTL) located at East Tennessee Technology Park (ETTP) in Oak Ridge, Tennessee. ORNL's experimental role was to test IMTL's membranes using flammable gas mixtures, initially using surrogate binary gas mixtures (e.g. $\mathrm{H}_{2}+\mathrm{CH}_{4}$ or $\mathrm{H}_{2}+\mathrm{C}_{2} \mathrm{H}_{6}$ ), and later (funding permitting) using gas mixtures generated by a laboratory-scale catalytic cracker that had been offered for this purpose by Phillips Petroleum. This report, however, discusses preliminary separation tests on synthetic binary gas mixtures.

The gas membranes tested are in the form of tubes. The test bed is intended to hold one short section of such a tube. Full-scale application will involve many longer parallel tubes. The goal of this work is to determine the capability of specialized inorganic membranes to separate hydrogen from hydrocarbon streams. Realistic gas separation measurements will yield separation factors that incorporate a number of inherent inefficiencies that can be fairly well characterized and predicted from gas transport

measurements. To be able to predict performance under conditions other than the specific ones examined experimentally, it is necessary to make the appropriate measurements that allow one to factor out these known, predictable inefficiencies in order to reveal the inherent ideal separation efficiency of the membrane.

Gas separation efficiency will be interpreted by the equation:

$$
(\alpha ! 1)=\mathrm{E}_{\mathrm{P}} \mathrm{E}_{\mathrm{M}} \mathrm{E}_{\mathrm{C}} \mathrm{E}_{\mathrm{B}}\left(\alpha^{*} ! 1\right) .
$$

In this equation, $\alpha$ is the measured separation factor, a function of the concentrations of the components in the two product streams:

$$
\alpha=[\mathrm{Y} /(1 ! \mathrm{Y})] /[\mathrm{X} /(1 ! \mathrm{X})]
$$

where $\mathrm{Y}$ is the mole fraction of the desired component flowing out the enriched stream and $\mathrm{X}$ is the mole fraction of that component flowing out from the depleted stream. In Eq. (1), $\mathrm{E}_{\mathrm{P}}$ is a back-pressure correction factor (the ratio of the pressure drop across the membrane to the high-side pressure); $\mathrm{E}_{\mathrm{M}}$ is a mixing efficiency, a function of the flow and composition-dependent gas transport parameters, such as the diffusivity and viscosity of the gases; and $\mathrm{E}_{\mathrm{C}}$ is a cut correction factor, a function of the fraction of the gas that transits the membrane. These factors will be calculated from measurable experimental parameters following the formulations presented in Ebel [Ref. 1] and Hoglund [Ref. 2]. The specific equations used for these correction factors are summarized in Appendix A.

Two variables in the above equation that have not been mentioned are $\mathrm{E}_{\mathrm{B}}$, the membrane (i.e., barrier) efficiency, and $\alpha^{*}$, the ideal separation factor. Separation relying purely on the relative velocity of gas molecules, the so-called "Knudsen flow" (from whence the term "Knudsen membrane" derives), has an $\alpha^{*}$ equal to the ratio of the average molecular velocities. A design variation on this is the "molecular sieve" membrane, which has pores sufficiently small that it relies on both the molecular velocities plus the effect of different molecular sizes to improve separation of light, small molecules over larger, heavy ones. If the pore size distribution is known, the ideal separation factor for this type of membrane can also be estimated. For these two membrane designs, $\alpha^{*}$ can be readily calculated, leaving $\mathrm{E}_{\mathrm{B}}$ as the ultimate parameter to be determined from the experiment. A third design strategy, the "surface flow" membrane, involves transport via surface adsorption, surface diffusion, and desorption of the more adsorption-prone 
component. Its ideal separation factor is not as well defined, and the experimental parameters to be determined are the combined factor " $\mathrm{E}_{\mathrm{B}}\left(\alpha^{*} ! 1\right)$." In the data presented below, $\alpha^{*}$ will be taken as the Knudsen ideal separation factor; all effects unaccounted for by $\mathrm{E}_{\mathrm{C}}, \mathrm{E}_{\mathrm{M}}$, etc., will be subsumed into $\mathrm{E}_{\mathrm{B}}$, which will be our figure of merit for the membrane.

The IMTL-designed and manufactured membranes must, due to legacy classification issues, undergo a non-proliferation review prior to commercialization. At this writing, this has been successfully done for over a dozen membrane applications. The process is, however, sufficiently time-consuming that it is not appropriate to carry out during the R\&D stage of development and consequently, R\&D activities are conducted in a secure laboratory.

\section{EXPERIMENTAL APPARATUS AND METHOD}

\subsection{EXPERIMENTAL SYSTEM}

The experimental system, largely constructed in FY 2000, was completed, tested, and utilized for separation measurements on an IMTL Knudsen membrane in FY 2001. A simplified schematic of the experimental system is shown in Fig. 1.

The system utilizes premixed binary gas mixtures for the gas inlet supply. The gases are separated in a single pass through the membrane. After measurement (of flow, composition, and pressure), the two streams are safely discarded. Figure 2 shows a photograph of a membrane holder mounted in its temperature-controlled oven. The incoming gas enters the left-hand tube; within the module, the portion of the gas that permeates the membrane departs through the central tube. The portion that does not permeate the membrane departs through the right-hand tube.

The pressure (designated "P" in Fig. 1) in each stream is monitored as is the pressure difference between the two separated streams $(\Delta \mathrm{P})$. The pressure sensors are Sensotec FP 2000 series units, with the high-pressure sensor $\left(\mathrm{P}_{\mathrm{HI}}\right)$ having a $0-250$-psia range $\left(0-17.2\right.$ bar), the low-pressure side $\left(\mathrm{P}_{\mathrm{LO}}\right)$ having a $0-100$-psia range (0-6.9 bar), and the differential sensor $(\Delta \mathrm{P})$ having a range of ! 15 to +100 psid (! 1 to +6.9 bar). These sensors are located downstream of the membrane module. Calculations of flow resistance and of the pressure drop in this system between the membrane and the pressure gauges yielded values significantly lower than the smallest measurable increment of pressure $(0.01 \mathrm{psi}$ or $7 \mathrm{mbar})$ at the highest accessible flows.

In each stream, the pressures are controlled by back-pressure regulators (designated "BPRs") located downstream of the membrane. These units are TESCOM models 44-4762-24 and 44-2363-24. The highpressure side has a $0-250$-psig (1-18.2-bar) range, and the low-pressure side has a range from vacuum to $0-100$ psia (0-6.9 bar). The total flow in the system is controlled upstream of the membrane by a flow controller (designated "FC") and measured downstream in each stream by flowmeters (designated "FM"). These units are Hastings HFM (meter) or HFC (controller) 200-series units. The input unit has a range of $0-2000 \mathrm{sccm}$ (standard $\mathrm{cm}^{3} / \mathrm{min}$ ) as does the flow sensor on the high-pressure side. The flow sensor on the low-pressure side has a range of $0-1000 \mathrm{sccm}$. All the flow units are calibrated for $\mathrm{N}_{2}$. The response of this type of mass flow meter is different for different gases and gas mixtures. Calibration factors for the gases used in this study were obtained from manufacturer literature [Ref. 3]. 


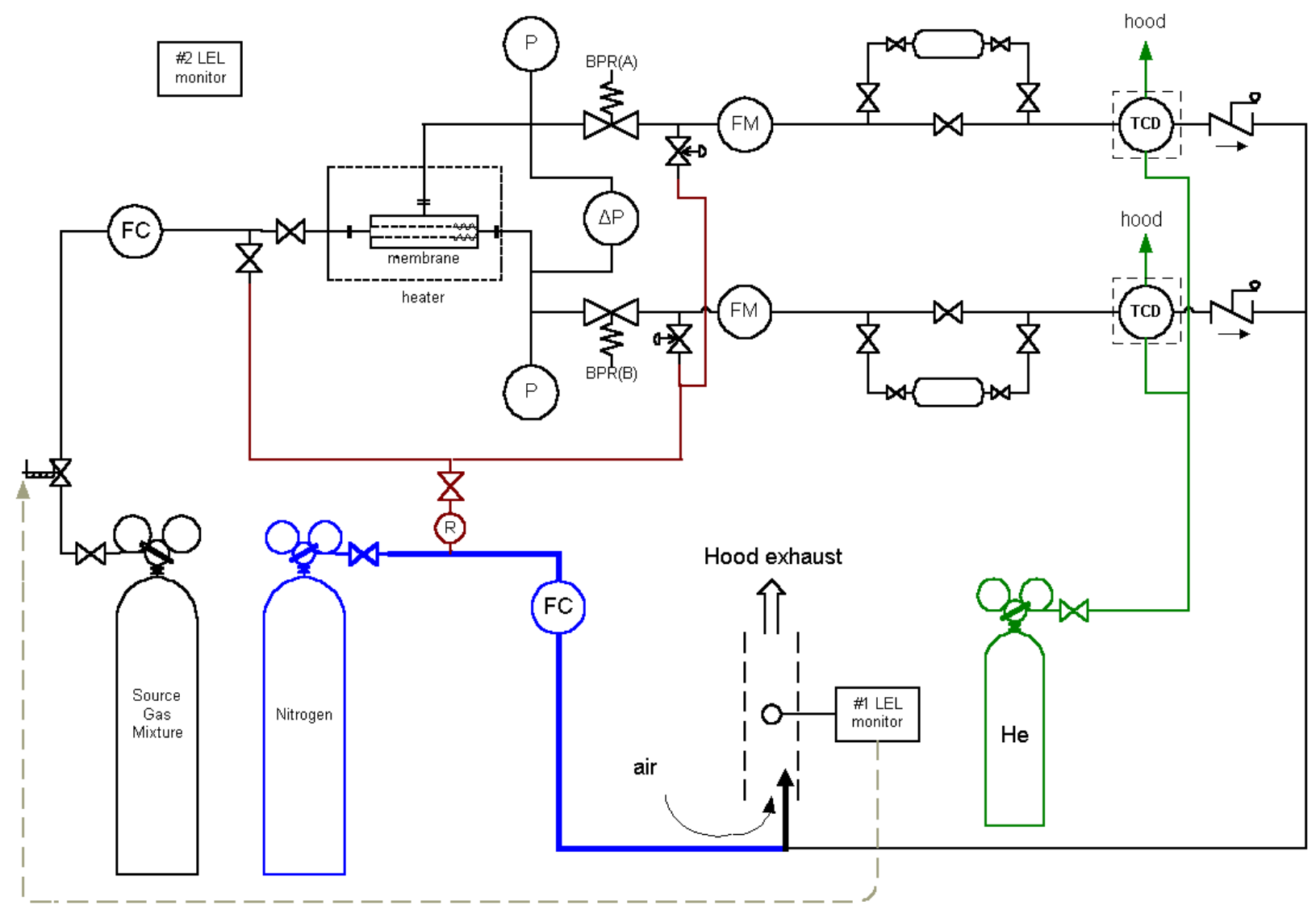

Fig. 1. Schematic of membrane test apparatus, showing major operation elements only.

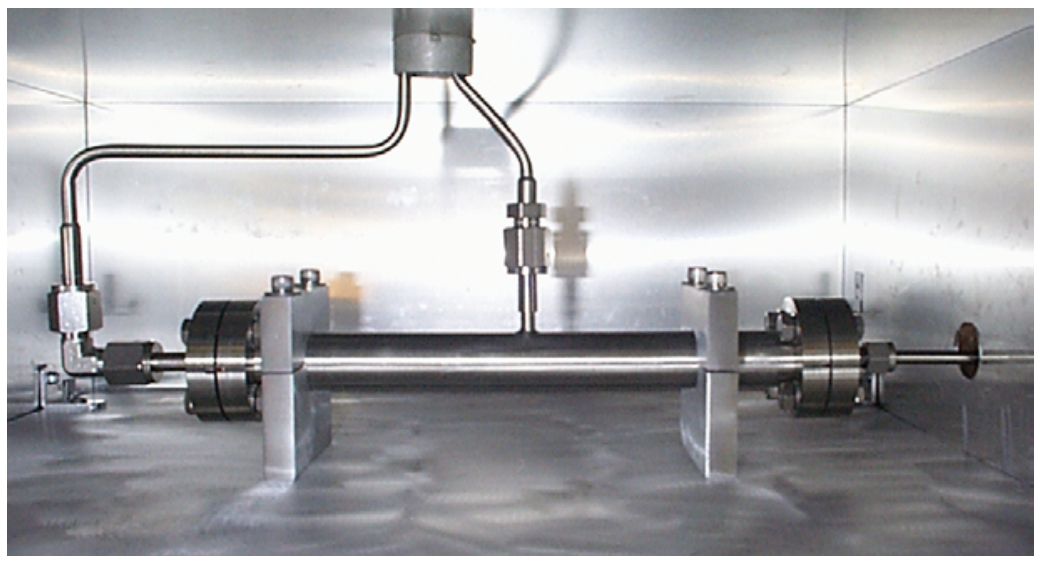

Fig. 2. Membrane holder mounted in oven. 
Each stream (or a side-stream thereof) passes through a Gowmac Series 20 thermal conductivity detector (TCD) to determine composition. These units provide a monotonic, though not quite linear, response to varying compositions of gas. The TCD units therefore were calibrated using pure gases or gas mixtures spanning the range of compositions expected in separation experiments. Typically, calibrations were performed using three compositions. For example, for an experiment in which the feed gas was $25 \% \mathrm{CH}_{4}$ and $75 \% \mathrm{H}_{2}$, the TCD signals were calibrated with 15,25 , and $50 \%$ mixtures of these two gases. Calibrated gas mixtures (both the primary feed gases and small calibration mixtures) were obtained from Air Liquide. From the response of each TCD to the three gas mixtures, a second-order composition-vs-signal curve was derived. Calibrations were usually made at the beginning and end of a series of experiments, and the composition-vs-signal parameters (which actually drifted very little during the course of a series occupying several hours) were interpolated for each measurement based on the time at which the data point was taken. For experiments that required a particularly long time to reach steady state, a single calibration was done immediately after taking the actual experimental data.

Downstream of the TCDs, the two gas streams are mixed and then diluted below the lower flammability limit with a controlled flow of nitrogen. The mix is then exhausted to the laboratory hood ventilation system. Control of the degree of dilution is set by the flow controllers on the source gas stream and the nitrogen diluent stream. To verify that the gas is indeed below the flammability limit, an LEL (lower explosion limit) device continuously monitors the exhaust stream. A second LEL device monitors the general atmosphere in the vicinity of the apparatus. Both LEL devices are MSA Ultima Gas Monitor units with combustible gas detectors.

Flow signals, pressures, temperatures, and TCD signals are measured and recorded by an on-line PC data acquisition system (DAQ; specifically an Instrunet-100 DAQ board using DasyLab version 5.03 software). The collected data acquisition files were post-processed to calculate the composition of the two gas streams. From those compositions, the raw flow readings were corrected to give the actual flows in the two streams.

During the course of an experiment, any of the data streams sent to the DAQ could be plotted in realtime on the PC. Parameters typically displayed were pressures, flows, and compositions. This was especially beneficial in determining when a particular experiment had reached steady state. Due to the finite volume of the tubing and instrumentation, a change in composition at the membrane (induced by a change in the flow, temperature, or pressures) will affect the various sensors at different times. Some time will pass before a new composition at the membrane will appear at the flowmeter, and additional time will elapse before the composition appears at the TCD. Only after the new composition has, in effect, flushed the downstream lines and instruments should the experimental data (temperature, pressure, flows, and compositions) be accepted for purposes of calculating separation performance. In computing this flushing time, one must also consider diffusion from dead-end segments of the piping and instrumentation (which are by design as short as possible). Monitoring real-time plots of flow and composition made it relatively easy to determine when it was appropriate to accept data for a given condition. This process was backed up by a utility program that used system volumes, flows, and pressures to predict the time to a steady-state condition.

\subsection{EXPERIMENTAL METHOD}

A typical experiment consists of the following steps:

1. The TCDs are calibrated.

2. The membrane holder is brought to the desired temperature.

3. A flow of diluent $\mathrm{N}_{2}$ is established that will keep the system effluent below the LEL for the mixture at the maximum feed flow contemplated. 
4. An open path is set up from the feed through the membrane and through the two TCDs.

5. Target conditions are selected (feed mixture flow, low-side and high-side pressures); the appropriate control elements (feed flowcontroller and the two BPRs) are set to achieve these conditions.

6. TCD outputs are tracked on the DAQ system computer. When the concentrations in both the high- and low-pressure sides of the membrane have stabilized, the outcome of the experiment is recorded - the time of steady state is noted and, as a backup to PC data loss, the key experimental parameters are recorded manually as well.

7. At this point, new target conditions can be selected and the process iterates through (5) and (6).

8. When all desired runs are complete, a second set of TCD calibrations is done.

\subsection{MEMBRANES TESTED}

Three separate inorganic membranes from IMTL have been tested during the course of this work. All are single tubes. The first tube (designated 1226678-1-1) was a relatively large pore membrane (average pore diameter of $4.5 \mathrm{~nm}$ ). This tube can be termed a Knudsen membrane since, at that pore size, the separative flow should be dominated by Knudsen flow (also termed "effusive" or "molecular" flow). During 2002, two additional membranes were made available for testing. These had a similar structure but were treated with TEOS (tetraethylorthosilicate) and TMA (trimethyl aluminum). Average pore diameters were closer to molecular dimensions $(0.8$ and $0.6 \mathrm{~nm})$. These characteristics are summarized in Table 1.

Table 1. Characteristics of membranes tested

\begin{tabular}{lccccc}
\hline Membrane ID & Support layer & $\begin{array}{c}\text { Separative } \\
\text { layer }\end{array}$ & $\begin{array}{c}\text { Additional } \\
\text { treatment }\end{array}$ & $\begin{array}{c}\text { Average pore } \\
\text { diam (nm) }\end{array}$ & Permeance $^{a}$ \\
\hline $1226678-1-1$ & $\mathrm{Ni}$ & $\mathrm{Al}_{2} \mathrm{O}_{3}$ & --- & 4.5 & 0.4 \\
$1230530-89$ & $\mathrm{Ni}$ & $\mathrm{Al}_{2} \mathrm{O}_{3}$ & TEOS/TMA & 0.8 & 0.01 \\
$1230530-108$ & $\mathrm{Ni}$ & $\mathrm{Al}_{2} \mathrm{O}_{3}$ & TEOS/TMA & 0.6 & 0.00012 \\
\hline
\end{tabular}

${ }^{a}$ Room-temperature $\mathrm{N}_{2}$ permeance in units of $\mathrm{sccm} /\left(\mathrm{cm} \mathrm{Hg} \mathrm{cm}^{2}\right)$ at an average pressure of 2 bar [Ref. 4]

Further information on these membranes can be found in Bischoff [Ref. 5].

On each end, the membranes used had a metal ferrule, which was sealed by a Swagelok compression fitting using a carbon fiber composite ferrule. The membrane module was assembled in a dry box at IMTL and provided (capped and filled with inert dry gas) fully assembled. Mounting in the separation system was done with minimal "open" time and with an inert gas flow issuing from the tubing being connected. After installation, an inert purge $\left(\mathrm{N}_{2}\right.$ or $\left.\mathrm{He}\right)$ was passed through the membrane for a period ranging from several hours to overnight. These measures were intended to minimize exposure to moisture from the atmosphere. 


\subsection{GASES USED IN TESTS}

Pure gases and mixtures were purchased from Air Liquide. Mixtures were certified to $0.02 \%$ absolute composition on a molar basis. The feed gases used were nominally $25 \mathrm{~mol} \%$ heavy component, $75 \%$ light component. Actual compositions of the heavy components of the several mixtures, per Air Liquide's analyses were as follows: $\mathrm{Ar}$ in $\mathrm{Ar} / \mathrm{He}: 25.00 \% ; \mathrm{CO}_{2}$ in $\mathrm{He} / \mathrm{CO}_{2}: 25.00 \% ; \mathrm{CH}_{4}$ in $\mathrm{H}_{2} / \mathrm{CH}_{4}$ : $25.00 \% ; \mathrm{C}_{2} \mathrm{H}_{6}$ in $\mathrm{H}_{2} / \mathrm{C}_{2} \mathrm{H}_{6}: 25.02 \%$; and $\mathrm{C}_{3} \mathrm{H}_{8}$ in $\mathrm{H}_{2} / \mathrm{C}_{3} \mathrm{H}_{8}: 24.97 \%$. Pure gases used for TCD reference streams $\left(\mathrm{H}_{2}\right.$ or $\left.\mathrm{He}\right)$ were $99.9997 \%$ pure.

\section{RESULTS}

In general, the same sorts of tests were conducted on all three membranes. After preliminary singlegas permeability tests confirmed that the membrane and its seals were intact after transport from IMTL and installation into the separation apparatus, separation tests were conducted using five gas mixtures $\left(\mathrm{H}_{2} / \mathrm{CH}_{4}, \mathrm{H}_{2} / \mathrm{C}_{2} \mathrm{H}_{6}, \mathrm{H}_{2} / \mathrm{C}_{3} \mathrm{H}_{8}, \mathrm{He} / \mathrm{CO}_{2}\right.$, and $\left.\mathrm{He} / \mathrm{Ar}\right)$. In all cases the gases consisted of approximately $75 \mathrm{~mol} \%$ of the light component $\left(\mathrm{He}\right.$ or $\left.\mathrm{H}_{2}\right)$ and $25 \mathrm{~mol} \%$ of the heavy component.

Experiments spanned the pressure and flow ranges accessible to the instrumentation. Because of the significant permeance differences in the three membranes (see Table 1), some differences existed between the membranes in the parameter space that could be explored. For the Knudsen membrane (1226678-1-1), flow sensor range limitations restricted some experiments (i.e., flows limited to a lower $\Delta \mathrm{P}$ than the pressure instruments would nominally allow), while for the smaller-pore membranes, the maximum readable $\Delta \mathrm{P}$ restricted the flow range of experiments. For the smallest-pore-diameter membrane (1230530-108), the minimum reliable flowmeter readings prevented measurements at low $\Delta \mathrm{P}$ and at low exhaust flow.

For each gas, experiments were run at three or four temperatures between room temperature and about $200^{\circ} \mathrm{C}$. A given series of experiments would yield as many as several dozen separation points at average pressures $(<\mathrm{P}>$, defined as the average of the high- and low-side membrane pressures), ranging from just over 1 bar to about 9 bar (absolute). The cut (the fraction of gas transiting the membrane) ranged from a low of $\sim 10 \%$ to a high of $\sim 90 \%$, though high cuts were not possible for the smallestdiameter membranes due to flowmeter range limitations. Many of the limitations on accessible flow and pressure conditions could be relieved by substitution of instrumentation of different ranges.

Accessible temperatures were limited by two factors. One was the heating system (easily modified if necessary), but the other was the membrane sealing system. The membrane must be sealed so that leakage from the high- to the low-pressure side is insignificant compared with the permeating gas flow. However, the system as a whole must also withstand thermal expansion differences as the temperature changes. The sealing system used on these membranes (essentially a compression fitting using a carbon fiber ferrule) handled these conditions satisfactorily to somewhat above $150^{\circ} \mathrm{C}$ but, in the $200^{\circ} \mathrm{C}$ range, proved to have a limited life before leaking. For the first membrane, the seal functioned in the $200^{\circ} \mathrm{C}$ range but leaked on later cooldown. For the other two membranes, the seal began leaking within a day of two of reaching the 200 to $220^{\circ} \mathrm{C}$ range. This, combined with the fact that experiments using the smallerpore membranes took a considerable time to reach steady state (many hours in the case of membrane 1230530-108), caused the number of high-temperature measurements to be limited. The R\&D that produced these sample membranes concentrated on development of membranes with favorable characteristics, and not on sealing, which is considered a tractable problem. Different sealing methods must be used to reach higher temperatures.

As previously discussed, experimental data were used to compute separation factors, which were then corrected for the known effects previously alluded to (cut, back pressure, and mixing). A membrane efficiency was then calculated. In effect, this membrane efficiency $\left(E_{B}\right)$ represents the efficiency of the membrane relative to that expected for an ideal Knudsen flow membrane. The factor $\mathrm{E}_{\mathrm{B}}$ collects all behavior not readily explained by known gas dynamic and mass balance effects. 
Listings of all relevant experimental conditions for each separation data point are included in a series of tables in Appendix B. Appendix B also contains plots of the calculated membrane efficiency $\mathrm{E}_{\mathrm{B}} \mathrm{vs}$ average pressure. These results are summarized in Table 2, which shows typical observed values of the membrane efficiency for the various gas mixtures and temperatures.

The general trends in separation efficiencies common to all three membranes are as follows:

1. At lower average pressure, the efficiency is typically higher than at higher average pressure. At higher pressures, one would expect a greater fraction of the flow to be in the nonseparative viscous flow regime. Surface flow effects should also typically be greater at higher pressures.

2. Higher temperatures tend to lead to higher separation efficiencies. This effect is markedly different for the three membranes studied. In the Knudsen membrane, the effect was evident but not large.

3. Mixtures containing more condensable gases (e.g., $\mathrm{CO}_{2}$ and $\mathrm{C}_{3} \mathrm{H}_{8}$ ) tend to have lower separation efficiencies and exhibit more of a temperature effect. This is what one would expect of a surface adsorption/flow effect.

Table 2 summarizes the separation efficiencies for the systems and temperatures examined at lower and higher average pressures and for several temperatures. Differences between the membranes can readily be seen. The Knudsen membrane (1226678-1-1) shows a moderate effect that we may attribute to surface-enhanced flow (i.e., lower separation factors, especially for the more condensable gases at lower temperatures). The effect, however, is much more evident in the data for the smaller-pore-diameter membranes. At room temperature and at the higher pressures, membrane 1230530-89 actually showed a reversal of the separation for the propane/hydrogen mixture - that is, the heavier propane preferentially separated through the membrane to the low-pressure side, contrary to normal Knudsen flow expectations. This effect diminished strongly with increasing temperature. The effect was also evident in other pressure regimes and with other gas mixtures, though to a lesser degree for the less condensable gases. A similar effect is seen for membrane 1230530-108. Due to the lower permeance of this membrane, the accessible experimental conditions did not allow measurements at the same high-pressure, low-temperature conditions at which separation reversal was observed in membrane 1230530-89.

Very small pore diameter membranes can in principle enhance separation by molecular sieving or screening. As the experimental data are presented here, this should lead to membrane efficiencies $\left(\mathrm{E}_{\mathrm{B}}\right)$ greater than $100 \%$. A modest (but reproducible) enhancement above the ideal Knudsen separation factor was seen for $\mathrm{He}-\mathrm{Ar}$ separations at higher temperatures for the two smaller-pore membranes. Membrane efficiencies $>100 \%$ were not seen for any of the $\mathrm{H}_{2} / \mathrm{HC}$ mixtures, but they were trending rapidly toward high efficiencies at the highest temperatures examined (see, for example, Figs. B.6, B.7, B.11 and B.12).

Absolute separation varies strongly with cut, but this phenomenon is accounted for by a cut correction factor $\left(E_{c}\right)$. After making that correction, separation in the Knudsen membrane (1226678-1-1) showed no further correlation with cut. Membrane 1230530-89, however, showed a significant further cut-related effect: separation efficiencies at low cut were systematically lower than those at high cuts. This effect was stronger at lower average pressures. The range of separation efficiencies for this membrane shown in Table 2 and in Figs. B.6 through B.10 is not scatter: the lower efficiency values are for lower cuts (typically 10 to $25 \%$ ), while the higher value is for high cuts (typically 75 to $90 \%$ ). Due to membrane permeance and apparatus limitations, high-cut experiments were not practical on membrane 1230530-108. Therefore, it is not known if this effect occurs in that membrane as well. 
Table 2. Experimental average membrane separation efficiency, $\mathbf{E}_{\mathbf{B}}$, expressed in percent ${ }^{a}$

\begin{tabular}{|c|c|c|c|c|c|c|c|c|c|}
\hline & \multicolumn{3}{|c|}{$1226678-1-1$} & \multicolumn{3}{|c|}{$1230530-89$} & \multicolumn{3}{|c|}{$1230530-108$} \\
\hline & \multirow[b]{2}{*}{$\mathrm{T}\left({ }^{\circ} \mathrm{C}\right)$} & \multirow{2}{*}{$\begin{array}{r}\text { Low }<\mathrm{P}> \\
\sim 1.5 \text { bar } \\
\mathrm{E}_{\mathrm{B}}\end{array}$} & \multirow{2}{*}{$\begin{array}{r}\text { High }<\mathrm{P}> \\
\sim 7 \mathrm{bar} \\
\mathrm{E}_{\mathrm{B}} \\
\end{array}$} & \multirow[b]{2}{*}{$\mathrm{T}\left({ }^{\circ} \mathrm{C}\right)$} & \multirow{2}{*}{$\begin{array}{r}\text { Low }<\mathrm{P}> \\
\sim 1.5 \text { bar } \\
\mathrm{E}_{\mathrm{B}} \\
\end{array}$} & \multirow{2}{*}{$\begin{array}{r}\text { High }<\mathrm{P}> \\
\sim 8 \text { bar } \\
\mathrm{E}_{\mathrm{B}_{3}}\end{array}$} & \multirow[b]{2}{*}{$\mathrm{T}\left({ }^{\circ} \mathrm{C}\right)$} & \multirow{2}{*}{$\begin{array}{r}\text { Low }<\text { P }> \\
\sim 4 \text { bar } \\
\mathrm{E}_{\mathrm{B}}\end{array}$} & \multirow{2}{*}{$\begin{array}{r}\text { High }<\mathrm{P}> \\
\sim 8 \text { bar } \\
\mathrm{E}_{\mathrm{B}}\end{array}$} \\
\hline & & & & & & & & & \\
\hline \multirow[t]{4}{*}{$\mathrm{H}_{2} / \mathrm{CH}_{4}$} & 23 & 78 & 63 & 19 & $50-58$ & 43 & 22 & 30 & 28 \\
\hline & 93 & 85 & 70 & 89 & $63-71$ & 56 & 92 & 40 & 35 \\
\hline & 130 & 85 & 70 & 150 & $72-82$ & 65 & 150 & 51 & 48 \\
\hline & 183 & 85 & 70 & --- & --- & --- & 210 & 88 & --- \\
\hline \multirow{4}{*}{$\mathrm{H}_{2} / \mathrm{C}_{2} \mathrm{H}_{6}$} & 24 & 75 & 55 & 23 & 24 & 13 & 22 & 22 & 17 \\
\hline & 88 & 75 & 57 & 88 & $41-46$ & 35 & 90 & 28 & 23 \\
\hline & 133 & 75 & 60 & 140 & $51-57$ & 43 & 150 & 37 & --- \\
\hline & 196 & 75 & 55 & --- & --- & --- & 210 & 63 & --- \\
\hline \multirow[t]{4}{*}{$\mathrm{H}_{2} / \mathrm{C}_{3} \mathrm{H}_{8}$} & 24 & 52 & 40 & 23 & 31 & -15 & 22 & 12 & --- \\
\hline & 90 & 60 & 50 & 88 & 29 & 18 & 90 & 21 & --- \\
\hline & 133 & 63 & 52 & 140 & $39-46$ & 34 & 150 & 33 & --- \\
\hline & 190 & 65 & 52 & 210 & 45 & --- & 202 & 53 & --- \\
\hline \multirow{4}{*}{$\mathrm{He} / \mathrm{CO}_{2}$} & 24 & 80 & 57 & 22 & 17 & 8 & 22 & 30 & 26 \\
\hline & 93 & 85 & 67 & 88 & $39-46$ & 34 & 90 & 46 & 42 \\
\hline & 130 & --- & --- & 145 & $53-64$ & 48 & 150 & 64 & 62 \\
\hline & 196 & 83 & 70 & --- & --- & --- & 210 & 93 & --- \\
\hline \multirow[t]{4}{*}{$\mathrm{He} / \mathrm{Ar}$} & 23 & 85 & 70 & 23 & $64-75$ & 55 & 22 & 39 & 35 \\
\hline & 93 & 85 & 70 & 84 & $80-96$ & 75 & 90 & 57 & 55 \\
\hline & 130 & --- & --- & 150 & $85-103$ & 75 & 150 & 85 & 81 \\
\hline & 196 & 85 & 70 & --- & --- & --- & 220 & $110-130$ & --- \\
\hline
\end{tabular}

${ }^{a}$ The value $<\mathrm{P}>$ is the average of the high- and low-side pressures of the membrane.

\section{DISCUSSION}

The results presented in this report utilize a data analysis formulation that attempts to correct for known gas dynamic and mass balance effects to elucidate underlying patterns of membrane behavior. Ultimately, this should make prediction of performance of these membranes more reliable, at least in the general realm of the experimental parameter space explored. It is recognized that the various correction factors used may not accurately represent all pertinent effects, but they do tend to collapse the experimental data to regular and recognizable patterns.

One obvious observation from these experiments is that separation efficiencies observed were on the order of that expected for Knudsen separation or even lower (i.e., $\mathrm{E}_{\mathrm{B}}<100 \%$ for most experiments). Although this performance could, of course, be expected for the Knudsen membrane, it was hoped that separation factors effectively exceeding Knudsen separation would be apparent for the small-porediameter membranes as a result of molecular screening effects. Estimated average pore diameters (Table 1) are only slightly larger than approximate molecular diameters (see Table 3 for approximate molecular diameters from viscosity data). In fact, values of $E_{B}>100 \%$ were seen for $\mathrm{He} / \mathrm{Ar}$ mixtures at 
the highest temperatures examined but not at lower temperatures, and no membrane efficiencies above $100 \%$ were observed for any of the hydrogen/hydrocarbon mixtures.

The most likely explanation for this behavior is adsorption and related surface effects. While no data were available to the author regarding adsorption on these specific membranes, some limited data were found relating to adsorption energies for several of the gases of interest on porous glass, a surface somewhat similar [Ref. 6]. Experimental desorption energies are listed in Table 3, and, assuming Langmuir adsorption behavior, estimated surface coverage is listed for two temperatures, 25 and $150^{\circ} \mathrm{C}$. In the coverage calculation, the light component is assumed to be present at 3 bar and the heavy component at 1 bar (i.e., following our feed gas 3:1 mole ratio). For a Knudsen membrane, high coverage of the heavy component would cause only a minor impediment to gas-phase transport of the light component (a reduction in the effective pore size). For the smaller membranes, however, high coverage - that is, high occupancy in the pore structure - could tend to physically impede transport of the light component. The degree of coverage says nothing directly about surface diffusion, but a moderate level of coverage would tend to enhance transport of the adsorbing species as well as inhibit transport of a relatively nonadsorbing species. This report does not address the theory of membrane transport in any detail. These coverage calculations are intended merely to illustrate the plausibility of such effects at the experimental conditions examined in this work.

The strong temperature effects seen in the small-pore membranes and the weaker effects seen in the Knudsen membrane are consistent with a significant surface adsorption and surface diffusion component in the observed separation. These effects are sufficiently strong that the mixture with the most condensable component $\left(\mathrm{H}_{2} / \mathrm{C}_{3} \mathrm{H}_{8}\right)$ showed preferential separation of the heavy component to the lowpressure side of the membrane at room temperature. Given the strong apparent surface effects, the simplest explanation for failure to observe dramatic molecular screening effects is that the latter are overshadowed by the former at the conditions examined. At higher temperatures and lower pressures, surface effects will diminish and screening effects should become more evident. Indeed for the gas mixture least prone to adsorption (He/Ar), membrane efficiencies greater than Knudsen separation were observed at the highest temperatures.

These observations have implications for future work. Given the trends in temperature (see, for example, Figs. B.6 through B.15), we would expect membrane efficiencies to improve with increasing temperature as surface effects dwindle. Since plausible operating temperatures in refinery applications are somewhat higher than the maximum we could achieve, it is likely that actual membrane efficiency would be higher than the values observed in this study.

Some additional practical implications of this work are as follows:

1. Performing surface adsorption measurements using the process gases of interest is advisable to assist in estimating the temperature regime in which to expect surface effects.

2. Multiple gas separation experiments are an important supplement to separation estimates derived from single-gas permeabilities, especially for small-pore membranes.

3. Higher-temperature experiments are required to determine the realistic separation behavior, and for this, an improved sealing system needs to be implemented. 
Table 3. Parameters relevant to molecular screening and surface effects

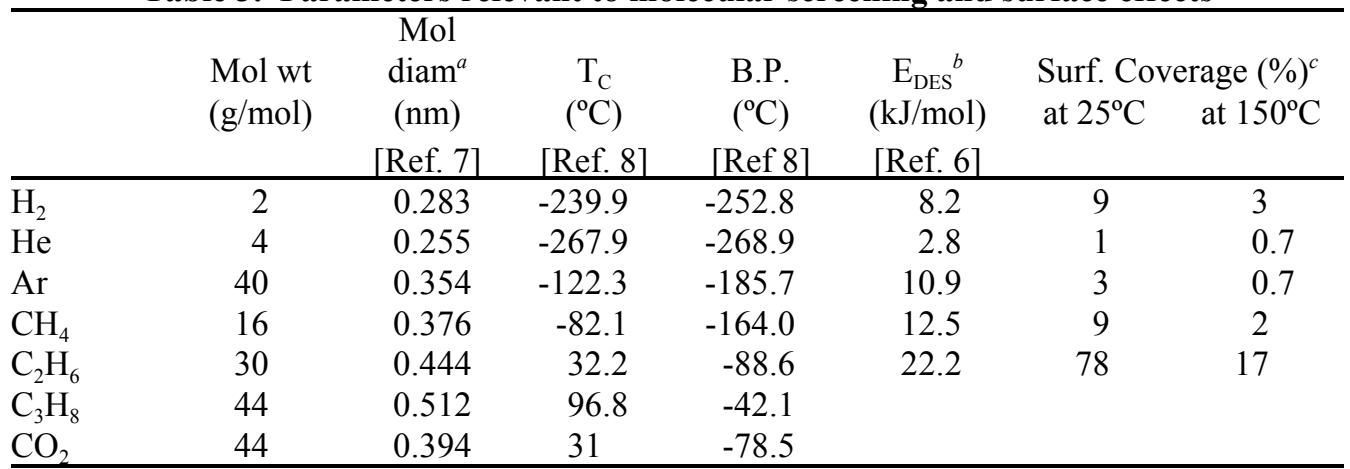

${ }^{a}$ Values listed here are the $\sigma$ parameter of the Lennard-Jones intermolecular potential function.

${ }^{b}$ Desorption energy for the indicated species on porous glass (i.e., silica)

${ }^{c}$ Estimated surface coverage assuming Langmuir isotherm behavior for indicated adsorption energy and pressure of 3 bar for light component and 1 bar for heavy component.

Bischoff [Ref. 5] recently reported results of a series of single-gas permeances $\left(\mathrm{He}, \mathrm{O}_{2}, \mathrm{CO}_{2}\right.$, and $\left.\mathrm{SF}_{6}\right)$ for one of the membranes discussed in this report (1230530-89). From those tests, permeance ratios were used to estimate the low-pressure separation factor $(\alpha$, extrapolated to average $\mathrm{P}=0)$. Bischoff's estimated value of $\alpha$ for $\mathrm{He} / \mathrm{CO}_{2}$ at $23^{\circ} \mathrm{C}$ was 1.20 , and at $250^{\circ} \mathrm{C}$, it ranged from 1.98 to 3.15. When analyzed as has been done in this work, the $\mathrm{E}_{\mathrm{B}}$ at $23^{\circ} \mathrm{C}$ would be $9 \%$ of Knudsen separation and would range from 42 to $93 \%$ at $250^{\circ} \mathrm{C}$. These results are generally in line with the binary gas separation results reported here for that membrane, though the room-temperature value is lower than was obtained in the present work. Permeability values for the other two membranes used in this study were not reported. Data were presented for several additional membranes that showed considerably higher potential selectivity than the membranes tested here [Ref. 5]. Those membranes were produced after this work was completed and unfortunately were not available for separation testing.

\section{CONCLUSIONS}

Separation efficiency for hydrogen/light hydrocarbon mixtures has been examined for three IMTLmanufactured inorganic membranes. One was a (relatively) large pore-diameter Knudsen membrane and the other two had much smaller pore sizes. In the smaller-pore membranes, separation efficiency was typically lower than Knudsen separation but strongly dependent on temperature, pressure, and gas mixture, with the most condensable gases showing the strongest effect. This finding suggests that the separation is strongly affected by surface effects (i.e., adsorption, diffusion), which enhance the transport of the heavier and more absorption-prone component and possibly also physically occlude the lighter component. In one series of experiments, separation reversal was observed (the heavier component preferentially separating to the low-pressure side of the membrane). This situation could be enhanced by judicious selection of temperatures and pressures, but the optimum conditions would be specific to the particular compounds and concentrations. Therefore, a multi-component separation would be complex.

Molecular sieving effects should enhance the permeation of smaller molecules relative to larger molecules. Separation efficiencies in excess of 100\% (ideal Knudsen flow) were observed only for $\mathrm{Ar}-\mathrm{He}$ separations. On a molecular size basis, $\mathrm{Ar} / \mathrm{He}$ was the least favorable gas mix in which to see this phenomenon. On the other hand, it was the most favorable from the standpoint of surface effects. For all the other gas mixtures, however, factors we attribute to surface effects were stronger and thus apparently overshadow molecular sieving effects. Surface effects diminish with increasing temperature, but 
temperatures at which molecular sieving could be seen for the examined hydrogen/hydrocarbon mixtures were not attained.

One overall implication of these experiments is that higher temperatures need to be explored. This would allow further elucidation of surface effects (e.g., help to determine at what temperature they become insignificant for a given gas and membrane), demonstrate the degree to which molecular sieving enhances separation, and also explore the upper limits of operation from the perspective of hydrocarbon thermal decomposition. Follow-on work in this area, should it be done, would require addressing the question of improved high-temperature seals and related questions of membrane and holder differential thermal expansion. 



\section{ACKNOWLEDGMENTS}

This research was sponsored by the U.S. Department of Energy, Office of Fossil Energy, National Petroleum Technology Office, under B\&R code DOE/FE AC1015000. Thanks are due to Dexter Sutterfield and Kathy Sterling of that office for funding the research as well as Tom Schmidt (retired) and Rod Judkins of the ORNL Fossil Energy Program for their encouragement and support. This work, of course, could not have been done without the cooperation and support of the personnel at IMTL who provided the membranes tested and offered helpful technical advice and discussions; Thanks go to Doug Fain, Bruce Marshall, Brian Bischoff, Larry Powell, and Dale Adcock for their efforts. Thanks also to Marsha Savage for editorial review of the manuscript. 



\section{REFERENCES}

1. R. A. Ebel and L. P. Pasquier, "Design of a Gaseous Diffusion Stage," Nuclear Engineering—Part XXIII, AIChE Symposium Series, 123(68), p. 107 (1972).

2. R. L. Hoglund, J. Shacter, and E. Von Halle, "Diffusion Separation Methods," pp. 639-723 in Encyclopedia of Chemical Technology, vol. 7, 3rd ed., Wiley \& Sons, New York, 1979.

3. R. Lutinsky ,Teledyne-Hastings, e-mail communication, to L. D. Trowbridge, May 3, 2001, containing a document titled "HFM 200 Nitrogen Conversion Factors," dated October 4, 2000. See also the MKS Instruments, Inc., FAQ webpage for mass flow controllers: http://www.mksinst.com/techmassflofaq.html (accessed May 21, 2001).

4. L. E. Powell, ORNL, personal communications to L. D. Trowbridge, June 20, 2001; August 30, 2002; and November 12, 2002.

5. B. L. Bischoff and R. R. Judkins, "Development of Inorganic Membranes for Hydrogen Separation," Proceedings of the 17th Annual Conference on Fossil Energy Materials, National Energy Technology Laboratory (US DOE), Baltimore, Md., April 22-24, 2003.

6. E. A. Flood, ed., The Solid-Gas Interface, Marcel Dekkar, Inc, New York, 1967, pp. 448 and 474.

7. A. H. P. Skelland, Diffusional Mass Transfer, Wiley \& Sons, New York, 1974.

8. R. C. Weast, ed., CRC Handbook of Chemistry and Physics, 65th ed., CRC Press, Boca Raton, Fla., 1984. 



\section{APPENDIX A, Data Analysis}

\section{Methods}

This appendix describes the method used for the interpretation of data from these hydrogen-hydrocarbon membrane separation experiments. Analysis of data in this study follows methodology presented by Ebel [Ref. A.1] and Hoglund [Ref. A.2]. These methods were developed for isotope separation processes (i.e., processes in which chemical differences between species do not exist and in which separation factors are relatively small). Many factors that influence separation of different chemical species cancel in an isotope separation process: individual adsorption characteristics, surface migration and cooperative effects, and molecular size, to mention a few.

The experimental separation factor, $\alpha$, for a binary mixture is defined as

$$
\alpha=\{\mathrm{Y} /(1 ! \mathrm{Y})\} /\{\mathrm{X} /(1 ! \mathrm{X})\}
$$

where $\mathrm{Y}$ is the mole fraction of the desired component in the enriched stream and $\mathrm{X}$ is the mole fraction of that component in the depleted stream. The separation factor can be related to the ideal stage separation factor in diffusion membranes by

$$
(\alpha ! 1)=\mathrm{E}_{\mathrm{B}} \mathrm{E}_{\mathrm{P}} \mathrm{E}_{\mathrm{M}} \mathrm{E}_{\mathrm{C}}\left(\alpha^{*} ! 1\right),
$$

where

$\alpha$ is the measured separation factor,

$\alpha^{*}$ is the ideal separation factor,

$\mathrm{E}_{\mathrm{B}}$ is the barrier efficiency,

$\mathrm{E}_{\mathrm{P}}$ is the back-pressure correction,

$\mathrm{E}_{\mathrm{M}}$ is the mixing efficiency,

$\mathrm{E}_{\mathrm{C}}$ is the cut correction factor.

The variables $\mathrm{E}_{\mathrm{P}}, \mathrm{E}_{\mathrm{M}}$, and $\mathrm{E}_{\mathrm{C}}$ correct for parameters related to gas dynamics and mass balance, and are readily calculated. Formulae for these correction factors are discussed below. The barrier efficiency, $\mathrm{E}_{\mathrm{B}}$, can be determined only if we know the ideal separation factor. For a Knudsen membrane, the ideal separation factor is the simply the ratio of the molecular velocities, proportional to the ratio of the square root of the molecular weights of the two species. Molecular sieve effects can be estimated from geometric considerations of the relative size of the two molecules and pore diameters and this can be modified for the effect of molecular diameters for a molecular sieve design. For a surface flow membrane, we will not know a priori the ideal separation factor. In practice, all factors that cannot be accounted for by $E_{P}, E_{M}$, and $E_{C}$ will be subsumed into the factor $E_{B}$. 


\section{Correction Factors}

The back-pressure correction factor, $\mathrm{E}_{\mathrm{p}}$, corrects for the fact that mass flow can pass both from the high-pressure side to the low-pressure side and from the low-pressure side to the high. The formula for the back-pressure correction is

$$
\left.\mathrm{E}_{\mathrm{P}}=1 ! \mathrm{P}_{\mathrm{LO}} / \mathrm{P}_{\mathrm{HI}}=\right) \mathrm{P} / \mathrm{P}_{\mathrm{HI}} \text {. }
$$

This is most easily understood for Knudsen flow, since (by definition) gas molecules move independently and thus can as readily move through the membrane in either direction. When there is a finite low-side pressure, the effective separation is of necessity degraded, since some of the (enriched) gas on the low-pressure side will return to the high side.

The cut correction factor, $\mathrm{E}_{\mathrm{C}}$, corrects for the fact that gas, as it travels down the tube, is stripped more and more of the preferentially separated component. This effect is related to the $c u t, \Theta$, which is fraction of the (molar) feed that permeates the membrane. The formula is

$$
\mathrm{E}_{\mathrm{C}}=1 / \Theta \text { (d) }[1 /(1 ! \Theta)] \text {. }
$$

As written, this correction factor has a value greater than one. It can account for raw separation factors greater than ideal separation factors.

The mixing efficiency, $\mathrm{E}_{\mathrm{M}}$, is an effect that relates to depletion species that preferentially permeates the wall of the membrane. It is a gas transport phenomenon and can be calculated for this membrane separation. The calculation used here [Refs. A.1 and A.2], depends on the assumption of fully developed viscous flow in a tube and would not be valid if other factors intervene. As formulated here, it relates to the diffusional mixing in the high-pressure side of the membrane but does not take into account similar effects in the low-pressure side of the membrane. Since separation along the membrane tube potentially can be fairly high, there is a possibility that effects other than pure laminar flow will apply (e.g., densitydriven convection). For our purposes, we will use the mixing efficiency correction as presented in by Ebel [Ref. A.1], recognizing that it is an approximation. Ebel gives the following formula for mixing efficiency:

$$
\mathrm{E}_{\mathrm{M}}=\exp ![(2 / \mathrm{f})(\mu / \mathrm{D} \rho)(\mathrm{v} / \mathrm{V})]
$$

where

$$
\begin{aligned}
& \mathrm{f}=\text { Fanning friction factor, } \\
& \mu=\text { viscosity }, \\
& \mathrm{D}=\text { diffusivity }, \\
& \rho=\text { mass density } \\
& \mathrm{v}=\text { average velocity of gas toward tube wall, } \\
& \mathrm{V}=\text { average gas velocity along the tube. }
\end{aligned}
$$


The value " $\mu$ / D- $\rho$ " is also known as the Schmidt number for the gas. The Fanning friction factor, $f$, is related to the Reynolds number, $\mathrm{N}_{\text {rey }}$. For gases, when $\mathrm{N}_{\text {rey }}<2100$, as applied in essentially all experiments here [Ref. A.3],

$$
\mathrm{f}=16 / \mathrm{N}_{\text {rey }} \text {. }
$$

Values for D and $\mu$ can be calculated for the gases of interest from molecular dynamics theory. The methods and formulae used are standard and repeated in many references. The details are too lengthy to repeat here, but we follow the method presented in Hirschfelder, Curtis, and Bird [Ref. A.4: p.528 for viscosity of single-component gases and binary mixtures; p.539 for binary diffusivity].

\section{Data Analysis}

Raw data obtained from a separation experiment consisted of the temperature; the feed flow reading; and, for both the high-pressure and low-pressure gas streams, a flowmeter reading and a thermal conductivity detector (TCD) reading.

TCD readings for gas samples of known composition were recorded before and after a series of separation experiments. Typically three compositions were used for this purpose: one being the feed gas mixture and the other two spanning a wider range of compositions than the expected experimental gas streams after separation. A second-order polynomial fit of TCD reading vs composition was derived from each set of three calibration data points. The polynomial fit parameters derived from calibration readings before and after the actual separation experiments may vary slightly. The fit parameters were assumed to change linearly in time from "before" to "after," and a specific calibration function was interpolated to the recorded time of each separation experiment reading. This calibration function was used to calculate the composition of the gas mixture. This process was performed for each gas stream (i.e., deriving from the high-pressure or low-pressure side of the membrane) and each recorded separation experiment.

Once the compositions of the two streams for a given experiment were known, the experimental separation factor, $\alpha$, was calculated per Eq. (A.1).

The thermal mass flowmeters exhibit differing sensitivities to different gases. For pure gases, the manufacturer has tabulated correction factors that enable one to correct the readings of an instrument calibrated for (as in this case) $\mathrm{N}_{2}$ for another gas (e.g., He). Single-gas correction factors are listed in Table A-1.

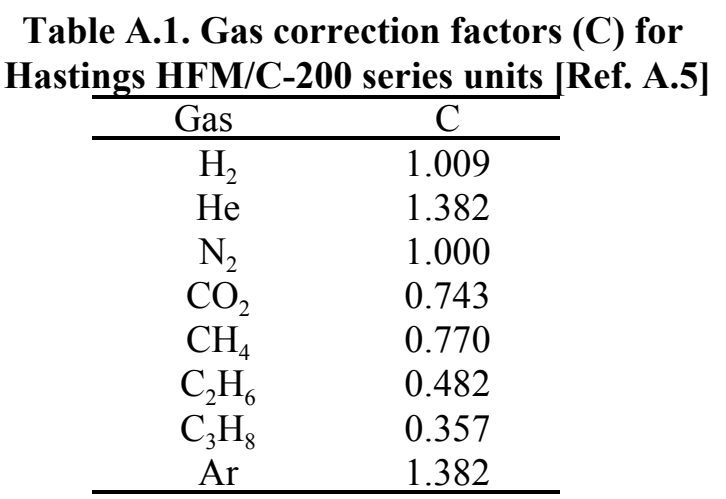

The correction factor for a binary gas mixture is given by

$$
\mathrm{C}_{1,2}=\left(\mathrm{X}_{1} / \mathrm{C}_{1}+\mathrm{X}_{2} / \mathrm{C}_{2}\right)^{-1}
$$

where $\mathrm{C}_{1,2}$ is the correction factor for the mixture consisting of mole fraction $\mathrm{X}_{1}$ of gas 1 and mole fraction $\mathrm{X}_{2}$ of gas 2 , and $\mathrm{C}_{1}$ and $\mathrm{C}_{2}$ are the corresponding single-gas correction factors. Applying these 
correction factors to the (known) feed composition and the measured high- and low-pressure stream compositions, the true flows are calculated from the indicated readings.

Pressure readings are taken from the low-pressure transducer and the $\Delta \mathrm{P}$ transducer. The temperature readings are taken directly form the instrumentation.

With these data, it is now possible to calculate the various correction factors: $\mathrm{E}_{\mathrm{P}}, \mathrm{E}_{\mathrm{M}}$, and $\mathrm{E}_{\mathrm{C}}$, as described above. For purposes of this work, the ideal separation factor, $\alpha^{*}$, is simply taken as the ideal Knudsen separation factor, namely

$$
\alpha^{*}=\left(M_{2} / M_{1}\right)^{1 / 2}
$$

While it would be possible to estimate screening effects, that is, differences in transmission probability due to differing sizes of molecules, membrane-to-membrane comparisons are more readily made using the simpler Knudsen factor for all three membranes.

From the correction factors, experimental separation factor, and ideal separation factor, the membrane efficiency, $E_{B}$, is calculated using Eq. (A.2). In effect, $E_{B}$ contains all non-Knudsen effects, be they surface flow, molecular screening, physical leaks, viscous flow, or inadequacy of approximations made in the correction factor formulations. Still, it is useful to utilize the various correction factors, since the raw separation factors vary widely, whereas $\mathrm{E}_{\mathrm{B}}$ shows trends and patterns much more conducive to direct interpretation of data or, more importantly, prediction of membrane behavior under different conditions.

\section{References for Appendix A}

A.1. R. A. Ebel and L. P. Pasquier, "Design of a Gaseous Diffusion Stage," Nuclear Engineering-Part XXIII, AIChE Symposium Series, 123(68), p. 107 (1972).

A.2. R. L. Hoglund, J. Shacter, and E. Von Halle, "Diffusion Separation Methods," pp. 639-723 in Encyclopedia of Chemical Technology, vol. 7, 3rd ed., Wiley \& Sons, New York, 1979.

A.3. J. H. Perry, Chemical Engineers Handbook, 3rd ed, McGraw-Hill, New York, 1950.

A.4. J. O. Hirschfelder, C. F. Curtis, and R. B. Bird, Molecular Theory of Gases and Liquids, Wiley \& Sons, New York, 1954.

A.5. R. Lutinsky, Teledyne-Hastings, e-mail communication, to L. D. Trowbridge, May 3, 2001, containing a document titled "HFM 200 Nitrogen Conversion Factors," dated October 4, 2000.

See also the MKS Instruments, Inc., FAQ webpage for mass flow controllers: http://www.mksinst.com/techmassflofaq.html (accessed May 21, 2001). 


\section{APPENDIX B, Experimental Data}

Tables B.1 through B.15 contain experimental data and the results derived from that data, which are also plotted in Figs. B.1 through B.15. Pressures and temperatures are taken from the data acquisition (DAQ) record of the instrument readings (unit-converted to bars in the case of pressure). Flows are converted from the flowmeter readings per the composition-related scaling discussed in Appendix A. Concentrations are interpreted from the thermal conductivity detector (TCD) readings of the separated streams and of calibration gases. The observed separation factor and the several correction factors are then calculated from these experimental data per the methods in Appendix A. The final result is the membrane efficiency, $\mathrm{E}_{\mathrm{B}}$, expressing the separation performance relative to that expected for perfect Knudsen separation (for which $\mathrm{E}_{\mathrm{B}}=1$ ). 
Table B.1. Separation results for IMTL membrane 1226678-1-1: $25.00 \% \mathrm{CH}_{4}$ in $\mathrm{H}_{2}$

\begin{tabular}{|c|c|c|c|c|c|c|c|c|c|c|c|}
\hline $\begin{array}{c}\mathrm{T} \\
\left({ }^{\circ} \mathrm{C}\right) \\
\end{array}$ & $\begin{array}{c}\mathrm{P}_{\mathrm{LO}} \\
\text { (bar) }\end{array}$ & $\begin{array}{c}\mathrm{dP} \\
\text { (bar) }\end{array}$ & $\begin{array}{c}\mathrm{F}_{\mathrm{LO}} \\
(\mathrm{sccm})\end{array}$ & $\begin{array}{c}\mathrm{F}_{\mathrm{HI}} \\
(\mathrm{sccm})\end{array}$ & $\begin{array}{c}\mathrm{X}_{\mathrm{LO}} \\
(\mathrm{mol} \% \mathrm{hvy})\end{array}$ & $\begin{array}{c}\mathrm{X}_{\mathrm{HI}} \\
\text { (mol \% hvy) }\end{array}$ & $\alpha$ & $\mathrm{E}_{\mathrm{P}}$ & $\mathrm{E}_{\mathrm{C}}$ & $\mathrm{E}_{\mathrm{M}}$ & $\mathrm{E}_{\mathrm{B}}$ \\
\hline 23.5 & 6.842 & 1.085 & 850.0 & 255.8 & $0.24 \%$ & $0.28 \%$ & 1.226 & 0.137 & 1.904 & 0.825 & 0.575 \\
\hline 23.5 & 4.254 & 1.060 & 805.1 & 299.0 & $0.23 \%$ & $0.29 \%$ & 1.323 & 0.199 & 1.792 & 0.833 & 0.593 \\
\hline 23.5 & 3.063 & 0.410 & 308.6 & 803.2 & $0.23 \%$ & $0.25 \%$ & 1.137 & 0.118 & 1.171 & 0.932 & 0.583 \\
\hline 23.4 & 2.736 & 0.736 & 554.0 & 556.5 & $0.22 \%$ & $0.27 \%$ & 1.295 & 0.212 & 1.385 & 0.882 & 0.623 \\
\hline 23.4 & 2.327 & 1.124 & 830.3 & 272.7 & $0.23 \%$ & $0.31 \%$ & 1.577 & 0.326 & 1.856 & 0.828 & 0.630 \\
\hline 23.4 & 1.822 & 0.367 & 271.4 & 839.9 & $0.22 \%$ & $0.25 \%$ & 1.209 & 0.168 & 1.147 & 0.940 & 0.633 \\
\hline 23.5 & 1.477 & 0.702 & 521.8 & 589.4 & $0.21 \%$ & $0.28 \%$ & 1.474 & 0.322 & 1.350 & 0.888 & 0.670 \\
\hline 23.5 & 1.108 & 1.052 & 770.4 & 335.2 & $0.21 \%$ & $0.33 \%$ & 1.883 & 0.487 & 1.713 & 0.840 & 0.689 \\
\hline 23.5 & 1.034 & 1.110 & 808.8 & 295.3 & $0.21 \%$ & $0.35 \%$ & 1.987 & 0.518 & 1.800 & 0.832 & 0.696 \\
\hline 23.5 & 1.017 & 0.713 & 519.8 & 212.7 & $0.21 \%$ & $0.33 \%$ & 1.810 & 0.412 & 1.743 & 0.889 & 0.694 \\
\hline 23.5 & 1.000 & 0.348 & 254.1 & 478.2 & $0.21 \%$ & $0.27 \%$ & 1.374 & 0.258 & 1.228 & 0.944 & 0.684 \\
\hline 23.5 & 1.000 & 0.325 & 235.4 & 219.9 & $0.22 \%$ & $0.28 \%$ & 1.394 & 0.245 & 1.408 & 0.948 & 0.658 \\
\hline 23.5 & 0.999 & 0.310 & 221.0 & 88.4 & $0.23 \%$ & $0.30 \%$ & 1.438 & 0.237 & 1.754 & 0.951 & 0.607 \\
\hline 23.6 & 2.059 & 0.320 & 234.2 & 220.6 & $0.23 \%$ & $0.26 \%$ & 1.197 & 0.135 & 1.405 & 0.948 & 0.601 \\
\hline 23.6 & 2.056 & 0.336 & 248.1 & 489.2 & $0.23 \%$ & $0.26 \%$ & 1.186 & 0.141 & 1.219 & 0.945 & 0.629 \\
\hline 23.6 & 2.032 & 0.711 & 524.5 & 212.2 & $0.23 \%$ & $0.30 \%$ & 1.476 & 0.259 & 1.748 & 0.888 & 0.647 \\
\hline 23.6 & 2.032 & 0.694 & 508.8 & 129.4 & $0.23 \%$ & $0.31 \%$ & 1.531 & 0.255 & 2.002 & 0.891 & 0.640 \\
\hline 23.7 & 4.274 & 0.683 & 519.1 & 216.6 & $0.24 \%$ & $0.28 \%$ & 1.238 & 0.138 & 1.733 & 0.889 & 0.613 \\
\hline 23.7 & 6.773 & 0.718 & 564.7 & 166.9 & $0.24 \%$ & $0.27 \%$ & 1.175 & 0.096 & 1.915 & 0.880 & 0.593 \\
\hline 23.5 & 1.022 & 1.203 & 901.9 & 885.7 & $0.19 \%$ & $0.30 \%$ & 1.781 & 0.541 & 1.392 & 0.815 & 0.696 \\
\hline 23.6 & 1.018 & 1.143 & 819.9 & 145.4 & $0.22 \%$ & $0.40 \%$ & 2.309 & 0.529 & 2.229 & 0.830 & 0.731 \\
\hline 23.5 & 1.017 & 1.124 & 799.0 & 82.3 & $0.23 \%$ & $0.43 \%$ & 2.529 & 0.525 & 2.615 & 0.834 & 0.730 \\
\hline 24.3 & 1.047 & 1.142 & 744.8 & 219.6 & $0.21 \%$ & $0.37 \%$ & 2.203 & 0.522 & 1.916 & 0.845 & 0.779 \\
\hline 24.3 & 1.050 & 1.170 & 788.9 & 1088.2 & $0.19 \%$ & $0.29 \%$ & 1.779 & 0.527 & 1.297 & 0.837 & 0.745 \\
\hline 24.3 & 1.679 & 0.571 & 386.6 & 1495.2 & $0.21 \%$ & $0.26 \%$ & 1.363 & 0.254 & 1.119 & 0.916 & 0.764 \\
\hline 24.4 & 4.313 & 0.984 & 682.5 & 429.9 & $0.23 \%$ & $0.28 \%$ & 1.302 & 0.186 & 1.550 & 0.857 & 0.669 \\
\hline 96.0 & 0.999 & 0.369 & 225.2 & 229.2 & $0.21 \%$ & $0.29 \%$ & 1.502 & 0.270 & 1.381 & 0.957 & 0.770 \\
\hline 95.2 & 0.999 & 0.411 & 254.1 & 477.6 & $20.16 \%$ & $27.43 \%$ & 1.497 & 0.291 & 1.228 & 0.952 & 0.799 \\
\hline 94.1 & 1.000 & 0.425 & 265.8 & 848.6 & $19.62 \%$ & $26.57 \%$ & 1.482 & 0.298 & 1.142 & 0.949 & 0.815 \\
\hline 92.9 & 1.000 & 0.423 & 293.5 & 1567.6 & $19.06 \%$ & $26.02 \%$ & 1.493 & 0.297 & 1.088 & 0.944 & 0.883 \\
\hline
\end{tabular}


Table B.1. Separation results for IMTL membrane 1226678-1-1: $25.00 \% \mathrm{CH}_{4}$ in $\mathrm{H}_{2}$

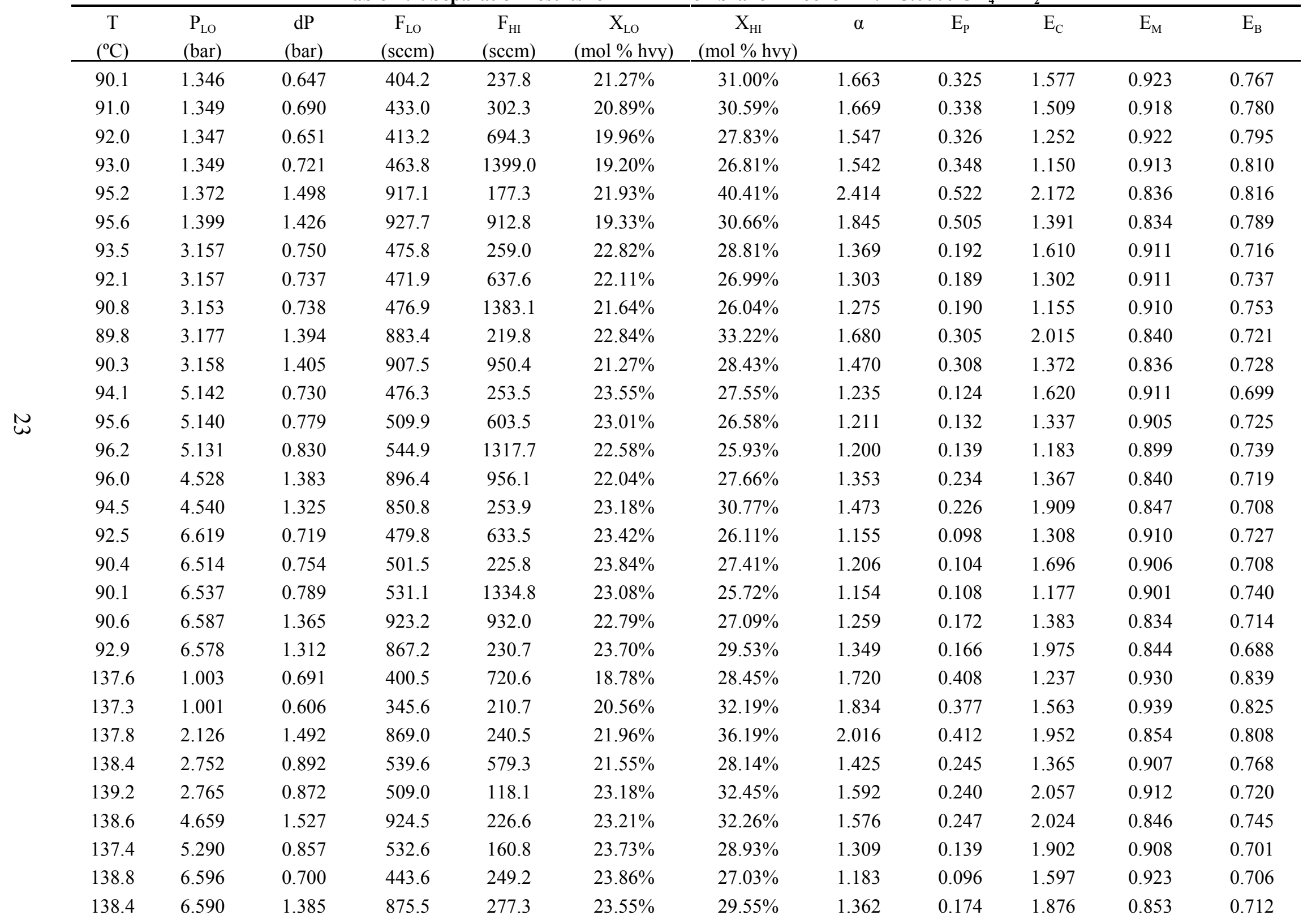


Table B.1. Separation results for IMTL membrane 1226678-1-1: $25.00 \% \mathrm{CH}_{4}$ in $\mathrm{H}_{2}$

\begin{tabular}{|c|c|c|c|c|c|c|c|c|c|c|c|}
\hline $\begin{array}{c}\mathrm{T} \\
\left({ }^{\circ} \mathrm{C}\right) \\
\end{array}$ & $\begin{array}{c}\mathrm{P}_{\mathrm{LO}} \\
\text { (bar) }\end{array}$ & $\begin{array}{c}\mathrm{dP} \\
\text { (bar) }\end{array}$ & $\begin{array}{c}\mathrm{F}_{\mathrm{LO}} \\
(\mathrm{sccm})\end{array}$ & $\begin{array}{c}\mathrm{F}_{\mathrm{HI}} \\
(\mathrm{sccm})\end{array}$ & $\begin{array}{c}\mathrm{X}_{\mathrm{LO}} \\
(\mathrm{mol} \% \mathrm{hvy})\end{array}$ & $\begin{array}{c}\mathrm{X}_{\mathrm{HI}} \\
\text { (mol \% hvy) }\end{array}$ & $\alpha$ & $\mathrm{E}_{\mathrm{P}}$ & $\mathrm{E}_{\mathrm{C}}$ & $\mathrm{E}_{\mathrm{M}}$ & $\mathrm{E}_{\mathrm{B}}$ \\
\hline 179.2 & 1.019 & 0.610 & 418.1 & 139.3 & $21.55 \%$ & $34.79 \%$ & 1.942 & 0.374 & 1.849 & 0.931 & 0.799 \\
\hline 180.9 & 1.171 & 1.222 & 869.0 & 241.6 & $20.99 \%$ & $38.84 \%$ & 2.391 & 0.511 & 1.950 & 0.863 & 0.885 \\
\hline 182.1 & 2.422 & 1.283 & 923.8 & 185.5 & $22.55 \%$ & $35.83 \%$ & 1.917 & 0.346 & 2.148 & 0.855 & 0.789 \\
\hline 182.7 & 3.168 & 0.596 & 441.6 & 677.2 & $22.21 \%$ & $26.36 \%$ & 1.253 & 0.158 & 1.272 & 0.928 & 0.742 \\
\hline 183.4 & 3.171 & 0.547 & 403.2 & 190.2 & $23.10 \%$ & $27.95 \%$ & 1.292 & 0.147 & 1.674 & 0.934 & 0.693 \\
\hline 184.5 & 4.601 & 0.522 & 391.6 & 200.8 & $23.52 \%$ & $26.88 \%$ & 1.195 & 0.102 & 1.637 & 0.936 & 0.683 \\
\hline 185.2 & 4.606 & 0.527 & 398.6 & 726.7 & $22.93 \%$ & $25.60 \%$ & 1.156 & 0.103 & 1.235 & 0.935 & 0.721 \\
\hline 185.7 & 4.619 & 1.150 & 862.6 & 256.1 & $23.05 \%$ & $30.03 \%$ & 1.433 & 0.199 & 1.912 & 0.865 & 0.718 \\
\hline 186.4 & 6.646 & 0.508 & 395.7 & 730.1 & $23.37 \%$ & $25.29 \%$ & 1.110 & 0.071 & 1.232 & 0.936 & 0.733 \\
\hline 186.9 & 6.650 & 0.485 & 375.5 & 218.2 & $23.74 \%$ & $25.96 \%$ & 1.127 & 0.068 & 1.583 & 0.939 & 0.685 \\
\hline 187.3 & 6.656 & 1.037 & 796.4 & 314.6 & $23.35 \%$ & $27.83 \%$ & 1.266 & 0.135 & 1.760 & 0.875 & 0.701 \\
\hline
\end{tabular}


Table B.2. Separation results for IMTL membrane 1226678-1-1: $25.02 \% \mathrm{C}_{2} \mathrm{H}_{6}$ in $\mathrm{H}_{2}$

\begin{tabular}{|c|c|c|c|c|c|c|c|c|c|c|c|}
\hline $\begin{array}{c}\mathrm{T} \\
\left({ }^{\circ} \mathrm{C}\right) \\
\end{array}$ & $\begin{array}{c}\mathrm{P}_{\mathrm{LO}} \\
\text { (bar) }\end{array}$ & $\begin{array}{c}\mathrm{dP} \\
\text { (bar) }\end{array}$ & $\begin{array}{c}\mathrm{F}_{\mathrm{LO}} \\
(\mathrm{sccm})\end{array}$ & $\begin{array}{c}\mathrm{F}_{\mathrm{HI}} \\
(\mathrm{sccm}) \\
\end{array}$ & $\begin{array}{c}\mathrm{X}_{\mathrm{LO}} \\
(\mathrm{mol} \% \mathrm{hvy})\end{array}$ & $\begin{array}{c}\mathrm{X}_{\mathrm{HI}} \\
\text { (mol \% hvy) }\end{array}$ & $\alpha$ & $\mathrm{E}_{\mathrm{P}}$ & $\mathrm{E}_{\mathrm{C}}$ & $\mathrm{E}_{\mathrm{M}}$ & $\mathrm{E}_{\mathrm{B}}$ \\
\hline 23.1 & 6.871 & 0.522 & 331.3 & 353.0 & $23.81 \%$ & $26.17 \%$ & 1.135 & 0.071 & 1.367 & 0.908 & 0.535 \\
\hline 23.1 & 6.876 & 0.535 & 341.5 & 755.0 & $23.48 \%$ & $25.66 \%$ & 1.125 & 0.072 & 1.198 & 0.905 & 0.555 \\
\hline 23.1 & 6.204 & 1.178 & 740.7 & 351.0 & $23.27 \%$ & $28.54 \%$ & 1.318 & 0.160 & 1.672 & 0.805 & 0.514 \\
\hline 23.1 & 4.246 & 0.512 & 313.7 & 196.1 & $23.44 \%$ & $27.50 \%$ & 1.239 & 0.108 & 1.553 & 0.912 & 0.546 \\
\hline 23.1 & 4.248 & 0.481 & 296.8 & 480.4 & $22.92 \%$ & $26.20 \%$ & 1.194 & 0.102 & 1.260 & 0.917 & 0.573 \\
\hline 23.1 & 3.443 & 1.288 & 777.1 & 150.9 & $23.23 \%$ & $33.84 \%$ & 1.691 & 0.272 & 2.169 & 0.797 & 0.511 \\
\hline 23.2 & 2.861 & 0.221 & 131.5 & 799.9 & $23.14 \%$ & $25.26 \%$ & 1.123 & 0.072 & 1.078 & 0.962 & 0.575 \\
\hline 23.2 & 1.746 & 1.269 & 755.6 & 172.1 & $22.00 \%$ & $38.20 \%$ & 2.191 & 0.421 & 2.068 & 0.802 & 0.594 \\
\hline 23.2 & 2.460 & 0.615 & 377.4 & 554.4 & $21.34 \%$ & $27.43 \%$ & 1.393 & 0.200 & 1.282 & 0.895 & 0.596 \\
\hline 23.2 & 2.451 & 0.563 & 337.0 & 127.8 & $22.77 \%$ & $30.83 \%$ & 1.512 & 0.187 & 1.781 & 0.906 & 0.591 \\
\hline 23.2 & 1.038 & 0.541 & 322.7 & 141.6 & $20.83 \%$ & $34.54 \%$ & 2.005 & 0.342 & 1.709 & 0.910 & 0.657 \\
\hline 23.3 & 1.047 & 0.655 & 406.2 & 529.7 & $18.79 \%$ & $29.85 \%$ & 1.839 & 0.385 & 1.311 & 0.888 & 0.651 \\
\hline 23.2 & 1.331 & 0.387 & 234.7 & 701.4 & $20.11 \%$ & $26.63 \%$ & 1.442 & 0.225 & 1.151 & 0.934 & 0.636 \\
\hline 23.2 & 1.080 & 1.234 & 736.3 & 196.2 & $20.89 \%$ & $40.65 \%$ & 2.593 & 0.533 & 1.974 & 0.806 & 0.654 \\
\hline 86.4 & 1.062 & 0.690 & 336.3 & 126.3 & $20.36 \%$ & $37.48 \%$ & 2.345 & 0.394 & 1.786 & 0.918 & 0.725 \\
\hline 86.9 & 1.064 & 0.724 & 345.7 & 424.9 & $18.28 \%$ & $30.58 \%$ & 1.968 & 0.405 & 1.327 & 0.916 & 0.685 \\
\hline 87.7 & 1.084 & 1.130 & 560.8 & 210.1 & $19.52 \%$ & $39.69 \%$ & 2.714 & 0.510 & 1.787 & 0.867 & 0.754 \\
\hline 89.0 & 1.880 & 1.300 & 633.7 & 136.8 & $21.67 \%$ & $40.60 \%$ & 2.470 & 0.409 & 2.102 & 0.852 & 0.699 \\
\hline 89.3 & 2.246 & 0.938 & 467.0 & 304.3 & $20.76 \%$ & $31.63 \%$ & 1.765 & 0.294 & 1.536 & 0.888 & 0.663 \\
\hline 88.6 & 2.240 & 0.906 & 442.7 & 136.3 & $21.89 \%$ & $35.10 \%$ & 1.929 & 0.288 & 1.892 & 0.894 & 0.664 \\
\hline 86.6 & 3.655 & 0.585 & 288.9 & 172.4 & $22.89 \%$ & $28.56 \%$ & 1.347 & 0.138 & 1.572 & 0.929 & 0.598 \\
\hline 87.1 & 3.605 & 0.634 & 298.1 & 475.0 & $22.12 \%$ & $26.79 \%$ & 1.288 & 0.149 & 1.263 & 0.927 & 0.573 \\
\hline 88.7 & 3.131 & 1.096 & 558.7 & 215.7 & $21.93 \%$ & $32.88 \%$ & 1.744 & 0.259 & 1.772 & 0.868 & 0.650 \\
\hline 89.2 & 6.412 & 1.104 & 563.8 & 209.9 & $23.27 \%$ & $29.47 \%$ & 1.378 & 0.147 & 1.790 & 0.867 & 0.577 \\
\hline 88.4 & 6.078 & 1.421 & 728.3 & 360.2 & $22.73 \%$ & $29.61 \%$ & 1.430 & 0.190 & 1.653 & 0.831 & 0.574 \\
\hline 86.7 & 5.966 & 0.362 & 183.3 & 200.2 & $23.95 \%$ & $26.04 \%$ & 1.118 & 0.057 & 1.360 & 0.954 & 0.554 \\
\hline 87.9 & 1.421 & 0.506 & 245.4 & 138.9 & $21.22 \%$ & $31.88 \%$ & 1.737 & 0.262 & 1.594 & 0.940 & 0.653 \\
\hline
\end{tabular}


Table B.2. Separation results for IMTL membrane 1226678-1-1: $25.02 \% \mathrm{C}_{2} \mathrm{H}_{6}$ in $\mathrm{H}_{2}$

\begin{tabular}{|c|c|c|c|c|c|c|c|c|c|c|c|}
\hline $\begin{array}{c}\mathrm{T} \\
\left({ }^{\circ} \mathrm{C}\right) \\
\end{array}$ & $\begin{array}{c}\mathrm{P}_{\mathrm{LO}} \\
\text { (bar) }\end{array}$ & $\begin{array}{c}\mathrm{dP} \\
\text { (bar) }\end{array}$ & $\begin{array}{c}\mathrm{F}_{\mathrm{LO}} \\
(\mathrm{sccm})\end{array}$ & $\begin{array}{c}\mathrm{F}_{\mathrm{HI}} \\
(\mathrm{sccm})\end{array}$ & $\begin{array}{c}\mathrm{X}_{\mathrm{LO}} \\
(\mathrm{mol} \% \text { hvy })\end{array}$ & $\begin{array}{c}\mathrm{X}_{\mathrm{HI}} \\
(\mathrm{mol} \% \mathrm{hvy})\end{array}$ & $\alpha$ & $\mathrm{E}_{\mathrm{P}}$ & $\mathrm{E}_{\mathrm{C}}$ & $\mathrm{E}_{\mathrm{M}}$ & $\mathrm{E}_{\mathrm{B}}$ \\
\hline 136.7 & 1.054 & 1.414 & 210.8 & 254.1 & $16.57 \%$ & $31.62 \%$ & 2.328 & 0.573 & 1.332 & 0.952 & 0.636 \\
\hline 136.1 & 1.042 & 1.028 & 248.6 & 215.8 & $17.50 \%$ & $33.51 \%$ & 2.376 & 0.497 & 1.432 & 0.944 & 0.714 \\
\hline 137.1 & 2.462 & 0.990 & 254.6 & 210.4 & $20.25 \%$ & $30.43 \%$ & 1.723 & 0.287 & 1.448 & 0.943 & 0.643 \\
\hline 136.5 & 2.461 & 0.989 & 258.4 & 206.3 & $20.28 \%$ & $30.53 \%$ & 1.728 & 0.287 & 1.460 & 0.942 & 0.643 \\
\hline 135.4 & 2.088 & 1.292 & 353.4 & 112.9 & $20.76 \%$ & $37.48 \%$ & 2.289 & 0.382 & 1.871 & 0.921 & 0.681 \\
\hline 136.0 & 2.114 & 1.358 & 400.4 & 370.1 & $18.88 \%$ & $31.39 \%$ & 1.966 & 0.391 & 1.411 & 0.911 & 0.669 \\
\hline 136.5 & 2.121 & 1.348 & 403.7 & 366.8 & $18.89 \%$ & $31.45 \%$ & 1.970 & 0.389 & 1.417 & 0.910 & 0.674 \\
\hline 136.7 & 2.147 & 2.037 & 637.9 & 132.8 & $21.07 \%$ & $42.23 \%$ & 2.738 & 0.487 & 2.124 & 0.862 & 0.678 \\
\hline 136.3 & 2.147 & 2.031 & 648.7 & 122.5 & $21.27 \%$ & $42.93 \%$ & 2.784 & 0.486 & 2.187 & 0.860 & 0.679 \\
\hline 135.9 & 2.147 & 2.026 & 658.3 & 113.1 & $21.47 \%$ & $43.60 \%$ & 2.827 & 0.485 & 2.250 & 0.858 & 0.679 \\
\hline 136.1 & 5.820 & 1.692 & 592.7 & 178.5 & $22.62 \%$ & $32.36 \%$ & 1.637 & 0.225 & 1.904 & 0.871 & 0.593 \\
\hline 136.8 & 6.719 & 0.824 & 297.6 & 473.1 & $22.55 \%$ & $26.30 \%$ & 1.225 & 0.109 & 1.264 & 0.933 & 0.609 \\
\hline 133.2 & 6.698 & 0.448 & 163.3 & 605.5 & $23.19 \%$ & $25.32 \%$ & 1.123 & 0.063 & 1.124 & 0.963 & 0.632 \\
\hline 129.2 & 1.742 & 0.857 & 310.1 & 155.5 & $20.41 \%$ & $33.83 \%$ & 1.993 & 0.330 & 1.647 & 0.930 & 0.685 \\
\hline 129.0 & 1.744 & 0.909 & 343.1 & 430.0 & $18.87 \%$ & $29.77 \%$ & 1.822 & 0.343 & 1.322 & 0.922 & 0.685 \\
\hline 130.3 & 1.756 & 1.570 & 592.4 & 181.2 & $20.28 \%$ & $40.12 \%$ & 2.634 & 0.472 & 1.895 & 0.870 & 0.731 \\
\hline 132.9 & 1.734 & 0.419 & 158.6 & 613.8 & $20.19 \%$ & $26.15 \%$ & 1.400 & 0.195 & 1.119 & 0.964 & 0.663 \\
\hline 134.6 & 1.114 & 1.031 & 410.8 & 362.2 & $17.65 \%$ & $33.27 \%$ & 2.327 & 0.481 & 1.426 & 0.909 & 0.741 \\
\hline 135.2 & 1.132 & 1.530 & 617.3 & 155.0 & $19.88 \%$ & $45.22 \%$ & 3.327 & 0.575 & 2.009 & 0.866 & 0.810 \\
\hline 135.0 & 1.132 & 1.525 & 622.2 & 149.8 & $19.99 \%$ & $45.63 \%$ & 3.360 & 0.574 & 2.034 & 0.865 & 0.813 \\
\hline 134.8 & 1.132 & 1.520 & 628.6 & 143.5 & $20.14 \%$ & $46.14 \%$ & 3.398 & 0.573 & 2.067 & 0.864 & 0.816 \\
\hline 134.8 & 1.133 & 1.526 & 636.9 & 135.5 & $20.33 \%$ & $46.73 \%$ & 3.439 & 0.574 & 2.111 & 0.862 & 0.813 \\
\hline 135.7 & 1.090 & 0.376 & 156.0 & 148.6 & $20.47 \%$ & $29.83 \%$ & 1.652 & 0.256 & 1.402 & 0.964 & 0.655 \\
\hline 135.9 & 1.091 & 0.378 & 159.0 & 146.1 & $20.38 \%$ & $29.96 \%$ & 1.671 & 0.257 & 1.413 & 0.964 & 0.667 \\
\hline 195.7 & 1.144 & 0.449 & 295.8 & 173.3 & $20.87 \%$ & $32.20 \%$ & 1.801 & 0.282 & 1.579 & 0.939 & 0.667 \\
\hline 195.8 & 1.161 & 0.510 & 349.3 & 596.3 & $18.95 \%$ & $28.54 \%$ & 1.709 & 0.305 & 1.248 & 0.929 & 0.697 \\
\hline 195.8 & 1.235 & 0.996 & 672.0 & 274.3 & $19.88 \%$ & $37.83 \%$ & 2.452 & 0.447 & 1.744 & 0.867 & 0.749 \\
\hline 195.9 & 2.086 & 0.981 & 660.1 & 286.4 & $21.12 \%$ & $34.03 \%$ & 1.927 & 0.320 & 1.714 & 0.869 & 0.676 \\
\hline 195.9 & 2.500 & 0.571 & 386.5 & 559.4 & $21.29 \%$ & $27.54 \%$ & 1.406 & 0.186 & 1.286 & 0.921 & 0.641 \\
\hline 195.9 & 2.509 & 0.507 & 335.3 & 166.5 & $22.60 \%$ & $29.74 \%$ & 1.450 & 0.168 & 1.651 & 0.931 & 0.606 \\
\hline
\end{tabular}


Table B.2. Separation results for IMTL membrane 1226678-1-1: $25.02 \% \mathrm{C}_{2} \mathrm{H}_{6}$ in $\mathrm{H}_{2}$

\begin{tabular}{cccccccccccc}
\hline $\begin{array}{c}\mathrm{T} \\
\left({ }^{\circ} \mathrm{C}\right)\end{array}$ & $\begin{array}{c}\mathrm{P}_{\mathrm{LO}} \\
(\mathrm{bar})\end{array}$ & $\begin{array}{c}\mathrm{dP} \\
(\mathrm{bar})\end{array}$ & $\begin{array}{c}\mathrm{F}_{\mathrm{LO}} \\
(\mathrm{sccm})\end{array}$ & $\begin{array}{c}\mathrm{F}_{\mathrm{HI}} \\
(\mathrm{sccm})\end{array}$ & $\begin{array}{c}\mathrm{X}_{\mathrm{LO}} \\
(\mathrm{mol} \% \mathrm{hvy})\end{array}$ & $\begin{array}{c}\mathrm{X}_{\mathrm{HI}} \\
(\mathrm{mol} \% \mathrm{hvy})\end{array}$ & $\alpha$ & $\mathrm{E}_{\mathrm{P}}$ & $\mathrm{E}_{\mathrm{C}}$ & $\mathrm{E}_{\mathrm{M}}$ & $\mathrm{E}_{\mathrm{B}}$ \\
\hline 195.9 & 4.103 & 0.479 & 321.1 & 180.3 & $23.40 \%$ & $27.87 \%$ & 1.265 & 0.105 & 1.597 & 0.934 & 0.590 \\
196.0 & 4.107 & 0.482 & 326.8 & 616.8 & $22.73 \%$ & $26.21 \%$ & 1.207 & 0.105 & 1.228 & 0.933 & 0.600 \\
196.0 & 4.123 & 0.955 & 647.8 & 297.3 & $22.60 \%$ & $30.27 \%$ & 1.487 & 0.188 & 1.687 & 0.872 & 0.612 \\
196.1 & 5.235 & 0.968 & 660.9 & 283.5 & $23.05 \%$ & $29.54 \%$ & 1.400 & 0.156 & 1.719 & 0.869 & 0.597 \\
196.0 & 5.239 & 0.459 & 315.0 & 629.2 & $23.12 \%$ & $25.91 \%$ & 1.163 & 0.081 & 1.217 & 0.935 & 0.619 \\
196.0 & 5.242 & 0.432 & 294.1 & 175.8 & $23.76 \%$ & $26.98 \%$ & 1.186 & 0.076 & 1.571 & 0.940 & 0.575 \\
196.2 & 6.686 & 0.437 & 301.1 & 167.8 & $24.07 \%$ & $26.73 \%$ & 1.151 & 0.061 & 1.600 & 0.938 & 0.568 \\
196.2 & 6.694 & 0.439 & 304.9 & 637.1 & $23.58 \%$ & $25.70 \%$ & 1.121 & 0.061 & 1.208 & 0.937 & 0.604 \\
196.2 & 6.700 & 0.939 & 652.6 & 293.4 & $23.44 \%$ & $28.71 \%$ & 1.315 & 0.123 & 1.697 & 0.871 & 0.604 \\
\hline
\end{tabular}


Table B.3. Separation results for IMTL membrane 1226678-1-1: $24.97 \% \mathrm{C}_{3} \mathrm{H}_{8}$ in $\mathrm{H}_{2}$

\begin{tabular}{|c|c|c|c|c|c|c|c|c|c|c|c|}
\hline $\begin{array}{c}\mathrm{T} \\
\left({ }^{\circ} \mathrm{C}\right) \\
\end{array}$ & $\begin{array}{c}\mathrm{P}_{\mathrm{LO}} \\
\text { (bar) }\end{array}$ & $\begin{array}{c}\mathrm{dP} \\
\text { (bar) }\end{array}$ & $\begin{array}{c}\mathrm{F}_{\mathrm{LO}} \\
(\mathrm{sccm})\end{array}$ & $\begin{array}{c}\mathrm{F}_{\mathrm{HI}} \\
(\mathrm{sccm}) \\
\end{array}$ & $\begin{array}{c}\mathrm{X}_{\mathrm{LO}} \\
(\mathrm{mol} \% \mathrm{hvy})\end{array}$ & $\begin{array}{c}\mathrm{X}_{\mathrm{HI}} \\
(\mathrm{mol} \% \mathrm{hvy}) \\
\end{array}$ & $\alpha$ & $\mathrm{E}_{\mathrm{P}}$ & $\mathrm{E}_{\mathrm{C}}$ & $\mathrm{E}_{\mathrm{M}}$ & $\mathrm{E}_{\mathrm{B}}$ \\
\hline 23.9 & 0.993 & 0.264 & 144.5 & 122.1 & $21.66 \%$ & $29.05 \%$ & 1.481 & 0.210 & 1.441 & 0.879 & 0.490 \\
\hline 23.9 & 0.994 & 0.281 & 157.5 & 282.3 & $20.68 \%$ & $27.46 \%$ & 1.452 & 0.221 & 1.238 & 0.833 & 0.539 \\
\hline 23.9 & 1.001 & 0.536 & 300.4 & 141.7 & $20.84 \%$ & $33.71 \%$ & 1.932 & 0.349 & 1.675 & 0.932 & 0.464 \\
\hline 23.9 & 1.003 & 0.615 & 341.3 & 101.6 & $21.44 \%$ & $36.76 \%$ & 2.130 & 0.380 & 1.911 & 0.882 & 0.478 \\
\hline 23.9 & 2.082 & 0.395 & 219.5 & 221.4 & $22.36 \%$ & $27.70 \%$ & 1.330 & 0.159 & 1.384 & 0.828 & 0.489 \\
\hline 24.0 & 1.830 & 0.600 & 331.0 & 111.6 & $22.52 \%$ & $32.26 \%$ & 1.638 & 0.247 & 1.843 & 0.940 & 0.404 \\
\hline 24.0 & 2.285 & 0.192 & 104.8 & 334.8 & $23.16 \%$ & $25.58 \%$ & 1.141 & 0.078 & 1.142 & 0.888 & 0.484 \\
\hline 24.0 & 4.155 & 0.544 & 300.8 & 141.3 & $23.63 \%$ & $27.89 \%$ & 1.250 & 0.116 & 1.676 & 0.840 & 0.415 \\
\hline 24.0 & 4.148 & 0.554 & 309.1 & 505.8 & $23.01 \%$ & $26.29 \%$ & 1.194 & 0.118 & 1.257 & 0.832 & 0.427 \\
\hline 24.0 & 6.404 & 0.525 & 290.8 & 146.5 & $24.11 \%$ & $26.74 \%$ & 1.149 & 0.076 & 1.645 & 0.889 & 0.364 \\
\hline 24.1 & 6.405 & 0.562 & 315.8 & 635.2 & $23.59 \%$ & $25.71 \%$ & 1.121 & 0.081 & 1.215 & 0.944 & 0.353 \\
\hline 88.8 & 0.991 & 0.292 & 140.7 & 126.1 & $20.91 \%$ & $29.44 \%$ & 1.579 & 0.227 & 1.421 & 0.958 & 0.507 \\
\hline 89.1 & 0.992 & 0.346 & 172.3 & 266.5 & $19.62 \%$ & $28.35 \%$ & 1.621 & 0.259 & 1.270 & 0.949 & 0.539 \\
\hline 90.1 & 0.996 & 0.584 & 291.3 & 149.8 & $19.77 \%$ & $34.60 \%$ & 2.147 & 0.369 & 1.635 & 0.915 & 0.562 \\
\hline 90.3 & 0.999 & 0.691 & 340.2 & 101.6 & $20.56 \%$ & $38.98 \%$ & 2.469 & 0.409 & 1.909 & 0.901 & 0.566 \\
\hline 89.4 & 2.111 & 0.676 & 340.1 & 101.3 & $22.22 \%$ & $33.93 \%$ & 1.798 & 0.242 & 1.911 & 0.901 & 0.518 \\
\hline 89.2 & 2.494 & 0.295 & 144.4 & 293.4 & $22.37 \%$ & $26.17 \%$ & 1.230 & 0.106 & 1.213 & 0.957 & 0.508 \\
\hline 90.4 & 4.172 & 0.575 & 287.4 & 152.9 & $23.09 \%$ & $28.25 \%$ & 1.312 & 0.121 & 1.621 & 0.916 & 0.470 \\
\hline 90.2 & 4.162 & 0.601 & 305.5 & 647.4 & $22.16 \%$ & $26.25 \%$ & 1.250 & 0.126 & 1.206 & 0.911 & 0.490 \\
\hline 89.8 & 6.602 & 0.586 & 300.1 & 140.3 & $23.79 \%$ & $27.35 \%$ & 1.206 & 0.081 & 1.679 & 0.912 & 0.447 \\
\hline 90.5 & 6.600 & 0.584 & 302.7 & 631.5 & $23.15 \%$ & $25.81 \%$ & 1.155 & 0.081 & 1.209 & 0.912 & 0.468 \\
\hline 132.1 & 0.994 & 0.349 & 156.7 & 110.9 & $20.30 \%$ & $31.53 \%$ & 1.807 & 0.260 & 1.504 & 0.957 & 0.585 \\
\hline 132.3 & 0.995 & 0.364 & 169.8 & 270.6 & $18.97 \%$ & $28.75 \%$ & 1.724 & 0.268 & 1.263 & 0.953 & 0.608 \\
\hline 133.4 & 1.002 & 0.644 & 308.3 & 134.1 & $19.44 \%$ & $37.44 \%$ & 2.481 & 0.391 & 1.713 & 0.917 & 0.653 \\
\hline 133.9 & 2.055 & 0.686 & 339.1 & 105.1 & $21.72 \%$ & $35.06 \%$ & 1.946 & 0.250 & 1.888 & 0.909 & 0.596 \\
\hline 132.4 & 2.436 & 0.314 & 151.6 & 289.5 & $22.00 \%$ & $26.42 \%$ & 1.273 & 0.114 & 1.225 & 0.958 & 0.551 \\
\hline 134.1 & 6.583 & 0.616 & 312.9 & 130.6 & $23.64 \%$ & $27.81 \%$ & 1.245 & 0.086 & 1.733 & 0.916 & 0.488 \\
\hline 132.3 & 6.580 & 0.613 & 318.9 & 631.5 & $22.84 \%$ & $25.97 \%$ & 1.185 & 0.085 & 1.218 & 0.914 & 0.529 \\
\hline 125.2 & 4.114 & 0.626 & 320.4 & 119.1 & $23.12 \%$ & $29.67 \%$ & 1.403 & 0.132 & 1.791 & 0.912 & 0.505 \\
\hline
\end{tabular}


Table B.3. Separation results for IMTL membrane 1226678-1-1: $24.97 \% \mathrm{C}_{3} \mathrm{H}_{8}$ in $\mathrm{H}_{2}$

\begin{tabular}{|c|c|c|c|c|c|c|c|c|c|c|c|}
\hline $\begin{array}{c}\mathrm{T} \\
\left({ }^{\circ} \mathrm{C}\right) \\
\end{array}$ & $\begin{array}{c}\mathrm{P}_{\mathrm{LO}} \\
\text { (bar) }\end{array}$ & $\begin{array}{c}\mathrm{dP} \\
\text { (bar) }\end{array}$ & $\begin{array}{c}\mathrm{F}_{\mathrm{LO}} \\
(\mathrm{sccm})\end{array}$ & $\begin{array}{c}\begin{array}{c}\mathrm{F}_{\mathrm{HI}} \\
(\mathrm{sccm})\end{array} \\
\end{array}$ & $\begin{array}{c}\mathrm{X}_{\mathrm{LO}} \\
(\mathrm{mol} \% \mathrm{hvy})\end{array}$ & $\begin{array}{c}\mathrm{X}_{\mathrm{HI}} \\
\text { (mol \% hvy) }\end{array}$ & $\alpha$ & $\mathrm{E}_{\mathrm{P}}$ & $\mathrm{E}_{\mathrm{C}}$ & $\mathrm{E}_{\mathrm{M}}$ & $\mathrm{E}_{\mathrm{B}}$ \\
\hline 124.6 & 4.116 & 0.703 & 371.4 & 583.9 & $21.77 \%$ & $26.99 \%$ & 1.328 & 0.146 & 1.266 & 0.899 & 0.536 \\
\hline 189.2 & 1.031 & 0.443 & 269.6 & 137.9 & $20.37 \%$ & $34.01 \%$ & 2.015 & 0.300 & 1.638 & 0.933 & 0.599 \\
\hline 189.4 & 1.037 & 0.467 & 298.1 & 520.8 & $18.22 \%$ & $28.88 \%$ & 1.823 & 0.310 & 1.243 & 0.926 & 0.624 \\
\hline 189.5 & 1.072 & 0.879 & 551.9 & 269.3 & $18.88 \%$ & $37.45 \%$ & 2.572 & 0.451 & 1.659 & 0.867 & 0.657 \\
\hline 189.9 & 2.815 & 0.881 & 551.4 & 271.2 & $21.60 \%$ & $31.93 \%$ & 1.702 & 0.238 & 1.655 & 0.867 & 0.556 \\
\hline 189.8 & 3.227 & 0.508 & 318.3 & 501.6 & $21.83 \%$ & $26.97 \%$ & 1.323 & 0.136 & 1.266 & 0.921 & 0.551 \\
\hline 189.9 & 3.263 & 0.439 & 279.4 & 132.9 & $22.99 \%$ & $29.00 \%$ & 1.368 & 0.119 & 1.671 & 0.930 & 0.542 \\
\hline 190.0 & 5.294 & 0.424 & 264.7 & 147.3 & $23.73 \%$ & $27.30 \%$ & 1.207 & 0.074 & 1.601 & 0.934 & 0.506 \\
\hline 190.1 & 5.299 & 0.416 & 262.5 & 559.6 & $23.19 \%$ & $25.87 \%$ & 1.156 & 0.073 & 1.205 & 0.935 & 0.514 \\
\hline 190.1 & 5.311 & 0.802 & 511.3 & 316.3 & $22.80 \%$ & $28.43 \%$ & 1.345 & 0.131 & 1.557 & 0.877 & 0.522 \\
\hline 190.2 & 6.508 & 1.006 & 640.9 & 186.5 & $23.47 \%$ & $30.07 \%$ & 1.402 & 0.134 & 1.923 & 0.848 & 0.499 \\
\hline 190.2 & 6.518 & 0.488 & 312.4 & 509.6 & $23.28 \%$ & $26.00 \%$ & 1.158 & 0.070 & 1.258 & 0.923 & 0.529 \\
\hline 190.1 & 2.098 & 0.973 & 609.7 & 216.5 & $21.21 \%$ & $35.66 \%$ & 2.059 & 0.317 & 1.815 & 0.855 & 0.584 \\
\hline 190.1 & 2.085 & 0.495 & 312.6 & 511.7 & $20.67 \%$ & $27.64 \%$ & 1.466 & 0.192 & 1.257 & 0.923 & 0.568 \\
\hline 190.1 & 2.090 & 0.420 & 257.9 & 153.3 & $22.08 \%$ & $29.73 \%$ & 1.493 & 0.167 & 1.573 & 0.936 & 0.542 \\
\hline
\end{tabular}


Table B.4. Separation results for IMTL membrane 1226678-1-1: $25 \% \mathrm{CO}_{2}$ in $\mathrm{He}$

\begin{tabular}{|c|c|c|c|c|c|c|c|c|c|c|c|}
\hline $\begin{array}{c}\mathrm{T} \\
\left({ }^{\circ} \mathrm{C}\right) \\
\end{array}$ & $\begin{array}{c}\mathrm{P}_{\mathrm{LO}} \\
\text { (bar) }\end{array}$ & $\begin{array}{c}\mathrm{dP} \\
\text { (bar) }\end{array}$ & $\begin{array}{c}\mathrm{F}_{\mathrm{LO}} \\
(\mathrm{sccm})\end{array}$ & $\begin{array}{c}\mathrm{F}_{\mathrm{HI}} \\
(\mathrm{sccm}) \\
\end{array}$ & $\begin{array}{c}\mathrm{X}_{\mathrm{LO}} \\
\text { (mol \% hvy) }\end{array}$ & $\begin{array}{c}\mathrm{X}_{\mathrm{HI}} \\
(\mathrm{mol} \% \text { hvy) }\end{array}$ & $\alpha$ & $\mathrm{E}_{\mathrm{P}}$ & $\mathrm{E}_{\mathrm{C}}$ & $\mathrm{E}_{\mathrm{M}}$ & $\mathrm{E}_{\mathrm{B}}$ \\
\hline 23.8 & 1.051 & 0.743 & 367.6 & 76.2 & $21.46 \%$ & $42.19 \%$ & 2.671 & 0.414 & 2.128 & 0.901 & 0.909 \\
\hline 23.7 & 1.030 & 0.789 & 408.1 & 374.4 & $18.57 \%$ & $32.52 \%$ & 2.113 & 0.434 & 1.413 & 0.890 & 0.880 \\
\hline 23.8 & 1.038 & 0.878 & 466.7 & 1350.8 & $16.95 \%$ & $28.36 \%$ & 1.940 & 0.458 & 1.156 & 0.876 & 0.875 \\
\hline 23.9 & 4.196 & 1.932 & 1009.0 & 804.0 & $21.31 \%$ & $29.93 \%$ & 1.577 & 0.315 & 1.461 & 0.751 & 0.721 \\
\hline 23.9 & 3.180 & 0.605 & 307.8 & 361.2 & $22.01 \%$ & $27.82 \%$ & 1.366 & 0.160 & 1.340 & 0.916 & 0.806 \\
\hline 29.3 & 3.184 & 0.605 & 307.0 & 364.2 & $21.91 \%$ & $27.79 \%$ & 1.371 & 0.160 & 1.337 & 0.917 & 0.818 \\
\hline 25.2 & 1.010 & 0.790 & 392.2 & 55.8 & $22.25 \%$ & $44.09 \%$ & 2.756 & 0.439 & 2.379 & 0.895 & 0.812 \\
\hline 25.2 & 2.320 & 2.162 & 1111.4 & 581.1 & $20.97 \%$ & $32.79 \%$ & 1.839 & 0.482 & 1.628 & 0.730 & 0.632 \\
\hline 25.3 & 6.198 & 2.117 & 1120.8 & 1130.5 & $22.12 \%$ & $27.84 \%$ & 1.358 & 0.255 & 1.384 & 0.728 & 0.603 \\
\hline 25.4 & 4.194 & 1.937 & 1009.1 & 800.6 & $21.60 \%$ & $29.36 \%$ & 1.509 & 0.316 & 1.463 & 0.751 & 0.633 \\
\hline 24 & 1.010 & 0.451 & 226.3 & 104.7 & $21.34 \%$ & $33.27 \%$ & 1.838 & 0.309 & 1.683 & 0.938 & 0.742 \\
\hline 24 & 1.003 & 0.288 & 144.3 & 186.3 & $21.05 \%$ & $28.11 \%$ & 1.466 & 0.223 & 1.314 & 0.960 & 0.715 \\
\hline 24 & 1.040 & 0.750 & 374.7 & 67.5 & $22.10 \%$ & $42.25 \%$ & 2.580 & 0.419 & 2.218 & 0.899 & 0.817 \\
\hline 24 & 1.029 & 0.755 & 375.8 & 66.1 & $22.13 \%$ & $42.71 \%$ & 2.623 & 0.423 & 2.234 & 0.899 & 0.824 \\
\hline 24 & 1.030 & 0.761 & 389.2 & 168.1 & $20.35 \%$ & $36.18 \%$ & 2.219 & 0.425 & 1.716 & 0.895 & 0.806 \\
\hline 24 & 1.031 & 0.786 & 410.6 & 373.2 & $18.95 \%$ & $31.78 \%$ & 1.992 & 0.433 & 1.416 & 0.890 & 0.785 \\
\hline 24 & 1.035 & 0.845 & 452.4 & 1245.0 & $17.42 \%$ & $27.78 \%$ & 1.824 & 0.450 & 1.163 & 0.879 & 0.774 \\
\hline 24 & 1.034 & 0.843 & 451.4 & 1247.0 & $17.38 \%$ & $27.77 \%$ & 1.828 & 0.449 & 1.162 & 0.880 & 0.778 \\
\hline 24 & 1.036 & 0.879 & 473.7 & 1793.2 & $17.01 \%$ & $27.10 \%$ & 1.814 & 0.459 & 1.122 & 0.874 & 0.781 \\
\hline 24 & 2.281 & 2.246 & 1168.6 & 1082.7 & $20.23 \%$ & $30.30 \%$ & 1.714 & 0.496 & 1.410 & 0.717 & 0.614 \\
\hline 24 & 2.278 & 2.175 & 1118.7 & 568.3 & $21.07 \%$ & $32.94 \%$ & 1.840 & 0.489 & 1.641 & 0.728 & 0.622 \\
\hline 24 & 2.278 & 2.173 & 1108.3 & 386.7 & $21.64 \%$ & $34.93 \%$ & 1.944 & 0.488 & 1.824 & 0.730 & 0.627 \\
\hline 24 & 2.277 & 2.138 & 1063.6 & 109.0 & $23.43 \%$ & $41.19 \%$ & 2.289 & 0.484 & 2.619 & 0.739 & 0.593 \\
\hline 24 & 2.275 & 2.117 & 1043.7 & 57.8 & $24.08 \%$ & $43.31 \%$ & 2.408 & 0.482 & 3.111 & 0.743 & 0.545 \\
\hline 24 & 4.158 & 1.892 & 969.5 & 201.2 & $23.22 \%$ & $33.97 \%$ & 1.701 & 0.313 & 2.126 & 0.759 & 0.600 \\
\hline 24 & 4.192 & 1.941 & 1015.6 & 800.4 & $21.67 \%$ & $29.34 \%$ & 1.501 & 0.317 & 1.465 & 0.749 & 0.623 \\
\hline 24 & 4.205 & 1.959 & 1031.3 & 1229.4 & $21.22 \%$ & $28.24 \%$ & 1.461 & 0.318 & 1.335 & 0.746 & 0.629 \\
\hline 24 & 6.201 & 2.119 & 1120.4 & 1132.2 & $22.17 \%$ & $27.85 \%$ & 1.355 & 0.255 & 1.383 & 0.727 & 0.599 \\
\hline 24 & 6.214 & 2.079 & 1092.3 & 595.6 & $22.69 \%$ & $29.24 \%$ & 1.409 & 0.251 & 1.610 & 0.733 & 0.596 \\
\hline 24 & 6.224 & 2.053 & 1062.5 & 173.1 & $23.84 \%$ & $32.21 \%$ & 1.518 & 0.248 & 2.286 & 0.739 & 0.534 \\
\hline
\end{tabular}


Table B.4. Separation results for IMTL membrane 1226678-1-1: 25\% $\mathrm{CO}_{2}$ in $\mathrm{He}$

\begin{tabular}{|c|c|c|c|c|c|c|c|c|c|c|c|}
\hline $\begin{array}{c}\mathrm{T} \\
\left({ }^{\circ} \mathrm{C}\right) \\
\end{array}$ & $\begin{array}{c}\mathrm{P}_{\mathrm{LO}} \\
\text { (bar) }\end{array}$ & $\begin{array}{c}\mathrm{dP} \\
\text { (bar) }\end{array}$ & $\begin{array}{c}\mathrm{F}_{\mathrm{LO}} \\
(\mathrm{sccm}) \\
\end{array}$ & $\begin{array}{c}\mathrm{F}_{\mathrm{HI}} \\
(\mathrm{sccm}) \\
\end{array}$ & $\begin{array}{c}\mathrm{X}_{\mathrm{LO}} \\
\text { (mol \% hvy) }\end{array}$ & $\begin{array}{c}\mathrm{X}_{\mathrm{HI}} \\
\text { (mol \% hvy) }\end{array}$ & $\alpha$ & $\mathrm{E}_{\mathrm{P}}$ & $\mathrm{E}_{\mathrm{C}}$ & $\mathrm{E}_{\mathrm{M}}$ & $\mathrm{E}_{\mathrm{B}}$ \\
\hline 85.9 & 3.176 & 0.584 & 260.1 & 239.7 & $22.19 \%$ & $28.12 \%$ & 1.372 & 0.155 & 1.412 & 0.937 & 0.782 \\
\hline 92.3 & 3.186 & 0.572 & 250.0 & 124.8 & $22.81 \%$ & $29.31 \%$ & 1.403 & 0.152 & 1.649 & 0.940 & 0.738 \\
\hline 93.7 & 3.171 & 0.642 & 285.6 & 602.3 & $21.45 \%$ & $26.82 \%$ & 1.341 & 0.168 & 1.207 & 0.932 & 0.778 \\
\hline 90.6 & 3.188 & 0.673 & 302.2 & 1103.5 & $21.07 \%$ & $26.21 \%$ & 1.330 & 0.174 & 1.126 & 0.928 & 0.783 \\
\hline 89.2 & 6.171 & 1.419 & 663.6 & 1597.8 & $21.51 \%$ & $26.57 \%$ & 1.321 & 0.187 & 1.184 & 0.848 & 0.738 \\
\hline 90.6 & 6.167 & 1.336 & 621.2 & 1072.2 & $21.78 \%$ & $26.94 \%$ & 1.324 & 0.178 & 1.246 & 0.857 & 0.736 \\
\hline 92.6 & 6.171 & 1.325 & 610.1 & 507.7 & $22.28 \%$ & $28.23 \%$ & 1.372 & 0.177 & 1.446 & 0.860 & 0.731 \\
\hline 94.8 & 6.171 & 1.303 & 592.0 & 239.9 & $22.94 \%$ & $29.90 \%$ & 1.433 & 0.174 & 1.747 & 0.864 & 0.709 \\
\hline 95.7 & 6.171 & 1.276 & 573.8 & 146.1 & $23.41 \%$ & $31.01 \%$ & 1.471 & 0.171 & 2.001 & 0.868 & 0.683 \\
\hline 92.0 & 6.148 & 2.232 & 1011.1 & 273.8 & $22.96 \%$ & $32.50 \%$ & 1.615 & 0.266 & 1.965 & 0.778 & 0.652 \\
\hline 90.6 & 6.163 & 2.277 & 1046.6 & 645.7 & $22.08 \%$ & $29.81 \%$ & 1.499 & 0.270 & 1.558 & 0.771 & 0.664 \\
\hline 89.8 & 6.174 & 2.310 & 1072.9 & 1180.2 & $21.53 \%$ & $28.25 \%$ & 1.435 & 0.272 & 1.358 & 0.766 & 0.663 \\
\hline 91.7 & 3.789 & 2.101 & 935.0 & 185.0 & $22.73 \%$ & $36.60 \%$ & 1.962 & 0.357 & 2.157 & 0.793 & 0.681 \\
\hline 93.4 & 3.789 & 2.153 & 981.0 & 707.2 & $20.95 \%$ & $30.80 \%$ & 1.680 & 0.362 & 1.497 & 0.785 & 0.689 \\
\hline 95.0 & 3.789 & 2.176 & 999.2 & 1257.6 & $20.27 \%$ & $28.89 \%$ & 1.598 & 0.365 & 1.321 & 0.782 & 0.685 \\
\hline 96.0 & 3.788 & 2.106 & 946.8 & 393.8 & $21.66 \%$ & $33.14 \%$ & 1.793 & 0.357 & 1.735 & 0.792 & 0.697 \\
\hline 95.7 & 1.017 & 1.991 & 875.1 & 240.0 & $20.10 \%$ & $43.59 \%$ & 3.072 & 0.662 & 1.957 & 0.806 & 0.856 \\
\hline 93.3 & 1.016 & 1.936 & 840.5 & 135.8 & $21.29 \%$ & $49.01 \%$ & 3.553 & 0.656 & 2.291 & 0.812 & 0.903 \\
\hline 92.1 & 1.017 & 1.966 & 888.2 & 460.7 & $18.72 \%$ & $37.61 \%$ & 2.617 & 0.659 & 1.632 & 0.802 & 0.809 \\
\hline 91.1 & 1.018 & 2.010 & 922.3 & 772.7 & $17.80 \%$ & $33.92 \%$ & 2.372 & 0.664 & 1.444 & 0.795 & 0.777 \\
\hline 90.3 & 1.018 & 2.018 & 941.6 & 1315.7 & $16.93 \%$ & $30.98 \%$ & 2.202 & 0.665 & 1.294 & 0.791 & 0.762 \\
\hline 196.3 & 1.070 & 0.921 & 468.4 & 887.3 & $17.63 \%$ & $28.93 \%$ & 1.901 & 0.462 & 1.227 & 0.906 & 0.756 \\
\hline 196.3 & 1.117 & 1.617 & 890.1 & 465.7 & $18.86 \%$ & $36.92 \%$ & 2.518 & 0.591 & 1.628 & 0.830 & 0.820 \\
\hline 196.2 & 2.260 & 1.453 & 854.2 & 503.1 & $20.34 \%$ & $32.93 \%$ & 1.923 & 0.391 & 1.577 & 0.836 & 0.772 \\
\hline 196.2 & 2.273 & 0.829 & 462.2 & 893.6 & $20.08 \%$ & $27.54 \%$ & 1.513 & 0.267 & 1.223 & 0.908 & 0.747 \\
\hline 196.2 & 4.376 & 1.500 & 829.7 & 529.1 & $21.79 \%$ & $29.90 \%$ & 1.531 & 0.255 & 1.545 & 0.840 & 0.692 \\
\hline 196.1 & 4.369 & 0.800 & 441.6 & 914.0 & $21.96 \%$ & $26.43 \%$ & 1.277 & 0.155 & 1.210 & 0.912 & 0.700 \\
\hline 196.0 & 6.412 & 0.803 & 448.5 & 907.1 & $22.74 \%$ & $26.07 \%$ & 1.198 & 0.111 & 1.214 & 0.910 & 0.695 \\
\hline 196.0 & 6.428 & 1.578 & 881.4 & 477.2 & $22.71 \%$ & $29.21 \%$ & 1.404 & 0.197 & 1.613 & 0.831 & 0.660 \\
\hline
\end{tabular}


Table B.5. Separation results for IMTL membrane 1226678-1-1: $25 \% \mathrm{Ar}$ in He

\begin{tabular}{|c|c|c|c|c|c|c|c|c|c|c|c|}
\hline $\begin{array}{c}\mathrm{T} \\
\left({ }^{\circ} \mathrm{C}\right) \\
\end{array}$ & $\begin{array}{c}\mathrm{P}_{\mathrm{LO}} \\
\text { (bar) }\end{array}$ & $\begin{array}{c}\mathrm{dP} \\
\text { (bar) }\end{array}$ & $\begin{array}{c}\mathrm{F}_{\mathrm{LO}} \\
(\mathrm{sccm}) \\
\end{array}$ & $\begin{array}{c}\mathrm{F}_{\mathrm{HI}} \\
(\mathrm{sccm}) \\
\end{array}$ & $\begin{array}{c}\mathrm{X}_{\mathrm{LO}} \\
(\mathrm{mol} \% \mathrm{hvy})\end{array}$ & $\begin{array}{c}\mathrm{X}_{\mathrm{HI}} \\
(\mathrm{mol} \% \mathrm{hvy}) \\
\end{array}$ & $\alpha$ & $\mathrm{E}_{\mathrm{P}}$ & $\mathrm{E}_{\mathrm{C}}$ & $\mathrm{E}_{\mathrm{M}}$ & $\mathrm{E}_{\mathrm{B}}$ \\
\hline 23.0 & 1.038 & 0.648 & 325.5 & 96.7 & $21.27 \%$ & $37.96 \%$ & 2.264 & 0.384 & 1.911 & 0.929 & 0.857 \\
\hline 23.1 & 1.039 & 0.646 & 335.2 & 490.5 & $18.49 \%$ & $29.30 \%$ & 1.827 & 0.383 & 1.283 & 0.927 & 0.839 \\
\hline 23.2 & 1.045 & 0.666 & 349.7 & 1454.5 & $17.39 \%$ & $26.66 \%$ & 1.727 & 0.389 & 1.112 & 0.923 & 0.842 \\
\hline 23.3 & 1.051 & 0.761 & 405.8 & 2356.8 & $16.78 \%$ & $26.22 \%$ & 1.763 & 0.420 & 1.082 & 0.912 & 0.852 \\
\hline 23.2 & 1.115 & 2.081 & 1095.3 & 1666.3 & $17.19 \%$ & $30.04 \%$ & 2.068 & 0.651 & 1.274 & 0.779 & 0.764 \\
\hline 23.5 & 3.752 & 2.167 & 1060.2 & 1541.8 & $20.17 \%$ & $28.53 \%$ & 1.581 & 0.366 & 1.284 & 0.786 & 0.727 \\
\hline 23.5 & 4.912 & 0.986 & 526.5 & 2236.3 & $21.31 \%$ & $25.57 \%$ & 1.269 & 0.167 & 1.109 & 0.887 & 0.755 \\
\hline 23.4 & 4.909 & 0.928 & 492.9 & 1459.4 & $21.57 \%$ & $25.82 \%$ & 1.266 & 0.159 & 1.153 & 0.894 & 0.750 \\
\hline 23.5 & 4.910 & 0.904 & 476.0 & 494.0 & $22.20 \%$ & $27.17 \%$ & 1.307 & 0.155 & 1.375 & 0.897 & 0.740 \\
\hline 23.4 & 4.910 & 0.872 & 452.4 & 173.6 & $23.04 \%$ & $29.16 \%$ & 1.375 & 0.151 & 1.775 & 0.902 & 0.718 \\
\hline 23.5 & 6.396 & 0.561 & 294.3 & 1078.8 & $22.96 \%$ & $25.23 \%$ & 1.132 & 0.081 & 1.125 & 0.935 & 0.720 \\
\hline 23.5 & 6.387 & 1.290 & 689.9 & 685.9 & $22.27 \%$ & $27.25 \%$ & 1.307 & 0.168 & 1.388 & 0.855 & 0.712 \\
\hline 23.6 & 6.443 & 1.886 & 1001.0 & 372.6 & $22.71 \%$ & $30.25 \%$ & 1.476 & 0.226 & 1.790 & 0.796 & 0.682 \\
\hline 23.6 & 3.440 & 2.359 & 1197.9 & 171.6 & $22.92 \%$ & $38.01 \%$ & 2.062 & 0.407 & 2.375 & 0.761 & 0.668 \\
\hline 23.6 & 3.426 & 1.829 & 949.8 & 425.1 & $21.44 \%$ & $32.40 \%$ & 1.756 & 0.348 & 1.699 & 0.806 & 0.734 \\
\hline 23.6 & 3.409 & 0.952 & 497.8 & 878.1 & $20.95 \%$ & $26.96 \%$ & 1.393 & 0.218 & 1.241 & 0.893 & 0.751 \\
\hline 23.6 & 3.413 & 0.390 & 199.9 & 1175.3 & $22.27 \%$ & $25.19 \%$ & 1.175 & 0.103 & 1.081 & 0.956 & 0.765 \\
\hline 23.7 & 1.051 & 0.595 & 295.9 & 114.0 & $20.87 \%$ & $35.28 \%$ & 2.067 & 0.362 & 1.773 & 0.935 & 0.823 \\
\hline 25.0 & 1.052 & 0.598 & 297.0 & 112.8 & $20.88 \%$ & $35.41 \%$ & 2.077 & 0.363 & 1.780 & 0.935 & 0.826 \\
\hline 93.4 & 1.054 & 0.668 & 290.8 & 117.8 & $20.60 \%$ & $35.80 \%$ & 2.149 & 0.388 & 1.748 & 0.944 & 0.830 \\
\hline 89.9 & 1.054 & 0.668 & 291.6 & 116.8 & $20.64 \%$ & $35.88 \%$ & 2.152 & 0.388 & 1.753 & 0.944 & 0.830 \\
\hline 89.2 & 1.054 & 0.668 & 292.8 & 115.9 & $20.66 \%$ & $35.98 \%$ & 2.158 & 0.388 & 1.759 & 0.943 & 0.832 \\
\hline 93.5 & 1.054 & 0.671 & 292.5 & 116.0 & $20.66 \%$ & $36.01 \%$ & 2.161 & 0.389 & 1.758 & 0.944 & 0.832 \\
\hline 95.8 & 1.055 & 0.687 & 310.7 & 721.0 & $17.80 \%$ & $28.06 \%$ & 1.800 & 0.394 & 1.190 & 0.941 & 0.839 \\
\hline 95.1 & 1.062 & 0.804 & 370.2 & 1290.0 & $16.99 \%$ & $27.26 \%$ & 1.830 & 0.431 & 1.131 & 0.930 & 0.847 \\
\hline 93.4 & 1.054 & 0.664 & 296.2 & 313.1 & $18.93 \%$ & $30.76 \%$ & 1.902 & 0.387 & 1.370 & 0.943 & 0.836 \\
\hline 89.8 & 1.573 & 2.759 & 1210.5 & 162.7 & $22.06 \%$ & $48.12 \%$ & 3.278 & 0.637 & 2.420 & 0.786 & 0.870 \\
\hline 90.7 & 1.575 & 2.809 & 1260.4 & 397.4 & $20.42 \%$ & $40.36 \%$ & 2.637 & 0.641 & 1.879 & 0.779 & 0.808 \\
\hline
\end{tabular}


Table B.5. Separation results for IMTL membrane 1226678-1-1: $25 \% \mathrm{Ar}$ in He

\begin{tabular}{|c|c|c|c|c|c|c|c|c|c|c|c|}
\hline $\begin{array}{c}\mathrm{T} \\
\left({ }^{\circ} \mathrm{C}\right) \\
\end{array}$ & $\begin{array}{l}\mathrm{P}_{\mathrm{LO}} \\
\text { (bar) }\end{array}$ & $\begin{array}{c}\mathrm{dP} \\
\text { (bar) }\end{array}$ & $\begin{array}{c}\mathrm{F}_{\mathrm{LO}} \\
(\mathrm{sccm})\end{array}$ & $\begin{array}{c}\mathrm{F}_{\mathrm{HI}} \\
(\mathrm{sccm}) \\
\end{array}$ & $\begin{array}{c}\mathrm{X}_{\mathrm{LO}} \\
\text { (mol \% hvy) }\end{array}$ & $\begin{array}{c}\mathrm{X}_{\mathrm{HI}} \\
\text { (mol \% hvy) }\end{array}$ & $\alpha$ & $\mathrm{E}_{\mathrm{P}}$ & $\mathrm{E}_{\mathrm{C}}$ & $\mathrm{E}_{\mathrm{M}}$ & $\mathrm{E}_{\mathrm{B}}$ \\
\hline 92.3 & 1.575 & 2.858 & 1318.8 & 1340.1 & $18.29 \%$ & $31.89 \%$ & 2.092 & 0.645 & 1.381 & 0.770 & 0.736 \\
\hline 95.7 & 3.396 & 2.902 & 1313.6 & 525.4 & $21.25 \%$ & $34.63 \%$ & 1.964 & 0.461 & 1.754 & 0.772 & 0.714 \\
\hline 95.9 & 3.413 & 2.887 & 1292.8 & 308.7 & $22.04 \%$ & $37.68 \%$ & 2.139 & 0.458 & 2.039 & 0.775 & 0.727 \\
\hline 95.2 & 3.439 & 2.951 & 1359.1 & 1293.7 & $20.04 \%$ & $30.36 \%$ & 1.739 & 0.462 & 1.402 & 0.765 & 0.690 \\
\hline 91.5 & 5.057 & 2.620 & 1187.7 & 182.7 & $23.19 \%$ & $36.73 \%$ & 1.922 & 0.341 & 2.325 & 0.790 & 0.680 \\
\hline 90.1 & 5.029 & 2.613 & 1209.3 & 589.9 & $21.76 \%$ & $31.77 \%$ & 1.675 & 0.342 & 1.659 & 0.786 & 0.700 \\
\hline 91.4 & 5.051 & 2.644 & 1241.2 & 1269.7 & $20.89 \%$ & $29.05 \%$ & 1.551 & 0.344 & 1.379 & 0.782 & 0.687 \\
\hline 95.5 & 5.041 & 2.616 & 1216.5 & 797.8 & $21.37 \%$ & $30.60 \%$ & 1.622 & 0.342 & 1.534 & 0.787 & 0.698 \\
\hline 95.5 & 6.703 & 1.873 & 866.4 & 510.4 & $22.38 \%$ & $29.40 \%$ & 1.445 & 0.218 & 1.577 & 0.843 & 0.708 \\
\hline 91.3 & 6.709 & 2.519 & 1162.6 & 210.0 & $23.38 \%$ & $33.99 \%$ & 1.687 & 0.273 & 2.216 & 0.794 & 0.662 \\
\hline 90.0 & 6.688 & 2.540 & 1204.1 & 1165.8 & $21.64 \%$ & $28.52 \%$ & 1.444 & 0.275 & 1.396 & 0.787 & 0.680 \\
\hline 91.8 & 6.627 & 0.969 & 452.4 & 921.7 & $22.52 \%$ & $26.19 \%$ & 1.221 & 0.128 & 1.213 & 0.914 & 0.723 \\
\hline 94.4 & 6.644 & 1.025 & 483.4 & 1609.6 & $22.22 \%$ & $25.82 \%$ & 1.219 & 0.134 & 1.137 & 0.909 & 0.732 \\
\hline 95.8 & 6.654 & 1.059 & 498.6 & 2281.2 & $22.04 \%$ & $25.63 \%$ & 1.219 & 0.137 & 1.102 & 0.907 & 0.737 \\
\hline 93.9 & 6.644 & 0.989 & 454.4 & 137.8 & $23.70 \%$ & $29.23 \%$ & 1.330 & 0.130 & 1.900 & 0.914 & 0.678 \\
\hline 196.0 & 1.080 & 2.084 & 1151.6 & 512.7 & $19.06 \%$ & $39.38 \%$ & 2.759 & 0.659 & 1.702 & 0.824 & 0.881 \\
\hline 196.0 & 1.052 & 1.155 & 658.3 & 1009.0 & $17.22 \%$ & $30.32 \%$ & 2.092 & 0.523 & 1.272 & 0.895 & 0.847 \\
\hline 196.0 & 2.419 & 0.995 & 557.8 & 1108.4 & $19.90 \%$ & $27.57 \%$ & 1.532 & 0.291 & 1.218 & 0.911 & 0.762 \\
\hline 196.0 & 2.445 & 2.054 & 1137.0 & 529.4 & $20.59 \%$ & $34.81 \%$ & 2.060 & 0.457 & 1.681 & 0.826 & 0.773 \\
\hline 196.0 & 4.182 & 2.100 & 1166.8 & 498.1 & $21.81 \%$ & $32.70 \%$ & 1.742 & 0.334 & 1.722 & 0.822 & 0.725 \\
\hline 196.0 & 4.239 & 0.982 & 569.2 & 1084.4 & $21.47 \%$ & $26.91 \%$ & 1.346 & 0.188 & 1.226 & 0.909 & 0.765 \\
\hline 196.0 & 6.486 & 0.969 & 549.8 & 1114.9 & $22.48 \%$ & $26.20 \%$ & 1.224 & 0.130 & 1.214 & 0.912 & 0.719 \\
\hline 195.9 & 6.504 & 2.079 & 1169.3 & 495.5 & $22.64 \%$ & $30.68 \%$ & 1.512 & 0.242 & 1.725 & 0.822 & 0.689 \\
\hline
\end{tabular}


Table B.6. Separation results for IMTL membrane 1230530-89: $25.00 \% \mathrm{CH}_{4}$ in $\mathrm{H}_{2}$

\begin{tabular}{|c|c|c|c|c|c|c|c|c|c|c|c|}
\hline $\begin{array}{c}\mathrm{T} \\
\left({ }^{\circ} \mathrm{C}\right) \\
\end{array}$ & $\begin{array}{c}\mathrm{P}_{\mathrm{LO}} \\
\text { (bar) }\end{array}$ & $\begin{array}{c}\mathrm{dP} \\
\text { (bar) }\end{array}$ & $\begin{array}{c}\mathrm{F}_{\mathrm{LO}} \\
(\mathrm{sccm})\end{array}$ & $\begin{array}{c}\mathrm{F}_{\mathrm{HI}} \\
(\mathrm{sccm})\end{array}$ & $\begin{array}{c}\mathrm{X}_{\mathrm{LO}} \\
\text { (mol \% hvy) }\end{array}$ & $\begin{array}{c}\mathrm{X}_{\mathrm{HI}} \\
\text { (mol \% hvy) }\end{array}$ & $\alpha$ & $\mathrm{E}_{\mathrm{P}}$ & $\mathrm{E}_{\mathrm{C}}$ & $\mathrm{E}_{\mathrm{M}}$ & $\mathrm{E}_{\mathrm{B}}$ \\
\hline 19.4 & 1.053 & 3.504 & 303.5 & 73.8 & $21.12 \%$ & $40.30 \%$ & 2.521 & 0.769 & 2.029 & 0.933 & 0.572 \\
\hline 19.4 & 1.054 & 3.502 & 308.6 & 296.1 & $18.85 \%$ & $31.08 \%$ & 1.942 & 0.769 & 1.399 & 0.932 & 0.514 \\
\hline 19.4 & 1.054 & 3.524 & 313.2 & 1119.5 & $17.53 \%$ & $26.89 \%$ & 1.731 & 0.770 & 1.128 & 0.931 & 0.495 \\
\hline 19.4 & 1.094 & 6.881 & 595.2 & 133.7 & $21.33 \%$ & $39.82 \%$ & 2.440 & 0.863 & 2.077 & 0.873 & 0.504 \\
\hline 19.5 & 1.094 & 6.892 & 607.2 & 554.0 & $19.10 \%$ & $30.97 \%$ & 1.901 & 0.863 & 1.415 & 0.870 & 0.464 \\
\hline 19.4 & 1.094 & 6.889 & 612.6 & 1303.5 & $18.21 \%$ & $27.92 \%$ & 1.739 & 0.863 & 1.205 & 0.869 & 0.448 \\
\hline 19.5 & 4.067 & 4.236 & 368.9 & 90.9 & $22.42 \%$ & $34.48 \%$ & 1.820 & 0.510 & 2.020 & 0.919 & 0.474 \\
\hline 19.4 & 4.068 & 4.248 & 372.5 & 186.0 & $21.53 \%$ & $31.40 \%$ & 1.669 & 0.511 & 1.649 & 0.918 & 0.473 \\
\hline 19.6 & 4.069 & 4.270 & 375.5 & 370.1 & $20.76 \%$ & $28.92 \%$ & 1.553 & 0.512 & 1.391 & 0.918 & 0.463 \\
\hline 19.5 & 4.081 & 4.287 & 381.7 & 1529.7 & $19.86 \%$ & $26.12 \%$ & 1.427 & 0.512 & 1.116 & 0.916 & 0.446 \\
\hline 19.6 & 6.758 & 5.139 & 464.1 & 1449.6 & $20.86 \%$ & $26.15 \%$ & 1.343 & 0.432 & 1.145 & 0.899 & 0.422 \\
\hline 19.6 & 6.759 & 5.119 & 459.6 & 468.6 & $21.51 \%$ & $28.07 \%$ & 1.424 & 0.431 & 1.380 & 0.900 & 0.433 \\
\hline 19.6 & 6.760 & 5.093 & 451.6 & 125.5 & $22.87 \%$ & $32.04 \%$ & 1.589 & 0.430 & 1.950 & 0.902 & 0.427 \\
\hline 19.5 & 1.056 & 3.495 & 300.0 & 82.7 & $20.94 \%$ & $39.12 \%$ & 2.426 & 0.768 & 1.955 & 0.934 & 0.557 \\
\hline 86.6 & 1.012 & 3.492 & 268.1 & 94.0 & $19.59 \%$ & $39.77 \%$ & 2.710 & 0.775 & 1.821 & 0.948 & 0.698 \\
\hline 88.2 & 1.012 & 3.500 & 274.0 & 266.2 & $17.63 \%$ & $32.19 \%$ & 2.218 & 0.776 & 1.395 & 0.947 & 0.650 \\
\hline 87.7 & 1.013 & 3.517 & 280.4 & 1056.6 & $16.09 \%$ & $27.21 \%$ & 1.949 & 0.776 & 1.122 & 0.946 & 0.630 \\
\hline 87.9 & 1.032 & 6.806 & 522.9 & 129.1 & $20.28 \%$ & $42.84 \%$ & 2.946 & 0.868 & 2.019 & 0.902 & 0.673 \\
\hline 89.6 & 1.032 & 6.813 & 536.4 & 512.3 & $17.75 \%$ & $32.18 \%$ & 2.199 & 0.868 & 1.401 & 0.900 & 0.599 \\
\hline 89.5 & 1.033 & 6.824 & 544.3 & 1371.6 & $16.58 \%$ & $28.14 \%$ & 1.970 & 0.869 & 1.176 & 0.898 & 0.578 \\
\hline 88.8 & 4.105 & 3.736 & 287.7 & 89.1 & $21.72 \%$ & $35.10 \%$ & 1.949 & 0.476 & 1.888 & 0.945 & 0.611 \\
\hline 90.0 & 4.105 & 3.741 & 292.3 & 284.4 & $20.10 \%$ & $29.82 \%$ & 1.689 & 0.477 & 1.395 & 0.944 & 0.600 \\
\hline 89.5 & 4.103 & 3.750 & 296.7 & 1125.1 & $19.06 \%$ & $26.47 \%$ & 1.528 & 0.478 & 1.122 & 0.943 & 0.572 \\
\hline 86.8 & 6.864 & 5.075 & 409.4 & 1035.1 & $20.02 \%$ & $26.84 \%$ & 1.466 & 0.425 & 1.176 & 0.922 & 0.553 \\
\hline 87.4 & 6.865 & 5.049 & 403.7 & 409.3 & $20.72 \%$ & $28.93 \%$ & 1.557 & 0.424 & 1.382 & 0.923 & 0.564 \\
\hline 86.5 & 6.866 & 5.026 & 396.3 & 116.5 & $22.32 \%$ & $33.68 \%$ & 1.767 & 0.423 & 1.918 & 0.924 & 0.560 \\
\hline 88.9 & 1.030 & 3.483 & 266.7 & 89.1 & $19.68 \%$ & $40.23 \%$ & 2.747 & 0.772 & 1.847 & 0.949 & 0.706 \\
\hline 152.1 & 1.052 & 3.520 & 249.7 & 75.2 & $19.48 \%$ & $42.75 \%$ & 3.087 & 0.770 & 1.904 & 0.957 & 0.814 \\
\hline 152.2 & 1.054 & 3.526 & 256.8 & 235.1 & $17.14 \%$ & $33.39 \%$ & 2.424 & 0.770 & 1.414 & 0.955 & 0.749 \\
\hline
\end{tabular}


Table B.6. Separation results for IMTL membrane 1230530-89: $25.00 \% \mathrm{CH}_{4}$ in $\mathrm{H}_{2}$

\begin{tabular}{|c|c|c|c|c|c|c|c|c|c|c|c|}
\hline $\begin{array}{c}\mathrm{T} \\
\left({ }^{\circ} \mathrm{C}\right) \\
\end{array}$ & $\begin{array}{l}\mathrm{P}_{\mathrm{LO}} \\
\text { (bar) } \\
\end{array}$ & $\begin{array}{c}\mathrm{dP} \\
\text { (bar) }\end{array}$ & $\begin{array}{c}\mathrm{F}_{\mathrm{LO}} \\
(\mathrm{sccm})\end{array}$ & $\begin{array}{c}\mathrm{F}_{\mathrm{HI}} \\
(\mathrm{sccm}) \\
\end{array}$ & $\begin{array}{c}\mathrm{X}_{\mathrm{LO}} \\
\text { (mol \% hvy) }\end{array}$ & $\begin{array}{c}\mathrm{X}_{\mathrm{HI}} \\
\text { (mol \% hvy) }\end{array}$ & $\alpha$ & $\mathrm{E}_{\mathrm{P}}$ & $\mathrm{E}_{\mathrm{C}}$ & $\mathrm{E}_{\mathrm{M}}$ & $\mathrm{E}_{\mathrm{B}}$ \\
\hline 151.3 & 1.054 & 3.550 & 264.4 & 931.8 & $15.46 \%$ & $27.64 \%$ & 2.090 & 0.771 & 1.130 & 0.954 & 0.717 \\
\hline 150.2 & 1.114 & 6.752 & 485.7 & 128.1 & $19.70 \%$ & $43.94 \%$ & 3.195 & 0.858 & 1.980 & 0.917 & 0.770 \\
\hline 151.7 & 1.114 & 6.769 & 500.7 & 465.7 & $17.17 \%$ & $33.15 \%$ & 2.393 & 0.859 & 1.409 & 0.915 & 0.688 \\
\hline 152.9 & 1.115 & 6.776 & 509.6 & 1398.7 & $15.76 \%$ & $28.27 \%$ & 2.106 & 0.859 & 1.163 & 0.914 & 0.663 \\
\hline 151.2 & 4.035 & 3.506 & 249.9 & 71.7 & $21.63 \%$ & $36.56 \%$ & 2.088 & 0.465 & 1.932 & 0.957 & 0.693 \\
\hline 152.4 & 4.035 & 3.534 & 256.9 & 235.6 & $19.78 \%$ & $30.57 \%$ & 1.785 & 0.467 & 1.414 & 0.955 & 0.681 \\
\hline 151.0 & 4.035 & 3.566 & 263.3 & 962.8 & $18.51 \%$ & $26.74 \%$ & 1.606 & 0.469 & 1.126 & 0.954 & 0.658 \\
\hline 150.5 & 6.654 & 4.926 & 371.5 & 1536.9 & $19.21 \%$ & $26.38 \%$ & 1.507 & 0.425 & 1.112 & 0.936 & 0.626 \\
\hline 151.7 & 6.654 & 4.896 & 364.4 & 372.9 & $20.25 \%$ & $29.49 \%$ & 1.647 & 0.424 & 1.379 & 0.937 & 0.646 \\
\hline 151.0 & 6.657 & 4.889 & 356.1 & 95.1 & $22.17 \%$ & $35.53 \%$ & 1.934 & 0.423 & 1.973 & 0.939 & 0.652 \\
\hline 152.8 & 1.078 & 3.452 & 246.2 & 69.9 & $19.64 \%$ & $43.19 \%$ & 3.110 & 0.762 & 1.938 & 0.957 & 0.816 \\
\hline
\end{tabular}


Table B.7. Separation results for IMTL membrane 1230530-89: $25.02 \% \mathrm{C}_{2} \mathrm{H}_{6}$ in $\mathrm{H}_{2}$

\begin{tabular}{|c|c|c|c|c|c|c|c|c|c|c|c|}
\hline $\begin{array}{c}\mathrm{T} \\
\left({ }^{\circ} \mathrm{C}\right) \\
\end{array}$ & $\begin{array}{l}\mathrm{P}_{\mathrm{LO}} \\
\text { (bar) }\end{array}$ & $\begin{array}{c}\mathrm{dP} \\
\text { (bar) }\end{array}$ & $\begin{array}{c}\mathrm{F}_{\mathrm{LO}} \\
(\mathrm{sccm})\end{array}$ & $\begin{array}{c}\mathrm{F}_{\mathrm{HI}} \\
(\mathrm{sccm})\end{array}$ & $\begin{array}{c}\mathrm{X}_{\mathrm{LO}} \\
\text { (mol \% hvy) }\end{array}$ & $\begin{array}{c}\mathrm{X}_{\mathrm{HI}} \\
\text { (mol \% hvy) }\end{array}$ & $\alpha$ & $\mathrm{E}_{\mathrm{P}}$ & $\mathrm{E}_{\mathrm{C}}$ & $\mathrm{E}_{\mathrm{M}}$ & $\mathrm{E}_{\mathrm{B}}$ \\
\hline 22.7 & 1.045 & 3.543 & 287.3 & 69.1 & $21.99 \%$ & $36.45 \%$ & 2.034 & 0.772 & 2.036 & 0.919 & 0.249 \\
\hline 22.7 & 1.046 & 3.547 & 292.4 & 271.5 & $20.21 \%$ & $29.76 \%$ & 1.672 & 0.772 & 1.410 & 0.918 & 0.234 \\
\hline 22.7 & 1.045 & 3.568 & 297.6 & 1061.0 & $19.14 \%$ & $26.49 \%$ & 1.523 & 0.773 & 1.129 & 0.917 & 0.227 \\
\hline 22.7 & 1.035 & 6.924 & 550.9 & 131.5 & $22.51 \%$ & $34.51 \%$ & 1.815 & 0.870 & 2.040 & 0.851 & 0.188 \\
\hline 22.7 & 1.034 & 6.924 & 563.4 & 795.0 & $20.56 \%$ & $27.92 \%$ & 1.497 & 0.870 & 1.292 & 0.848 & 0.182 \\
\hline 22.7 & 1.034 & 6.924 & 565.2 & 1036.5 & $20.36 \%$ & $27.35 \%$ & 1.473 & 0.870 & 1.233 & 0.847 & 0.181 \\
\hline 22.8 & 4.450 & 3.592 & 284.4 & 75.6 & $23.51 \%$ & $30.19 \%$ & 1.407 & 0.447 & 1.976 & 0.920 & 0.175 \\
\hline 22.8 & 4.445 & 3.590 & 286.6 & 268.7 & $22.65 \%$ & $27.45 \%$ & 1.292 & 0.447 & 1.406 & 0.919 & 0.176 \\
\hline 22.8 & 4.448 & 3.599 & 289.1 & 1068.2 & $22.01 \%$ & $25.75 \%$ & 1.229 & 0.447 & 1.125 & 0.919 & 0.173 \\
\hline 22.9 & 6.915 & 4.473 & 348.8 & 112.4 & $23.92 \%$ & $28.21 \%$ & 1.250 & 0.393 & 1.867 & 0.903 & 0.131 \\
\hline 22.8 & 6.915 & 4.456 & 349.2 & 332.7 & $23.40 \%$ & $26.66 \%$ & 1.190 & 0.392 & 1.401 & 0.903 & 0.133 \\
\hline 22.8 & 6.914 & 4.450 & 351.5 & 1248.1 & $22.97 \%$ & $25.56 \%$ & 1.152 & 0.392 & 1.129 & 0.902 & 0.132 \\
\hline 22.8 & 1.127 & 3.489 & 280.0 & 78.3 & $21.94 \%$ & $35.55 \%$ & 1.963 & 0.756 & 1.946 & 0.921 & 0.247 \\
\hline 90.1 & 1.128 & 3.396 & 244.8 & 79.6 & $19.75 \%$ & $40.18 \%$ & 2.729 & 0.751 & 1.862 & 0.940 & 0.458 \\
\hline 90.2 & 1.132 & 3.417 & 253.4 & 241.0 & $17.71 \%$ & $32.41 \%$ & 2.228 & 0.751 & 1.402 & 0.938 & 0.433 \\
\hline 89.3 & 1.134 & 3.427 & 259.1 & 717.1 & $16.46 \%$ & $28.04 \%$ & 1.977 & 0.751 & 1.162 & 0.937 & 0.416 \\
\hline 87.9 & 1.049 & 6.666 & 496.7 & 478.1 & $17.88 \%$ & $32.10 \%$ & 2.172 & 0.864 & 1.398 & 0.882 & 0.383 \\
\hline 87.4 & 1.050 & 6.671 & 503.9 & 1096.2 & $16.90 \%$ & $28.67 \%$ & 1.976 & 0.864 & 1.201 & 0.880 & 0.372 \\
\hline 90.0 & 1.049 & 6.627 & 480.1 & 162.9 & $19.71 \%$ & $39.59 \%$ & 2.669 & 0.863 & 1.839 & 0.886 & 0.413 \\
\hline 91.0 & 6.624 & 4.869 & 356.9 & 282.6 & $21.18 \%$ & $29.74 \%$ & 1.576 & 0.424 & 1.463 & 0.914 & 0.354 \\
\hline 88.5 & 6.626 & 4.848 & 361.0 & 894.3 & $20.26 \%$ & $26.93 \%$ & 1.450 & 0.423 & 1.179 & 0.913 & 0.345 \\
\hline 89.9 & 6.627 & 4.829 & 350.6 & 130.1 & $22.17 \%$ & $32.33 \%$ & 1.677 & 0.422 & 1.792 & 0.915 & 0.341 \\
\hline 89.9 & 1.095 & 6.924 & 509.9 & 115.7 & $20.62 \%$ & $42.75 \%$ & 2.876 & 0.863 & 2.071 & 0.879 & 0.415 \\
\hline
\end{tabular}


Table B.7. Separation results for IMTL membrane 1230530-89: $25.02 \% \mathrm{C}_{2} \mathrm{H}_{6}$ in $\mathrm{H}_{2}$

\begin{tabular}{|c|c|c|c|c|c|c|c|c|c|c|c|}
\hline $\begin{array}{c}\mathrm{T} \\
\left({ }^{\circ} \mathrm{C}\right) \\
\end{array}$ & $\begin{array}{c}\mathrm{P}_{\mathrm{LO}} \\
\text { (bar) }\end{array}$ & $\begin{array}{c}\mathrm{dP} \\
\text { (bar) }\end{array}$ & $\begin{array}{c}\mathrm{F}_{\mathrm{LO}} \\
(\mathrm{sccm})\end{array}$ & $\begin{array}{c}\mathrm{F}_{\mathrm{HI}} \\
(\mathrm{sccm}) \\
\end{array}$ & $\begin{array}{c}\mathrm{X}_{\mathrm{LO}} \\
(\mathrm{mol} \% \mathrm{hvy}) \\
\end{array}$ & $\begin{array}{c}\mathrm{X}_{\mathrm{HI}} \\
\text { (mol \% hvy) }\end{array}$ & $\alpha$ & $\mathrm{E}_{\mathrm{P}}$ & $\mathrm{E}_{\mathrm{C}}$ & $\mathrm{E}_{\mathrm{M}}$ & $\mathrm{E}_{\mathrm{B}}$ \\
\hline 140.7 & 1.085 & 3.550 & 238.2 & 81.4 & $18.66 \%$ & $42.06 \%$ & 3.164 & 0.766 & 1.835 & 0.946 & 0.566 \\
\hline 138.5 & 1.086 & 3.537 & 245.7 & 209.9 & $16.73 \%$ & $34.09 \%$ & 2.575 & 0.765 & 1.437 & 0.945 & 0.528 \\
\hline 137.9 & 1.087 & 3.542 & 252.3 & 707.2 & $15.14 \%$ & $28.32 \%$ & 2.215 & 0.765 & 1.160 & 0.943 & 0.505 \\
\hline 143.0 & 1.154 & 6.924 & 488.4 & 433.3 & $16.74 \%$ & $33.67 \%$ & 2.524 & 0.857 & 1.424 & 0.894 & 0.486 \\
\hline 142.8 & 1.154 & 6.924 & 498.0 & 1106.0 & $15.49 \%$ & $29.02 \%$ & 2.230 & 0.857 & 1.197 & 0.892 & 0.468 \\
\hline 137.9 & 1.152 & 6.924 & 473.4 & 144.9 & $19.05 \%$ & $42.72 \%$ & 3.169 & 0.857 & 1.895 & 0.896 & 0.519 \\
\hline 138.0 & 6.808 & 5.679 & 394.2 & 350.4 & $20.03 \%$ & $30.27 \%$ & 1.733 & 0.455 & 1.424 & 0.913 & 0.432 \\
\hline 139.6 & 6.809 & 5.673 & 399.7 & 1037.1 & $19.01 \%$ & $27.19 \%$ & 1.591 & 0.454 & 1.172 & 0.912 & 0.424 \\
\hline 144.3 & 6.811 & 5.649 & 380.7 & 129.6 & $21.47 \%$ & $34.77 \%$ & 1.950 & 0.453 & 1.837 & 0.916 & 0.433 \\
\hline 144.1 & 1.103 & 3.540 & 237.1 & 83.3 & $18.62 \%$ & $42.00 \%$ & 3.166 & 0.762 & 1.821 & 0.947 & 0.573 \\
\hline
\end{tabular}


Table B.8. Separation results for IMTL membrane 1230530-89: $24.97 \% \mathrm{C}_{3} \mathrm{H}_{8}$ in $\mathrm{H}_{2}$

\begin{tabular}{|c|c|c|c|c|c|c|c|c|c|c|c|}
\hline $\begin{array}{c}\mathrm{T} \\
\left({ }^{\circ} \mathrm{C}\right) \\
\end{array}$ & $\begin{array}{c}\mathrm{P}_{\mathrm{LO}} \\
\text { (bar) }\end{array}$ & $\begin{array}{c}\mathrm{dP} \\
\text { (bar) }\end{array}$ & $\begin{array}{c}\mathrm{F}_{\mathrm{LO}} \\
(\mathrm{sccm})\end{array}$ & $\begin{array}{c}\mathrm{F}_{\mathrm{HI}} \\
(\mathrm{sccm}) \\
\end{array}$ & $\begin{array}{c}\mathrm{X}_{\mathrm{LO}} \\
\text { (mol \% hvy) }\end{array}$ & $\begin{array}{c}\mathrm{X}_{\mathrm{HI}} \\
\text { (mol \% hvy) }\end{array}$ & $\alpha$ & $\mathrm{E}_{\mathrm{P}}$ & $\mathrm{E}_{\mathrm{C}}$ & $\mathrm{E}_{\mathrm{M}}$ & $\mathrm{E}_{\mathrm{B}}$ \\
\hline 22.5 & 1.047 & 3.472 & 242.1 & 77.5 & $24.43 \%$ & $26.73 \%$ & 1.129 & 0.768 & 1.870 & 0.918 & 0.026 \\
\hline 22.5 & 1.048 & 3.476 & 241.3 & 240.7 & $24.20 \%$ & $25.69 \%$ & 1.083 & 0.768 & 1.387 & 0.918 & 0.023 \\
\hline 22.5 & 1.048 & 3.489 & 241.2 & 736.2 & $24.01 \%$ & $25.24 \%$ & 1.069 & 0.769 & 1.148 & 0.918 & 0.023 \\
\hline 22.5 & 1.028 & 1.095 & 85.4 & 186.5 & $22.71 \%$ & $25.96 \%$ & 1.194 & 0.516 & 1.200 & 0.970 & 0.087 \\
\hline 22.5 & 1.067 & 6.757 & 379.3 & 145.7 & $25.68 \%$ & $22.87 \%$ & 0.858 & 0.864 & 1.774 & 0.874 & -0.029 \\
\hline 22.5 & 1.067 & 6.775 & 373.6 & 387.8 & $26.26 \%$ & $23.61 \%$ & 0.868 & 0.864 & 1.375 & 0.876 & -0.034 \\
\hline 22.4 & 1.066 & 6.787 & 370.5 & 1021.6 & $26.66 \%$ & $24.30 \%$ & 0.883 & 0.864 & 1.163 & 0.877 & -0.036 \\
\hline 22.5 & 4.055 & 4.521 & 244.8 & 103.0 & $26.09 \%$ & $22.03 \%$ & 0.800 & 0.527 & 1.729 & 0.917 & -0.065 \\
\hline 22.5 & 4.055 & 4.517 & 239.8 & 246.2 & $26.93 \%$ & $22.89 \%$ & 0.806 & 0.527 & 1.378 & 0.918 & -0.079 \\
\hline 22.5 & 4.055 & 4.522 & 235.7 & 734.1 & $27.74 \%$ & $23.98 \%$ & 0.822 & 0.527 & 1.146 & 0.920 & -0.087 \\
\hline 22.6 & 6.680 & 5.305 & 226.3 & 259.3 & $28.32 \%$ & $21.88 \%$ & 0.709 & 0.443 & 1.346 & 0.923 & -0.144 \\
\hline 22.6 & 6.680 & 5.285 & 217.1 & 754.8 & $29.71 \%$ & $23.48 \%$ & 0.726 & 0.442 & 1.132 & 0.926 & -0.161 \\
\hline 22.6 & 6.682 & 5.277 & 230.5 & 137.9 & $27.35 \%$ & $21.06 \%$ & 0.709 & 0.441 & 1.571 & 0.922 & -0.124 \\
\hline 22.6 & 6.675 & 2.321 & 113.9 & 250.6 & $27.05 \%$ & $24.02 \%$ & 0.853 & 0.258 & 1.199 & 0.960 & -0.134 \\
\hline 22.4 & 1.089 & 10.240 & 440.1 & 950.9 & $29.41 \%$ & $22.86 \%$ & 0.711 & 0.904 & 1.202 & 0.855 & -0.084 \\
\hline 86.0 & 0.994 & 3.542 & 248.3 & 65.0 & $20.86 \%$ & $39.78 \%$ & 2.507 & 0.781 & 1.985 & 0.926 & 0.284 \\
\hline 87.7 & 0.995 & 3.553 & 255.3 & 212.1 & $18.67 \%$ & $32.23 \%$ & 2.071 & 0.781 & 1.447 & 0.925 & 0.278 \\
\hline 88.1 & 0.995 & 3.544 & 259.4 & 629.2 & $17.42 \%$ & $28.03 \%$ & 1.846 & 0.781 & 1.183 & 0.924 & 0.269 \\
\hline 86.3 & 1.004 & 6.924 & 466.0 & 113.9 & $21.52 \%$ & $38.28 \%$ & 2.262 & 0.873 & 2.025 & 0.867 & 0.223 \\
\hline 86.1 & 1.004 & 6.924 & 481.3 & 405.5 & $19.50 \%$ & $31.25 \%$ & 1.877 & 0.873 & 1.442 & 0.862 & 0.219 \\
\hline 86.4 & 1.004 & 6.924 & 488.6 & 899.7 & $18.59 \%$ & $28.36 \%$ & 1.734 & 0.873 & 1.233 & 0.861 & 0.215 \\
\hline 89.2 & 4.064 & 6.575 & 436.5 & 122.5 & $22.53 \%$ & $33.22 \%$ & 1.711 & 0.618 & 1.944 & 0.875 & 0.183 \\
\hline 88.1 & 4.064 & 6.569 & 444.2 & 400.5 & $21.19 \%$ & $29.15 \%$ & 1.531 & 0.618 & 1.419 & 0.873 & 0.188 \\
\hline 87.0 & 4.063 & 6.570 & 448.3 & 939.1 & $20.53 \%$ & $27.08 \%$ & 1.438 & 0.618 & 1.208 & 0.871 & 0.182 \\
\hline 88.0 & 1.052 & 3.445 & 240.6 & 71.0 & $20.61 \%$ & $38.93 \%$ & 2.456 & 0.766 & 1.916 & 0.929 & 0.289 \\
\hline 137.6 & 0.993 & 3.446 & 224.7 & 56.3 & $19.57 \%$ & $45.16 \%$ & 3.384 & 0.776 & 2.010 & 0.939 & 0.441 \\
\hline 136.9 & 0.994 & 3.445 & 233.9 & 178.6 & $17.02 \%$ & $34.90 \%$ & 2.615 & 0.776 & 1.476 & 0.937 & 0.408 \\
\hline 137.4 & 0.994 & 3.456 & 241.1 & 590.0 & $15.31 \%$ & $28.77 \%$ & 2.234 & 0.777 & 1.181 & 0.935 & 0.390 \\
\hline 138.8 & 1.001 & 6.661 & 448.8 & 383.7 & $17.10 \%$ & $33.68 \%$ & 2.463 & 0.869 & 1.437 & 0.882 & 0.360 \\
\hline 139.8 & 1.001 & 6.669 & 458.2 & 933.6 & $15.84 \%$ & $29.32 \%$ & 2.204 & 0.869 & 1.213 & 0.880 & 0.352 \\
\hline
\end{tabular}


Table B.8. Separation results for IMTL membrane 1230530-89: $24.97 \% \mathrm{C}_{3} \mathrm{H}_{8}$ in $\mathrm{H}_{2}$

\begin{tabular}{|c|c|c|c|c|c|c|c|c|c|c|c|}
\hline $\begin{array}{c}\mathrm{T} \\
\left({ }^{\circ} \mathrm{C}\right) \\
\end{array}$ & $\begin{array}{l}\mathrm{P}_{\mathrm{LO}} \\
\text { (bar) }\end{array}$ & $\begin{array}{c}\mathrm{dP} \\
\text { (bar) }\end{array}$ & $\begin{array}{c}\mathrm{F}_{\mathrm{LO}} \\
(\mathrm{sccm})\end{array}$ & $\begin{array}{c}\mathrm{F}_{\mathrm{HI}} \\
(\mathrm{sccm}) \\
\end{array}$ & $\begin{array}{c}\mathrm{X}_{\mathrm{LO}} \\
\text { (mol \% hvy) }\end{array}$ & $\begin{array}{c}\mathrm{X}_{\mathrm{HI}} \\
(\mathrm{mol} \% \mathrm{hvy})\end{array}$ & $\alpha$ & $\mathrm{E}_{\mathrm{P}}$ & $\mathrm{E}_{\mathrm{C}}$ & $\mathrm{E}_{\mathrm{M}}$ & $\mathrm{E}_{\mathrm{B}}$ \\
\hline 143.0 & 1.001 & 6.617 & 427.7 & 115.1 & $19.53 \%$ & $43.53 \%$ & 3.176 & 0.869 & 1.968 & 0.888 & 0.388 \\
\hline 146.3 & 4.153 & 6.712 & 428.9 & 112.6 & $21.22 \%$ & $38.49 \%$ & 2.323 & 0.618 & 1.983 & 0.888 & 0.329 \\
\hline 147.1 & 4.148 & 6.718 & 442.6 & 370.4 & $19.06 \%$ & $31.87 \%$ & 1.986 & 0.618 & 1.444 & 0.885 & 0.338 \\
\hline 147.2 & 4.148 & 6.709 & 449.9 & 937.1 & $17.95 \%$ & $28.31 \%$ & 1.806 & 0.618 & 1.209 & 0.883 & 0.331 \\
\hline 145.4 & 1.041 & 3.504 & 225.5 & 50.4 & $19.79 \%$ & $46.53 \%$ & 3.528 & 0.771 & 2.080 & 0.940 & 0.455 \\
\hline 209.1 & 1.000 & 3.525 & 283.3 & 83.5 & $18.88 \%$ & $43.46 \%$ & 3.302 & 0.779 & 1.916 & 0.931 & 0.449 \\
\hline 209.5 & 1.000 & 3.528 & 294.9 & 235.9 & $16.90 \%$ & $34.36 \%$ & 2.573 & 0.779 & 1.460 & 0.929 & 0.404 \\
\hline 210.0 & 1.007 & 3.541 & 493.3 & 553.8 & $19.31 \%$ & $29.78 \%$ & 1.772 & 0.779 & 1.352 & 0.884 & 0.225 \\
\hline 211.4 & 1.008 & 3.461 & 472.6 & 65.2 & $21.60 \%$ & $47.01 \%$ & 3.220 & 0.774 & 2.402 & 0.889 & 0.364 \\
\hline 212.2 & 1.009 & 2.826 & 530.4 & 105.1 & $21.84 \%$ & $39.86 \%$ & 2.371 & 0.737 & 2.156 & 0.876 & 0.267 \\
\hline 212.4 & 1.010 & 2.854 & 542.4 & 479.4 & $20.70 \%$ & $29.64 \%$ & 1.615 & 0.739 & 1.426 & 0.873 & 0.181 \\
\hline 212.8 & 3.440 & 3.010 & 699.6 & 210.7 & $22.68 \%$ & $32.29 \%$ & 1.625 & 0.467 & 1.904 & 0.840 & 0.227 \\
\hline 212.9 & 3.444 & 3.047 & 712.6 & 665.9 & $22.09 \%$ & $28.01 \%$ & 1.372 & 0.469 & 1.408 & 0.837 & 0.182 \\
\hline 213.2 & 6.700 & 2.287 & 658.6 & 174.4 & $23.67 \%$ & $29.81 \%$ & 1.370 & 0.255 & 1.978 & 0.849 & 0.235 \\
\hline 213.3 & 6.706 & 2.330 & 682.7 & 628.7 & $23.13 \%$ & $26.92 \%$ & 1.224 & 0.258 & 1.412 & 0.843 & 0.198 \\
\hline 213.5 & 1.020 & 3.493 & 667.5 & 171.6 & $21.60 \%$ & $37.24 \%$ & 2.154 & 0.774 & 1.995 & 0.847 & 0.239 \\
\hline 213.7 & 0.999 & 1.393 & 258.5 & 106.7 & $21.35 \%$ & $33.49 \%$ & 1.854 & 0.582 & 1.738 & 0.938 & 0.244 \\
\hline
\end{tabular}


Table B.9. Separation results for IMTL membrane 1230530-89: $25 \% \mathrm{CO}_{2}$ in $\mathrm{He}$

\begin{tabular}{|c|c|c|c|c|c|c|c|c|c|c|c|}
\hline $\begin{array}{c}\mathrm{T} \\
\left({ }^{\circ} \mathrm{C}\right) \\
\end{array}$ & $\begin{array}{c}\mathrm{P}_{\mathrm{LO}} \\
\text { (bar) }\end{array}$ & $\begin{array}{c}\mathrm{dP} \\
\text { (bar) }\end{array}$ & $\begin{array}{c}\mathrm{F}_{\mathrm{LO}} \\
(\mathrm{sccm})\end{array}$ & $\begin{array}{c}\mathrm{F}_{\mathrm{HI}} \\
(\mathrm{sccm})\end{array}$ & $\begin{array}{c}\mathrm{X}_{\mathrm{LO}} \\
(\mathrm{mol} \% \mathrm{hvy})\end{array}$ & $\begin{array}{c}\mathrm{X}_{\mathrm{HI}} \\
(\mathrm{mol} \% \text { hvy })\end{array}$ & $\alpha$ & $\mathrm{E}_{\mathrm{P}}$ & $\mathrm{E}_{\mathrm{C}}$ & $\mathrm{E}_{\mathrm{M}}$ & $\mathrm{E}_{\mathrm{B}}$ \\
\hline 22.0 & 1.061 & 4.406 & 259.8 & 314.1 & $23.95 \%$ & $28.65 \%$ & 1.276 & 0.806 & 1.331 & 0.929 & 0.119 \\
\hline 22.0 & 1.062 & 4.456 & 263.3 & 1222.7 & $23.28 \%$ & $26.98 \%$ & 1.218 & 0.808 & 1.101 & 0.928 & 0.114 \\
\hline 22.0 & 1.061 & 4.421 & 259.0 & 65.4 & $25.06 \%$ & $32.93 \%$ & 1.469 & 0.806 & 2.005 & 0.929 & 0.135 \\
\hline 22.0 & 1.018 & 3.498 & 206.3 & 58.3 & $24.79 \%$ & $32.66 \%$ & 1.472 & 0.775 & 1.940 & 0.943 & 0.144 \\
\hline 22.0 & 1.019 & 3.544 & 210.1 & 208.0 & $23.72 \%$ & $29.03 \%$ & 1.315 & 0.777 & 1.389 & 0.942 & 0.134 \\
\hline 22.1 & 1.018 & 3.568 & 212.6 & 825.5 & $22.92 \%$ & $26.99 \%$ & 1.243 & 0.778 & 1.119 & 0.941 & 0.128 \\
\hline 22.1 & 1.052 & 6.860 & 399.1 & 1456.2 & $23.50 \%$ & $26.84 \%$ & 1.194 & 0.867 & 1.126 & 0.892 & 0.096 \\
\hline 22.1 & 1.052 & 6.802 & 394.5 & 411.8 & $23.95 \%$ & $28.26 \%$ & 1.251 & 0.866 & 1.373 & 0.893 & 0.102 \\
\hline 22.0 & 1.053 & 6.783 & 392.0 & 100.1 & $24.80 \%$ & $31.75 \%$ & 1.411 & 0.866 & 1.999 & 0.894 & 0.115 \\
\hline 22.0 & 0.992 & 1.672 & 101.0 & 418.8 & $22.72 \%$ & $26.70 \%$ & 1.239 & 0.628 & 1.112 & 0.972 & 0.152 \\
\hline 22.1 & 0.992 & 1.661 & 100.2 & 100.4 & $23.35 \%$ & $28.61 \%$ & 1.315 & 0.626 & 1.386 & 0.972 & 0.162 \\
\hline 22.1 & 0.992 & 1.588 & 95.7 & 44.3 & $23.94 \%$ & $30.51 \%$ & 1.395 & 0.616 & 1.684 & 0.973 & 0.169 \\
\hline 22.2 & 3.427 & 6.722 & 383.5 & 396.7 & $24.37 \%$ & $27.14 \%$ & 1.156 & 0.662 & 1.376 & 0.896 & 0.082 \\
\hline 22.1 & 3.424 & 6.747 & 385.7 & 1473.3 & $23.97 \%$ & $26.14 \%$ & 1.123 & 0.663 & 1.121 & 0.896 & 0.079 \\
\hline 22.1 & 3.427 & 6.730 & 382.4 & 117.7 & $24.80 \%$ & $28.95 \%$ & 1.236 & 0.663 & 1.892 & 0.897 & 0.091 \\
\hline 22.2 & 3.421 & 3.586 & 208.4 & 778.2 & $23.68 \%$ & $26.05 \%$ & 1.135 & 0.512 & 1.123 & 0.942 & 0.108 \\
\hline 22.1 & 3.422 & 3.575 & 207.2 & 211.5 & $24.06 \%$ & $27.06 \%$ & 1.171 & 0.511 & 1.380 & 0.943 & 0.111 \\
\hline 22.2 & 3.424 & 3.556 & 205.5 & 73.4 & $24.45 \%$ & $28.61 \%$ & 1.238 & 0.509 & 1.812 & 0.943 & 0.118 \\
\hline 22.3 & 6.675 & 3.507 & 199.6 & 943.8 & $24.42 \%$ & $25.62 \%$ & 1.066 & 0.344 & 1.099 & 0.945 & 0.080 \\
\hline 22.3 & 6.677 & 3.467 & 197.2 & 221.9 & $24.64 \%$ & $26.06 \%$ & 1.078 & 0.342 & 1.351 & 0.945 & 0.077 \\
\hline 22.2 & 6.678 & 4.858 & 273.6 & 135.9 & $24.68 \%$ & $26.63 \%$ & 1.108 & 0.421 & 1.651 & 0.925 & 0.072 \\
\hline 22.2 & 6.679 & 4.863 & 273.5 & 312.2 & $24.44 \%$ & $26.02 \%$ & 1.087 & 0.421 & 1.347 & 0.925 & 0.072 \\
\hline 22.2 & 6.678 & 4.869 & 274.6 & 1180.0 & $24.17 \%$ & $25.44 \%$ & 1.071 & 0.422 & 1.108 & 0.925 & 0.071 \\
\hline 22.1 & 1.208 & 5.726 & 333.6 & 1413.6 & $22.03 \%$ & $25.89 \%$ & 1.236 & 0.826 & 1.110 & 0.909 & 0.122 \\
\hline 22.2 & 1.207 & 5.715 & 331.9 & 337.5 & $22.61 \%$ & $27.62 \%$ & 1.306 & 0.826 & 1.381 & 0.910 & 0.127 \\
\hline 22.2 & 1.207 & 5.695 & 329.5 & 105.5 & $23.34 \%$ & $30.51 \%$ & 1.443 & 0.825 & 1.870 & 0.910 & 0.136 \\
\hline 85.3 & 1.003 & 2.175 & 119.6 & 457.9 & $17.90 \%$ & $26.81 \%$ & 1.680 & 0.684 & 1.121 & 0.970 & 0.394 \\
\hline 86.1 & 1.003 & 2.142 & 116.6 & 118.4 & $19.13 \%$ & $30.69 \%$ & 1.872 & 0.681 & 1.382 & 0.971 & 0.412 \\
\hline 89.3 & 1.003 & 2.127 & 113.3 & 36.2 & $20.94 \%$ & $38.06 \%$ & 2.320 & 0.680 & 1.871 & 0.972 & 0.461 \\
\hline 87.1 & 1.016 & 4.286 & 236.0 & 978.2 & $17.36 \%$ & $26.79 \%$ & 1.742 & 0.808 & 1.112 & 0.943 & 0.378 \\
\hline 86.6 & 1.017 & 4.255 & 232.0 & 231.2 & $18.75 \%$ & $31.11 \%$ & 1.956 & 0.807 & 1.387 & 0.944 & 0.391 \\
\hline
\end{tabular}


Table B.9. Separation results for IMTL membrane 1230530-89: $25 \% \mathrm{CO}_{2}$ in $\mathrm{He}$

\begin{tabular}{|c|c|c|c|c|c|c|c|c|c|c|c|}
\hline $\begin{array}{c}\mathrm{T} \\
\left({ }^{\circ} \mathrm{C}\right) \\
\end{array}$ & $\begin{array}{c}\mathrm{P}_{\mathrm{LO}} \\
\text { (bar) }\end{array}$ & $\begin{array}{c}\mathrm{dP} \\
\text { (bar) }\end{array}$ & $\begin{array}{c}\mathrm{F}_{\mathrm{LO}} \\
(\mathrm{sccm}) \\
\end{array}$ & $\begin{array}{c}\mathrm{F}_{\mathrm{HI}} \\
(\mathrm{sccm}) \\
\end{array}$ & $\begin{array}{c}\mathrm{X}_{\mathrm{LO}} \\
\text { (mol \% hvy) }\end{array}$ & $\begin{array}{c}\mathrm{X}_{\mathrm{HI}} \\
\text { (mol \% hvy) }\end{array}$ & $\alpha$ & $\mathrm{E}_{\mathrm{P}}$ & $\mathrm{E}_{\mathrm{C}}$ & $\mathrm{E}_{\mathrm{M}}$ & $E_{B}$ \\
\hline 90.5 & 1.016 & 4.216 & 224.9 & 67.2 & $20.64 \%$ & $39.56 \%$ & 2.517 & 0.806 & 1.909 & 0.946 & 0.450 \\
\hline 90.8 & 1.034 & 6.862 & 375.0 & 1162.3 & $17.56 \%$ & $27.11 \%$ & 1.746 & 0.869 & 1.146 & 0.911 & 0.355 \\
\hline 89.4 & 1.032 & 6.695 & 362.1 & 321.9 & $18.94 \%$ & $31.63 \%$ & 1.981 & 0.866 & 1.424 & 0.914 & 0.376 \\
\hline 88.2 & 1.032 & 6.678 & 354.9 & 83.2 & $21.15 \%$ & $41.06 \%$ & 2.597 & 0.866 & 2.050 & 0.915 & 0.424 \\
\hline 90.7 & 3.423 & 4.039 & 219.1 & 810.5 & $19.55 \%$ & $26.40 \%$ & 1.476 & 0.541 & 1.124 & 0.947 & 0.356 \\
\hline 90.1 & 3.423 & 4.005 & 214.5 & 209.1 & $20.51 \%$ & $29.45 \%$ & 1.617 & 0.539 & 1.394 & 0.948 & 0.374 \\
\hline 87.2 & 3.384 & 6.794 & 371.4 & 1361.3 & $19.18 \%$ & $26.54 \%$ & 1.522 & 0.668 & 1.125 & 0.911 & 0.329 \\
\hline 87.4 & 3.389 & 6.804 & 368.4 & 343.5 & $20.26 \%$ & $29.97 \%$ & 1.684 & 0.668 & 1.408 & 0.912 & 0.344 \\
\hline 87.0 & 3.397 & 6.779 & 361.3 & 89.6 & $22.10 \%$ & $36.80 \%$ & 2.053 & 0.666 & 2.017 & 0.914 & 0.370 \\
\hline 89.4 & 6.698 & 4.488 & 243.5 & 909.0 & $21.03 \%$ & $26.02 \%$ & 1.321 & 0.401 & 1.123 & 0.941 & 0.327 \\
\hline 89.3 & 6.700 & 4.447 & 238.9 & 240.3 & $21.77 \%$ & $28.10 \%$ & 1.404 & 0.399 & 1.384 & 0.942 & 0.335 \\
\hline 90.5 & 6.702 & 4.422 & 235.0 & 64.6 & $23.12 \%$ & $31.87 \%$ & 1.556 & 0.398 & 1.956 & 0.943 & 0.327 \\
\hline 146.2 & 6.701 & 4.490 & 223.3 & 83.2 & $22.07 \%$ & $33.12 \%$ & 1.749 & 0.401 & 1.790 & 0.951 & 0.474 \\
\hline 146.8 & 6.702 & 4.486 & 225.1 & 190.0 & $21.00 \%$ & $29.88 \%$ & 1.603 & 0.401 & 1.441 & 0.950 & 0.474 \\
\hline 145.4 & 6.702 & 4.479 & 228.1 & 915.6 & $19.78 \%$ & $26.31 \%$ & 1.449 & 0.401 & 1.115 & 0.950 & 0.456 \\
\hline 142.1 & 3.453 & 6.677 & 334.0 & 95.6 & $20.91 \%$ & $39.43 \%$ & 2.462 & 0.659 & 1.933 & 0.927 & 0.534 \\
\hline 140.5 & 3.453 & 6.724 & 344.5 & 329.7 & $18.94 \%$ & $31.38 \%$ & 1.957 & 0.661 & 1.400 & 0.924 & 0.483 \\
\hline 146.6 & 3.455 & 6.773 & 349.7 & 1317.5 & $17.56 \%$ & $27.03 \%$ & 1.739 & 0.662 & 1.122 & 0.924 & 0.465 \\
\hline 147.6 & 3.452 & 3.543 & 177.4 & 171.7 & $19.62 \%$ & $30.62 \%$ & 1.808 & 0.507 & 1.396 & 0.961 & 0.513 \\
\hline 146.5 & 3.452 & 3.531 & 179.6 & 678.7 & $18.57 \%$ & $26.78 \%$ & 1.603 & 0.506 & 1.122 & 0.960 & 0.478 \\
\hline 146.2 & 1.048 & 6.731 & 334.6 & 84.3 & $19.97 \%$ & $45.38 \%$ & 3.330 & 0.865 & 2.007 & 0.927 & 0.624 \\
\hline 140.0 & 1.050 & 6.768 & 348.4 & 314.2 & $17.61 \%$ & $33.29 \%$ & 2.335 & 0.866 & 1.419 & 0.924 & 0.508 \\
\hline 142.2 & 1.050 & 6.775 & 353.7 & 1209.3 & $15.99 \%$ & $27.70 \%$ & 2.013 & 0.866 & 1.134 & 0.923 & 0.483 \\
\hline 145.6 & 1.027 & 4.118 & 205.4 & 72.6 & $19.25 \%$ & $41.65 \%$ & 2.994 & 0.800 & 1.817 & 0.955 & 0.620 \\
\hline 145.8 & 1.027 & 4.102 & 209.0 & 198.5 & $17.31 \%$ & $33.18 \%$ & 2.372 & 0.800 & 1.402 & 0.954 & 0.554 \\
\hline 147.1 & 1.027 & 4.094 & 212.5 & 786.2 & $15.69 \%$ & $27.54 \%$ & 2.042 & 0.800 & 1.124 & 0.953 & 0.525 \\
\hline 145.7 & 1.008 & 1.934 & 95.5 & 35.5 & $19.87 \%$ & $39.50 \%$ & 2.633 & 0.657 & 1.791 & 0.979 & 0.612 \\
\hline 145.1 & 1.009 & 1.946 & 98.1 & 90.2 & $18.06 \%$ & $32.68 \%$ & 2.202 & 0.659 & 1.413 & 0.978 & 0.570 \\
\hline 141.1 & 1.009 & 1.941 & 100.3 & 379.6 & $16.50 \%$ & $27.23 \%$ & 1.893 & 0.658 & 1.122 & 0.977 & 0.534 \\
\hline
\end{tabular}


Table B.10. Separation results for IMTL membrane 1230530-89: 25\% Ar in He

\begin{tabular}{|c|c|c|c|c|c|c|c|c|c|c|c|}
\hline $\begin{array}{c}\mathrm{T} \\
\left({ }^{\circ} \mathrm{C}\right) \\
\end{array}$ & $\begin{array}{l}\mathrm{P}_{\mathrm{LO}} \\
\text { (bar) }\end{array}$ & $\begin{array}{c}\mathrm{dP} \\
\text { (bar) }\end{array}$ & $\begin{array}{c}\mathrm{F}_{\mathrm{LO}} \\
(\mathrm{sccm})\end{array}$ & $\begin{array}{c}\mathrm{F}_{\mathrm{HI}} \\
(\mathrm{sccm})\end{array}$ & $\begin{array}{c}\mathrm{X}_{\mathrm{LO}} \\
\text { (mol \% hvy) }\end{array}$ & $\begin{array}{c}\mathrm{X}_{\mathrm{HI}} \\
\text { (mol \% hvy) }\end{array}$ & $\alpha$ & $\mathrm{E}_{\mathrm{P}}$ & $\mathrm{E}_{\mathrm{C}}$ & $\mathrm{E}_{\mathrm{M}}$ & $\mathrm{E}_{\mathrm{B}}$ \\
\hline 23.7 & 1.974 & 2.213 & 127.3 & 267.6 & $17.92 \%$ & $28.39 \%$ & 1.816 & 0.529 & 1.207 & 0.971 & 0.609 \\
\hline 23.8 & 1.018 & 3.428 & 199.9 & 195.6 & $16.77 \%$ & $33.40 \%$ & 2.488 & 0.771 & 1.393 & 0.956 & 0.670 \\
\hline 23.7 & 1.017 & 3.445 & 205.9 & 802.8 & $15.08 \%$ & $27.35 \%$ & 2.119 & 0.772 & 1.119 & 0.954 & 0.628 \\
\hline 23.6 & 1.052 & 6.691 & 392.8 & 215.9 & $17.76 \%$ & $38.20 \%$ & 2.862 & 0.864 & 1.606 & 0.915 & 0.678 \\
\hline 23.7 & 1.052 & 6.710 & 398.5 & 369.9 & $16.75 \%$ & $33.72 \%$ & 2.528 & 0.864 & 1.410 & 0.913 & 0.635 \\
\hline 23.8 & 1.091 & 6.711 & 408.7 & 1660.8 & $15.09 \%$ & $27.22 \%$ & 2.106 & 0.860 & 1.114 & 0.911 & 0.586 \\
\hline 23.7 & 3.427 & 6.816 & 411.7 & 1656.4 & $16.79 \%$ & $26.80 \%$ & 1.814 & 0.665 & 1.115 & 0.911 & 0.557 \\
\hline 23.8 & 3.427 & 6.811 & 404.4 & 365.9 & $18.35 \%$ & $32.15 \%$ & 2.107 & 0.665 & 1.418 & 0.912 & 0.595 \\
\hline 23.9 & 3.427 & 6.783 & 395.2 & 144.2 & $20.03 \%$ & $38.63 \%$ & 2.513 & 0.664 & 1.801 & 0.914 & 0.640 \\
\hline 23.9 & 3.412 & 3.674 & 209.9 & 74.8 & $20.86 \%$ & $37.15 \%$ & 2.242 & 0.519 & 1.813 & 0.953 & 0.641 \\
\hline 23.8 & 3.413 & 3.700 & 215.1 & 198.7 & $19.16 \%$ & $31.32 \%$ & 1.923 & 0.520 & 1.411 & 0.952 & 0.611 \\
\hline 23.9 & 3.411 & 3.708 & 219.6 & 1414.4 & $17.51 \%$ & $26.01 \%$ & 1.655 & 0.521 & 1.074 & 0.951 & 0.570 \\
\hline 23.8 & 6.835 & 5.123 & 307.1 & 1397.9 & $19.00 \%$ & $26.18 \%$ & 1.512 & 0.428 & 1.103 & 0.933 & 0.538 \\
\hline 23.9 & 6.836 & 5.112 & 302.4 & 316.7 & $20.09 \%$ & $29.50 \%$ & 1.665 & 0.428 & 1.372 & 0.934 & 0.561 \\
\hline 23.9 & 6.836 & 5.062 & 295.0 & 117.2 & $21.63 \%$ & $33.81 \%$ & 1.851 & 0.425 & 1.757 & 0.935 & 0.563 \\
\hline 24.0 & 1.089 & 6.718 & 390.4 & 140.0 & $18.95 \%$ & $42.63 \%$ & 3.178 & 0.861 & 1.809 & 0.915 & 0.707 \\
\hline 24.0 & 1.090 & 6.782 & 411.4 & 1655.7 & $15.42 \%$ & $27.49 \%$ & 2.080 & 0.861 & 1.115 & 0.911 & 0.571 \\
\hline 84.4 & 1.050 & 1.687 & 84.5 & 80.0 & $17.22 \%$ & $33.37 \%$ & 2.407 & 0.616 & 1.403 & 0.983 & 0.765 \\
\hline 82.0 & 1.049 & 1.650 & 80.4 & 26.0 & $19.73 \%$ & $42.18 \%$ & 2.969 & 0.611 & 1.865 & 0.984 & 0.811 \\
\hline 84.5 & 1.050 & 1.724 & 88.6 & 454.8 & $15.31 \%$ & $26.84 \%$ & 2.029 & 0.621 & 1.092 & 0.982 & 0.714 \\
\hline 84.5 & 1.050 & 1.748 & 90.5 & 784.6 & $14.76 \%$ & $25.86 \%$ & 2.014 & 0.625 & 1.056 & 0.982 & 0.724 \\
\hline 85.0 & 1.068 & 3.562 & 186.7 & 688.5 & $14.23 \%$ & $27.62 \%$ & 2.299 & 0.769 & 1.125 & 0.963 & 0.721 \\
\hline 83.6 & 1.067 & 3.489 & 178.7 & 157.3 & $16.08 \%$ & $34.72 \%$ & 2.776 & 0.766 & 1.427 & 0.965 & 0.779 \\
\hline 81.9 & 1.066 & 3.473 & 172.1 & 46.7 & $18.80 \%$ & $47.24 \%$ & 3.867 & 0.765 & 1.964 & 0.966 & 0.914 \\
\hline 83.2 & 1.067 & 3.541 & 186.8 & 1177.7 & $14.01 \%$ & $26.44 \%$ & 2.207 & 0.768 & 1.075 & 0.963 & 0.701 \\
\hline 84.5 & 1.092 & 6.834 & 363.5 & 1351.4 & $14.15 \%$ & $27.56 \%$ & 2.308 & 0.862 & 1.124 & 0.930 & 0.672 \\
\hline 83.0 & 1.092 & 6.797 & 353.2 & 343.7 & $15.73 \%$ & $34.04 \%$ & 2.765 & 0.862 & 1.395 & 0.931 & 0.729 \\
\hline 81.7 & 1.091 & 6.786 & 340.8 & 87.0 & $18.73 \%$ & $48.67 \%$ & 4.113 & 0.862 & 1.999 & 0.933 & 0.896 \\
\hline 81.9 & 3.477 & 6.554 & 346.2 & 1301.1 & $16.07 \%$ & $27.09 \%$ & 1.941 & 0.653 & 1.123 & 0.933 & 0.636 \\
\hline 83.4 & 3.481 & 5.017 & 262.3 & 1382.3 & $16.09 \%$ & $26.36 \%$ & 1.866 & 0.590 & 1.089 & 0.949 & 0.657 \\
\hline 84.8 & 3.486 & 5.045 & 257.7 & 229.5 & $17.84 \%$ & $32.43 \%$ & 2.211 & 0.591 & 1.423 & 0.950 & 0.701 \\
\hline
\end{tabular}


Table B.10. Separation results for IMTL membrane 1230530-89: 25\% Ar in He

\begin{tabular}{|c|c|c|c|c|c|c|c|c|c|c|c|}
\hline $\begin{array}{c}\mathrm{T} \\
\left({ }^{\circ} \mathrm{C}\right) \\
\end{array}$ & $\begin{array}{c}\mathrm{P}_{\mathrm{LO}} \\
\text { (bar) }\end{array}$ & $\begin{array}{c}\mathrm{dP} \\
\text { (bar) }\end{array}$ & $\begin{array}{c}\mathrm{F}_{\mathrm{LO}} \\
(\mathrm{sccm}) \\
\end{array}$ & $\begin{array}{c}\mathrm{F}_{\mathrm{HI}} \\
(\mathrm{sccm}) \\
\end{array}$ & $\begin{array}{c}\mathrm{X}_{\mathrm{LO}} \\
\text { (mol \% hvy) }\end{array}$ & $\begin{array}{c}\mathrm{X}_{\mathrm{HI}} \\
(\mathrm{mol} \% \text { hvy) }\end{array}$ & $\alpha$ & $\mathrm{E}_{\mathrm{P}}$ & $\mathrm{E}_{\mathrm{C}}$ & $\mathrm{E}_{\mathrm{M}}$ & $\mathrm{E}_{\mathrm{B}}$ \\
\hline 84.3 & 1.105 & 6.805 & 362.8 & 1287.4 & $14.39 \%$ & $27.99 \%$ & 2.311 & 0.860 & 1.129 & 0.930 & 0.672 \\
\hline 82.4 & 1.105 & 6.791 & 355.1 & 353.0 & $15.96 \%$ & $34.23 \%$ & 2.740 & 0.860 & 1.388 & 0.931 & 0.724 \\
\hline 81.7 & 1.104 & 6.775 & 338.7 & 72.2 & $19.49 \%$ & $52.23 \%$ & 4.516 & 0.860 & 2.110 & 0.934 & 0.960 \\
\hline 81.5 & 3.084 & 6.708 & 356.3 & 1294.5 & $15.96 \%$ & $27.57 \%$ & 2.005 & 0.685 & 1.126 & 0.931 & 0.647 \\
\hline 83.6 & 3.085 & 6.685 & 347.6 & 334.2 & $17.39 \%$ & $33.04 \%$ & 2.344 & 0.684 & 1.399 & 0.932 & 0.697 \\
\hline 84.2 & 3.084 & 6.133 & 334.7 & 97.7 & $20.01 \%$ & $43.85 \%$ & 3.123 & 0.665 & 1.922 & 0.935 & 0.821 \\
\hline 84.7 & 3.080 & 3.640 & 186.8 & 237.1 & $17.92 \%$ & $30.73 \%$ & 2.031 & 0.542 & 1.318 & 0.963 & 0.693 \\
\hline 84.7 & 3.080 & 3.682 & 190.5 & 757.3 & $16.75 \%$ & $27.14 \%$ & 1.851 & 0.545 & 1.116 & 0.962 & 0.673 \\
\hline 82.3 & 6.610 & 5.022 & 261.6 & 1046.2 & $18.35 \%$ & $26.72 \%$ & 1.623 & 0.432 & 1.116 & 0.949 & 0.630 \\
\hline 82.1 & 6.611 & 4.961 & 255.5 & 263.2 & $19.58 \%$ & $30.32 \%$ & 1.787 & 0.429 & 1.377 & 0.950 & 0.649 \\
\hline 85.0 & 6.611 & 4.946 & 249.5 & 117.2 & $20.84 \%$ & $34.13 \%$ & 1.968 & 0.428 & 1.677 & 0.951 & 0.656 \\
\hline 147.9 & 1.002 & 1.457 & 69.1 & 70.5 & $16.91 \%$ & $33.31 \%$ & 2.454 & 0.593 & 1.380 & 0.988 & 0.833 \\
\hline 144.7 & 1.002 & 1.497 & 73.6 & 606.4 & $14.78 \%$ & $26.34 \%$ & 2.062 & 0.599 & 1.058 & 0.987 & 0.785 \\
\hline 146.2 & 1.020 & 3.473 & 174.6 & 705.1 & $13.74 \%$ & $27.95 \%$ & 2.434 & 0.773 & 1.115 & 0.969 & 0.795 \\
\hline 148.6 & 1.019 & 3.417 & 166.7 & 165.6 & $15.55 \%$ & $34.96 \%$ & 2.920 & 0.770 & 1.388 & 0.970 & 0.856 \\
\hline 149.9 & 1.019 & 3.416 & 161.0 & 57.6 & $17.87 \%$ & $46.14 \%$ & 3.935 & 0.770 & 1.811 & 0.971 & 1.002 \\
\hline 150.1 & 1.050 & 6.884 & 349.8 & 1366.2 & $13.58 \%$ & $28.05 \%$ & 2.480 & 0.868 & 1.118 & 0.939 & 0.751 \\
\hline 151.2 & 1.050 & 6.864 & 339.9 & 340.1 & $15.26 \%$ & $35.07 \%$ & 2.999 & 0.867 & 1.386 & 0.941 & 0.817 \\
\hline 152.2 & 1.048 & 6.843 & 326.5 & 101.6 & $17.93 \%$ & $48.92 \%$ & 4.384 & 0.867 & 1.886 & 0.943 & 1.015 \\
\hline 150.6 & 3.426 & 3.508 & 170.7 & 645.0 & $16.69 \%$ & $27.29 \%$ & 1.873 & 0.506 & 1.122 & 0.970 & 0.734 \\
\hline 152.5 & 3.427 & 3.467 & 164.9 & 164.8 & $18.18 \%$ & $32.08 \%$ & 2.125 & 0.503 & 1.386 & 0.971 & 0.768 \\
\hline 151.3 & 3.432 & 6.711 & 336.4 & 1394.5 & $15.46 \%$ & $27.44 \%$ & 2.067 & 0.662 & 1.112 & 0.941 & 0.713 \\
\hline 150.7 & 3.435 & 6.662 & 327.2 & 349.8 & $16.89 \%$ & $32.84 \%$ & 2.406 & 0.660 & 1.366 & 0.943 & 0.765 \\
\hline 152.5 & 3.435 & 6.633 & 314.7 & 101.1 & $19.37 \%$ & $43.36 \%$ & 3.187 & 0.659 & 1.869 & 0.945 & 0.869 \\
\hline 150.9 & 6.720 & 4.810 & 235.2 & 1132.4 & $17.95 \%$ & $26.55 \%$ & 1.653 & 0.417 & 1.097 & 0.959 & 0.688 \\
\hline 150.9 & 6.721 & 4.769 & 229.4 & 236.2 & $19.22 \%$ & $30.64 \%$ & 1.856 & 0.415 & 1.377 & 0.960 & 0.722 \\
\hline 150.9 & 6.721 & 4.742 & 222.1 & 68.0 & $21.35 \%$ & $37.12 \%$ & 2.174 & 0.414 & 1.895 & 0.961 & 0.721 \\
\hline
\end{tabular}


Table B.11. Separation results for IMTL membrane 1230530-108: $25.00 \% \mathrm{CH}_{4}$ in $\mathrm{H}_{2}$

\begin{tabular}{|c|c|c|c|c|c|c|c|c|c|c|c|}
\hline $\begin{array}{c}\mathrm{T} \\
\left({ }^{\circ} \mathrm{C}\right) \\
\end{array}$ & $\begin{array}{c}\mathrm{P}_{\mathrm{LO}} \\
\text { (bar) }\end{array}$ & $\begin{array}{c}\mathrm{dP} \\
\text { (bar) }\end{array}$ & $\begin{array}{c}\mathrm{F}_{\mathrm{LO}} \\
(\mathrm{sccm}) \\
\end{array}$ & $\begin{array}{c}\mathrm{F}_{\mathrm{HI}} \\
(\mathrm{sccm}) \\
\end{array}$ & $\begin{array}{c}\mathrm{X}_{\mathrm{LO}} \\
\text { (mol \% hvy) }\end{array}$ & $\begin{array}{c}\mathrm{X}_{\mathrm{HI}} \\
\text { (mol \% hvy) }\end{array}$ & $\alpha$ & $\mathrm{E}_{\mathrm{P}}$ & $\mathrm{E}_{\mathrm{C}}$ & $\mathrm{E}_{\mathrm{M}}$ & $\mathrm{E}_{\mathrm{B}}$ \\
\hline 22.0 & 0.982 & 6.812 & 7.6 & 179.3 & $18.67 \%$ & $25.37 \%$ & 1.481 & 0.874 & 1.021 & 0.998 & 0.295 \\
\hline 22.2 & 3.277 & 6.924 & 8.7 & 176.9 & $19.91 \%$ & $25.23 \%$ & 1.358 & 0.679 & 1.024 & 0.998 & 0.282 \\
\hline 21.2 & 6.520 & 6.309 & 9.5 & 177.8 & $21.39 \%$ & $25.19 \%$ & 1.237 & 0.492 & 1.026 & 0.998 & 0.258 \\
\hline 95.1 & 0.992 & 6.569 & 7.0 & 77.9 & $17.45 \%$ & $25.68 \%$ & 1.635 & 0.869 & 1.044 & 0.999 & 0.384 \\
\hline 91.5 & 5.036 & 6.924 & 8.5 & 77.9 & $19.84 \%$ & $25.57 \%$ & 1.388 & 0.579 & 1.053 & 0.998 & 0.349 \\
\hline 148.5 & 4.197 & 6.875 & 7.4 & 173.9 & $17.99 \%$ & $25.29 \%$ & 1.543 & 0.621 & 1.021 & 0.999 & 0.469 \\
\hline 144.6 & 1.127 & 6.706 & 7.0 & 173.5 & $15.77 \%$ & $25.37 \%$ & 1.816 & 0.856 & 1.020 & 0.999 & 0.512 \\
\hline 209.1 & 0.995 & 6.831 & 10.7 & 171.4 & $12.47 \%$ & $25.76 \%$ & 2.435 & 0.873 & 1.031 & 0.998 & 0.874 \\
\hline
\end{tabular}

Table B.12. Separation results for IMTL membrane 1230530-108: $25.02 \% \mathrm{C}_{2} \mathrm{H}_{6}$ in $\mathrm{H}_{2}$

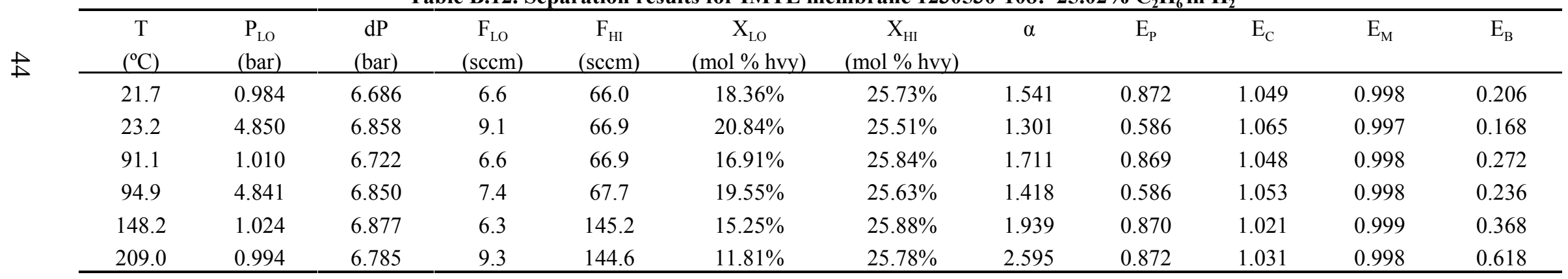


Table B.13. Separation results for IMTL membrane 1230530-108: $24.97 \% \mathrm{C}_{3} \mathrm{H}_{8}$ in $\mathrm{H}_{2}$

\begin{tabular}{|c|c|c|c|c|c|c|c|c|c|c|c|}
\hline $\begin{array}{c}\mathrm{T} \\
\left({ }^{\circ} \mathrm{C}\right) \\
\end{array}$ & $\begin{array}{c}\mathrm{P}_{\mathrm{LO}} \\
\text { (bar) }\end{array}$ & $\begin{array}{c}\mathrm{dP} \\
\text { (bar) }\end{array}$ & $\begin{array}{c}\mathrm{F}_{\mathrm{LO}} \\
(\mathrm{sccm})\end{array}$ & $\begin{array}{c}\mathrm{F}_{\mathrm{HI}} \\
(\mathrm{sccm}) \\
\end{array}$ & $\begin{array}{c}\mathrm{X}_{\mathrm{LO}} \\
\text { (mol \% hvy) }\end{array}$ & $\begin{array}{c}\mathrm{X}_{\mathrm{HI}} \\
\text { (mol \% hvy) }\end{array}$ & $\alpha$ & $\mathrm{E}_{\mathrm{P}}$ & $\mathrm{E}_{\mathrm{C}}$ & $\mathrm{E}_{\mathrm{M}}$ & $\mathrm{E}_{\mathrm{B}}$ \\
\hline 22.8 & 0.993 & 6.862 & 6.6 & 59.3 & $19.15 \%$ & $25.57 \%$ & 1.451 & 0.874 & 1.053 & 0.998 & 0.133 \\
\hline 150.9 & 1.005 & 6.778 & 6.0 & 126.9 & $14.51 \%$ & $25.47 \%$ & 2.013 & 0.871 & 1.023 & 0.998 & 0.309 \\
\hline 202.5 & 0.995 & 6.803 & 9.6 & 124.2 & $11.29 \%$ & $26.00 \%$ & 2.762 & 0.872 & 1.038 & 0.998 & 0.529 \\
\hline
\end{tabular}

Table B.14. Separation results for IMTL membrane 1230530-108: $25 \% \mathrm{CO}_{2}$ in $\mathrm{He}$

\begin{tabular}{|c|c|c|c|c|c|c|c|c|c|c|c|}
\hline $\begin{array}{c}\mathrm{T} \\
\left({ }^{\circ} \mathrm{C}\right) \\
\end{array}$ & $\begin{array}{l}\mathrm{P}_{\mathrm{LO}} \\
\text { (bar) }\end{array}$ & $\begin{array}{c}\mathrm{dP} \\
\text { (bar) }\end{array}$ & $\begin{array}{c}\mathrm{F}_{\mathrm{LO}} \\
(\mathrm{sccm}) \\
\end{array}$ & $\begin{array}{c}\mathrm{F}_{\mathrm{HI}} \\
(\mathrm{sccm}) \\
\end{array}$ & $\begin{array}{c}\mathrm{X}_{\mathrm{LO}} \\
(\mathrm{mol} \% \text { hvy })\end{array}$ & $\begin{array}{c}\mathrm{X}_{\mathrm{HI}} \\
(\mathrm{mol} \% \text { hvy) } \\
\end{array}$ & $\alpha$ & $\mathrm{E}_{\mathrm{P}}$ & $\mathrm{E}_{\mathrm{C}}$ & $\mathrm{E}_{\mathrm{M}}$ & $\mathrm{E}_{\mathrm{B}}$ \\
\hline 21.3 & 0.975 & 6.704 & 4.9 & 332.1 & $17.44 \%$ & $25.11 \%$ & 1.587 & 0.873 & 1.007 & 0.999 & 0.289 \\
\hline 89.8 & 1.256 & 6.733 & 5.9 & 214.4 & $15.04 \%$ & $25.22 \%$ & 1.904 & 0.843 & 1.014 & 0.999 & 0.458 \\
\hline 90.0 & 4.145 & 6.692 & 5.6 & 213.0 & $17.24 \%$ & $25.20 \%$ & 1.617 & 0.618 & 1.013 & 0.999 & 0.426 \\
\hline 151.2 & 4.654 & 6.798 & 5.1 & 213.7 & $15.35 \%$ & $25.25 \%$ & 1.863 & 0.594 & 1.012 & 0.999 & 0.621 \\
\hline 139.7 & 1.134 & 6.801 & 23.9 & 201.7 & $12.64 \%$ & $25.28 \%$ & 2.338 & 0.857 & 1.057 & 0.995 & 0.641 \\
\hline 196.6 & 0.994 & 6.839 & 6.7 & 214.2 & $10.49 \%$ & $25.40 \%$ & 2.904 & 0.873 & 1.015 & 0.999 & 0.928 \\
\hline
\end{tabular}

Table B.15. Separation results for IMTL membrane 1230530-108: $25 \% \mathrm{Ar}$ in He.

\begin{tabular}{|c|c|c|c|c|c|c|c|c|c|c|c|}
\hline $\begin{array}{c}\mathrm{T} \\
\left({ }^{\circ} \mathrm{C}\right) \\
\end{array}$ & $\begin{array}{c}\mathrm{P}_{\mathrm{LO}} \\
\text { (bar) }\end{array}$ & $\begin{array}{c}\mathrm{dP} \\
\text { (bar) }\end{array}$ & $\begin{array}{c}\mathrm{F}_{\mathrm{LO}} \\
(\mathrm{sccm})\end{array}$ & $\begin{array}{c}\mathrm{F}_{\mathrm{HI}} \\
(\mathrm{sccm}) \\
\end{array}$ & $\begin{array}{c}\mathrm{X}_{\mathrm{LO}} \\
\text { (mol \% hvy) }\end{array}$ & $\begin{array}{c}\mathrm{X}_{\mathrm{HI}} \\
\text { (mol \% hvy) }\end{array}$ & $\alpha$ & $\mathrm{E}_{\mathrm{P}}$ & $\mathrm{E}_{\mathrm{C}}$ & $\mathrm{E}_{\mathrm{M}}$ & $\mathrm{E}_{\mathrm{B}}$ \\
\hline 21.6 & 4.612 & 6.837 & 5.9 & 404.0 & $18.72 \%$ & $25.09 \%$ & 1.454 & 0.597 & 1.007 & 0.999 & 0.350 \\
\hline 21.8 & 1.104 & 6.746 & 4.9 & 404.6 & $16.21 \%$ & $25.11 \%$ & 1.732 & 0.859 & 1.006 & 0.999 & 0.392 \\
\hline 90.1 & 4.973 & 6.428 & 5.9 & 262.9 & $16.74 \%$ & $25.19 \%$ & 1.674 & 0.564 & 1.011 & 0.999 & 0.548 \\
\hline 90.1 & 1.165 & 6.784 & 6.6 & 263.9 & $14.07 \%$ & $25.18 \%$ & 2.055 & 0.853 & 1.012 & 0.999 & 0.566 \\
\hline 148.6 & 4.752 & 6.620 & 5.6 & 262.2 & $14.24 \%$ & $25.23 \%$ & 2.032 & 0.582 & 1.011 & 0.999 & 0.812 \\
\hline 149.7 & 1.036 & 6.759 & 5.5 & 262.1 & $11.49 \%$ & $25.28 \%$ & 2.607 & 0.867 & 1.010 & 0.999 & 0.849 \\
\hline 209.2 & 0.993 & 6.531 & 8.3 & 10.3 & $11.70 \%$ & $35.75 \%$ & 4.200 & 0.868 & 1.325 & 0.999 & 1.289 \\
\hline 198.5 & 0.995 & 6.818 & 10.1 & 259.1 & $8.93 \%$ & $25.57 \%$ & 3.502 & 0.873 & 1.019 & 0.998 & 1.303 \\
\hline
\end{tabular}




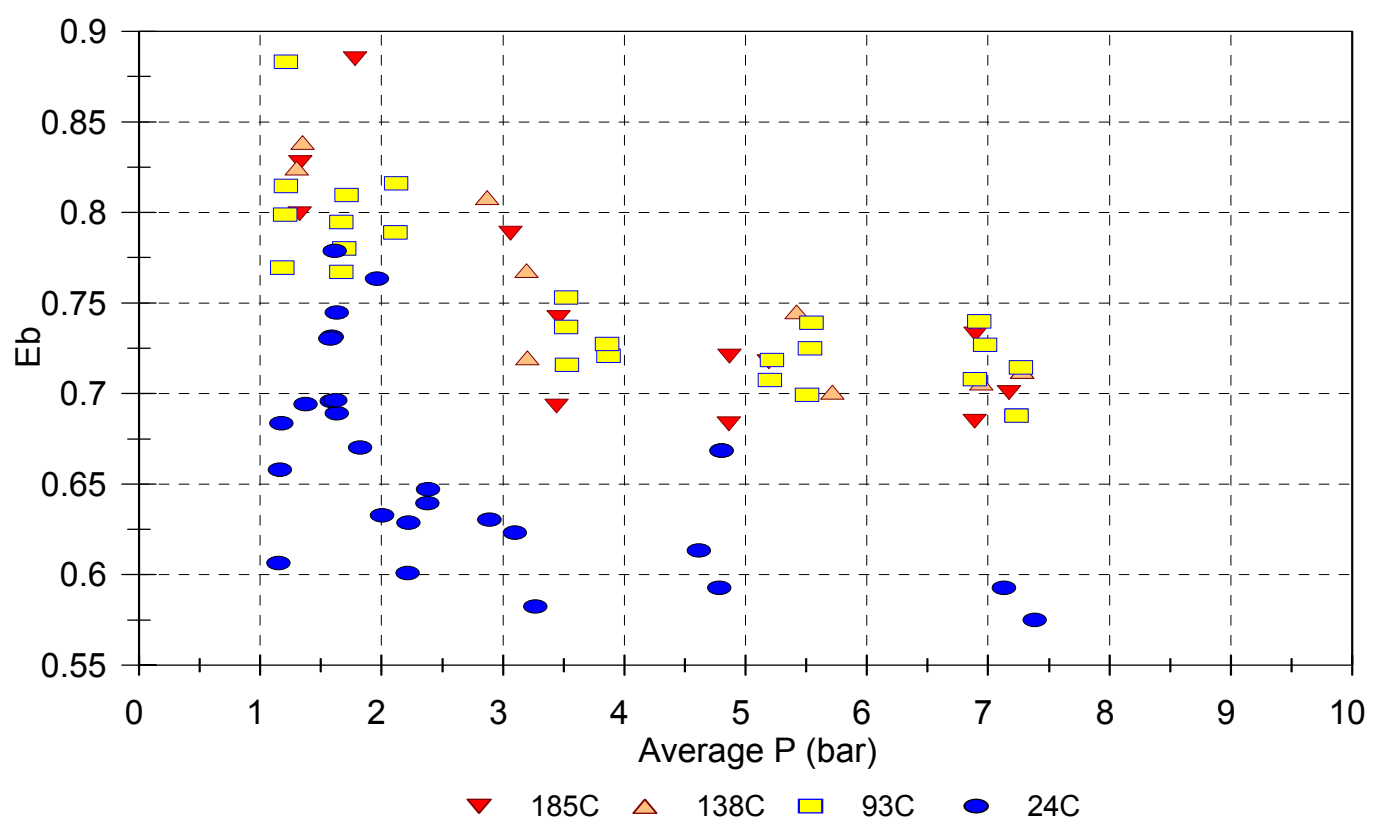

Fig. B.1. Membrane efficiency vs average pressure: Membrane 1226678-1-1, 25\% $\mathrm{CH}_{4}$ in $\mathrm{H}_{2}$.

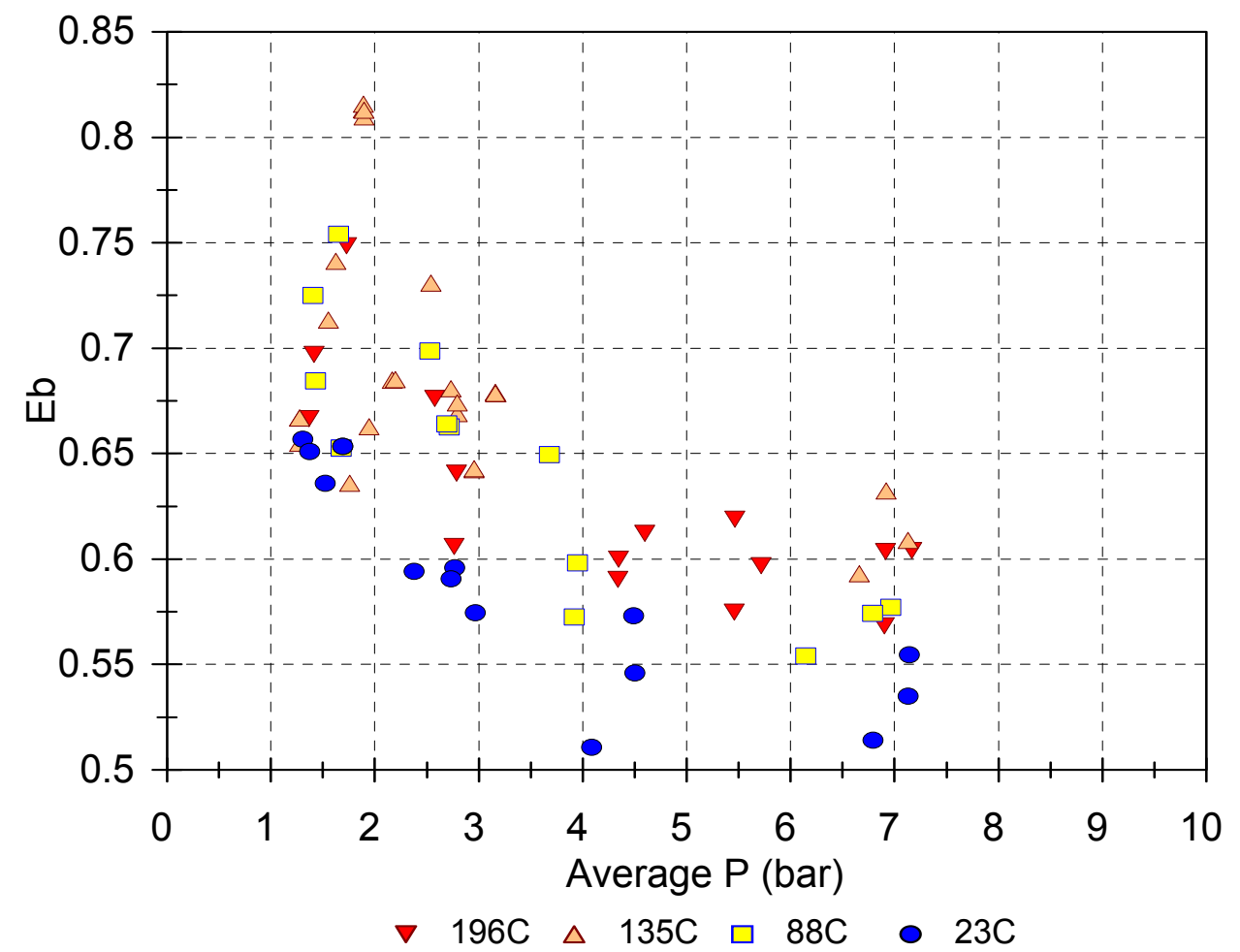

Fig. B.2. Membrane efficiency vs average pressure: Membrane 1226678-1-1, $25.02 \% \mathrm{C}_{2} \mathrm{H}_{6}$ in $\mathrm{H}_{2}$. 


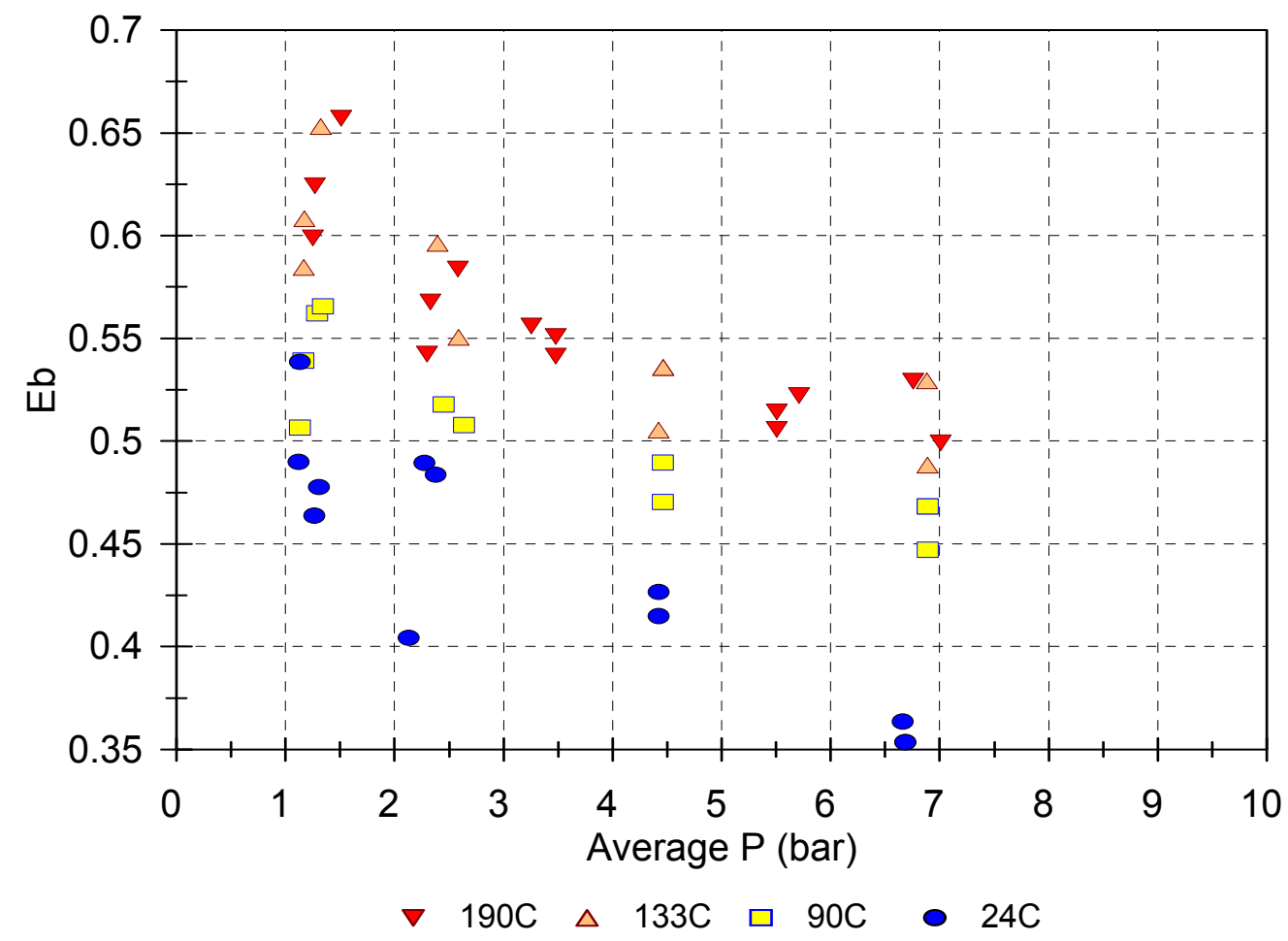

Fig. B.3. Membrane efficiency vs average pressure: Membrane 1226678-1-1, 24.97\% $\mathrm{C}_{3} \mathrm{H}_{8}$ in $\mathrm{H}_{2}$.

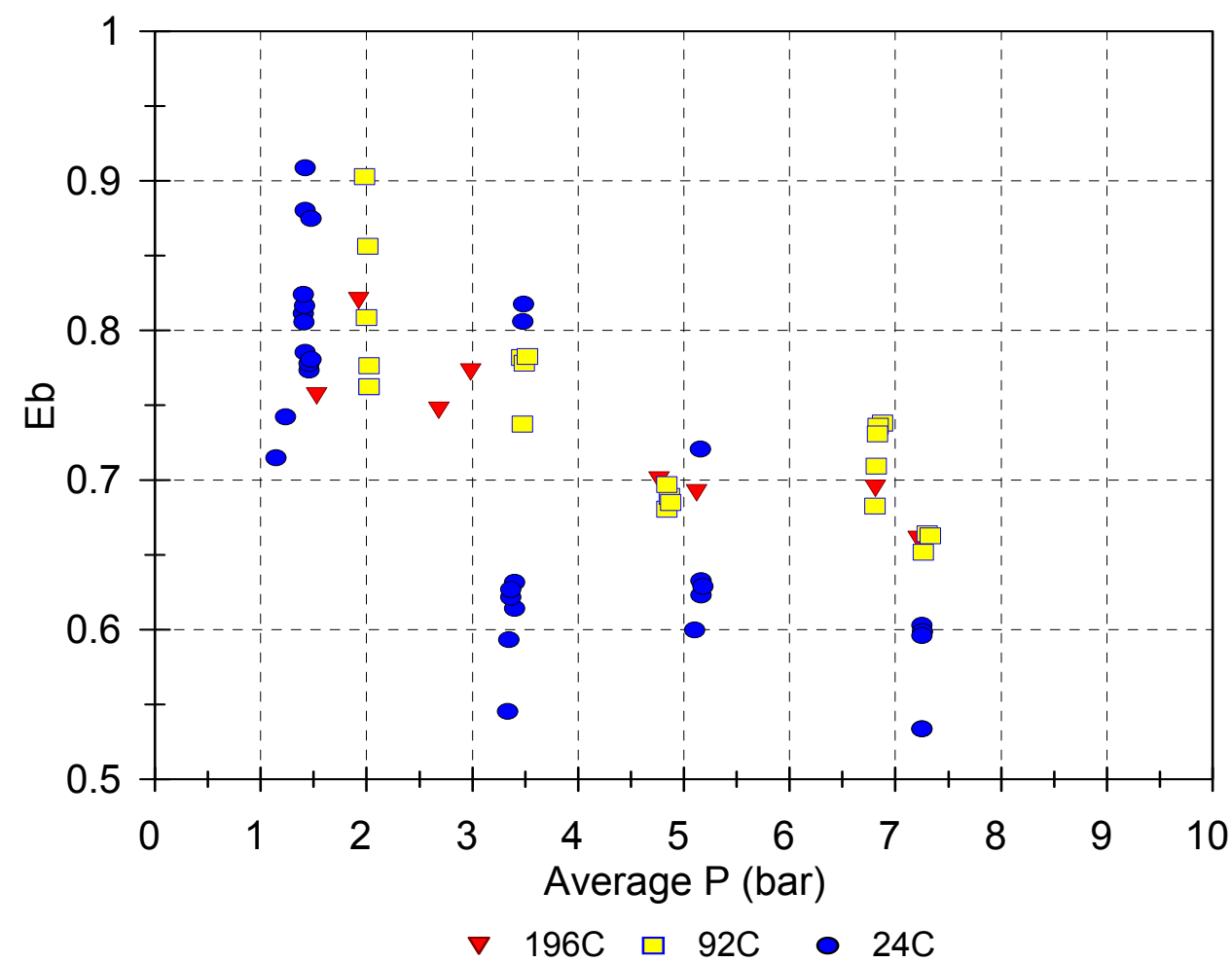

Fig. B.4. Membrane efficiency vs average pressure: Membrane 1226678-1-1, 25\% $\mathrm{CO}_{2}$ in $\mathrm{He}$. 


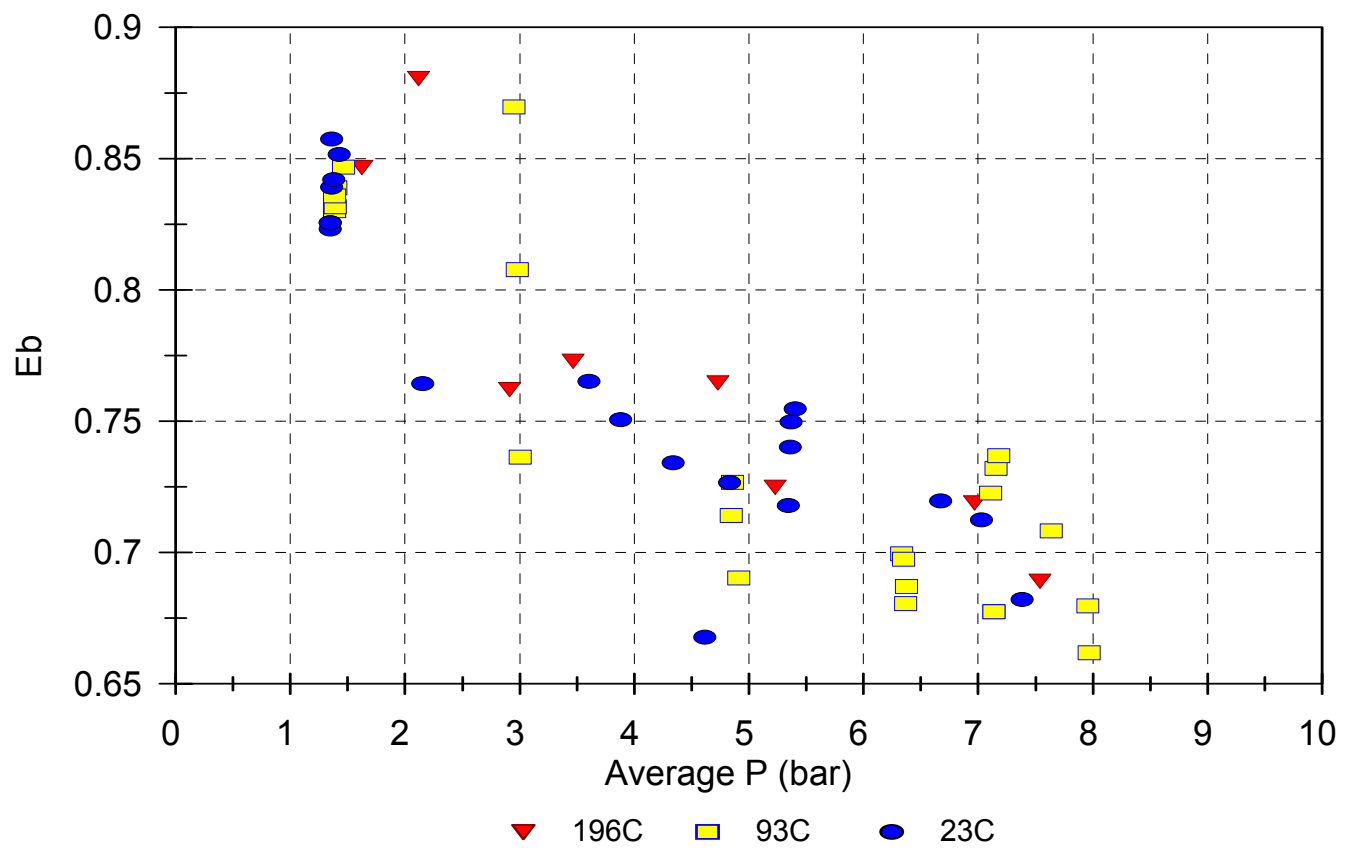

Fig. B.5. Membrane efficiency vs average pressure: Membrane 1226678-1-1, 25\% Ar in He.

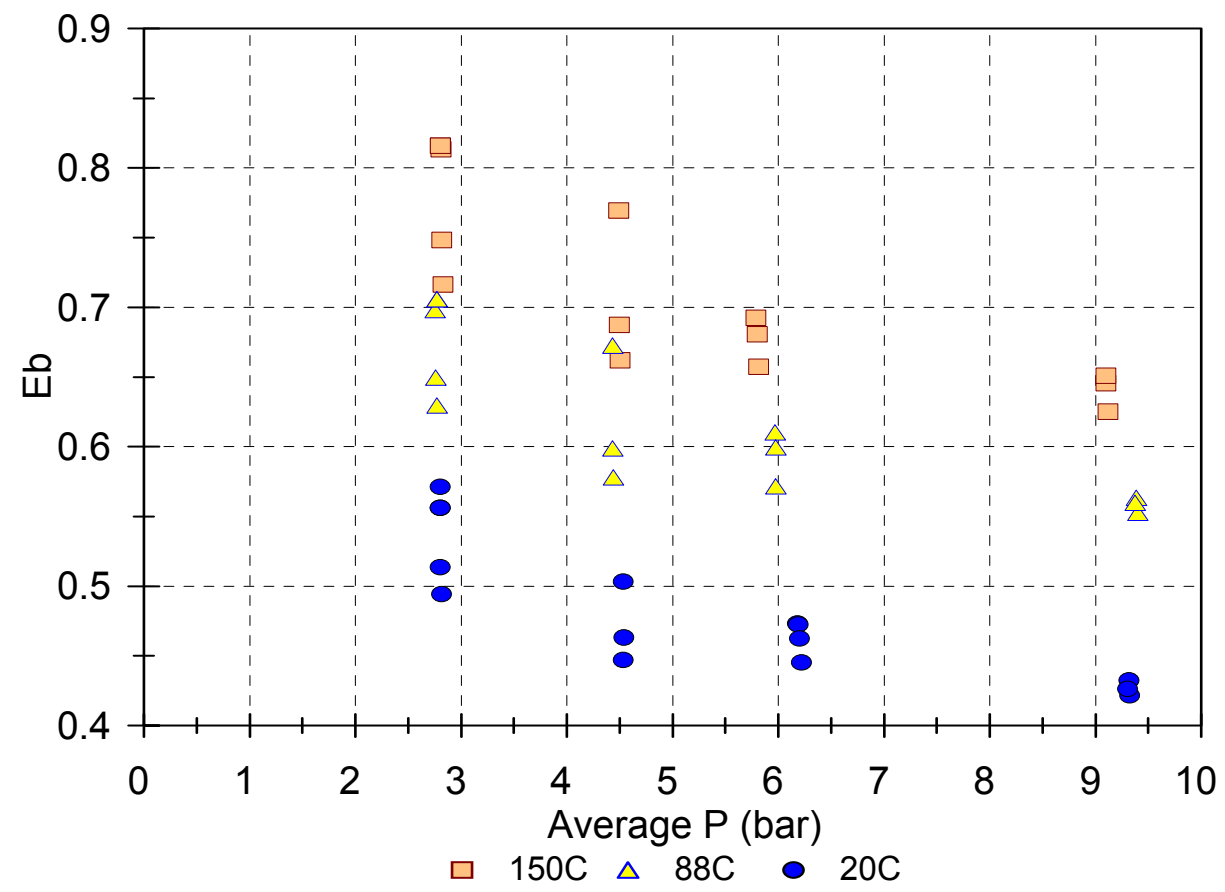

Fig. B.6. Membrane efficiency vs average pressure: Membrane $1230530-89,25 \% \mathrm{CH}_{4}$ in $\mathrm{H}_{2}$. 


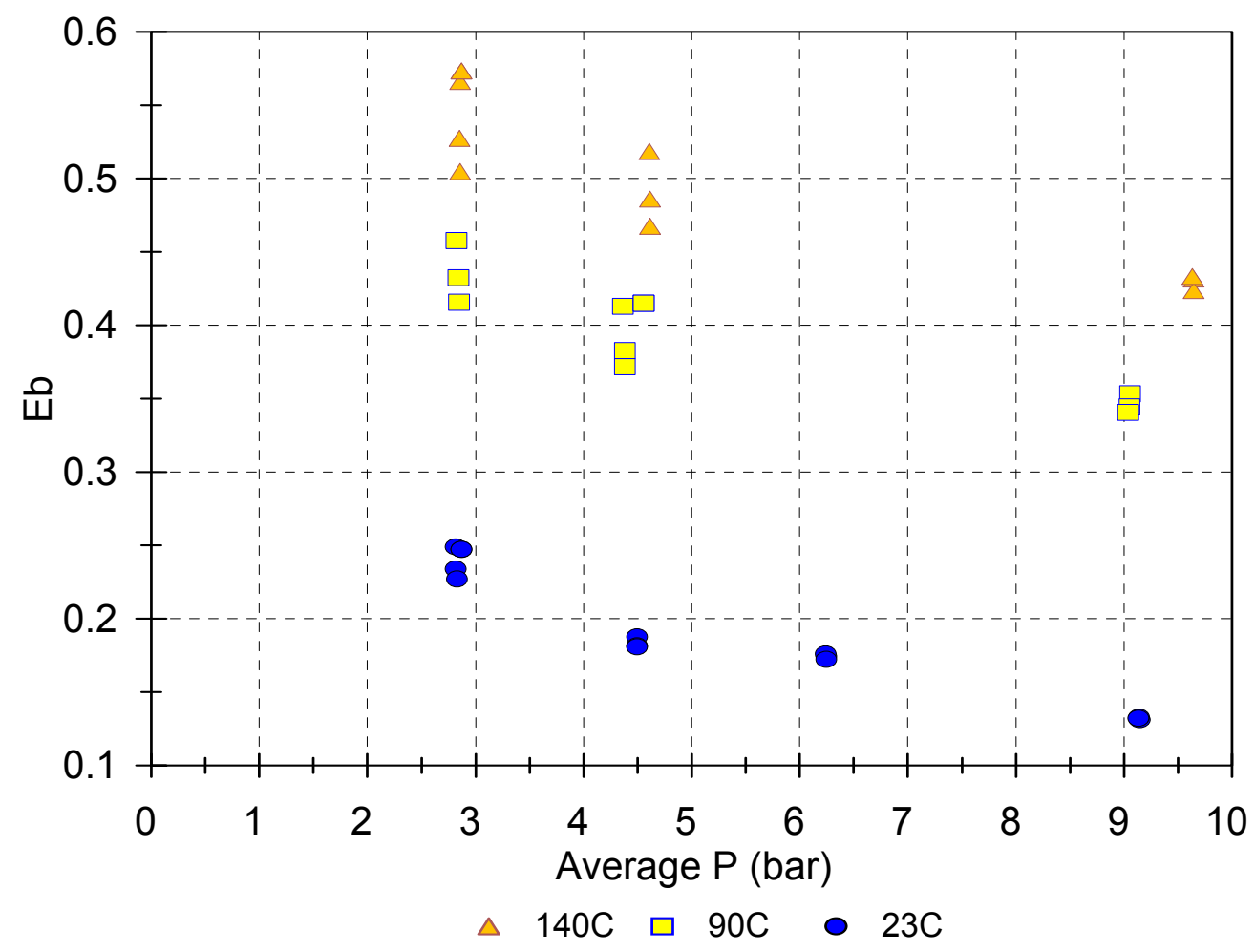

Fig. B.7. Membrane efficiency vs average pressure: Membrane 1230530-89, $25.02 \%$ $\mathrm{C}_{2} \mathrm{H}_{6}$ in $\mathrm{H}_{2}$.

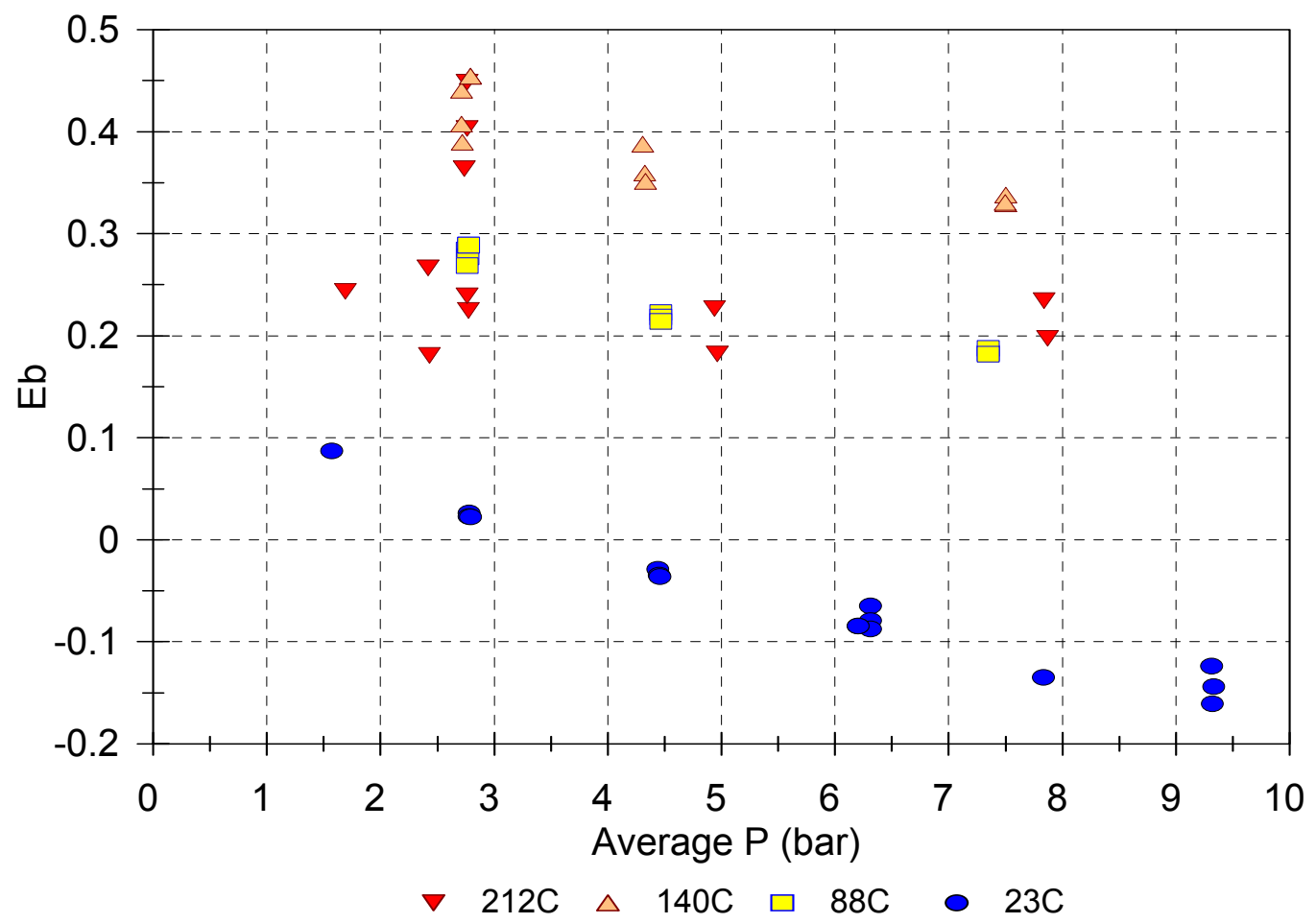

Fig. B.8. Membrane efficiency vs average pressure: Membrane 1230530-89, 24.97\% $\mathrm{C}_{3} \mathrm{H}_{8}$ in $\mathbf{H}_{2}$. 


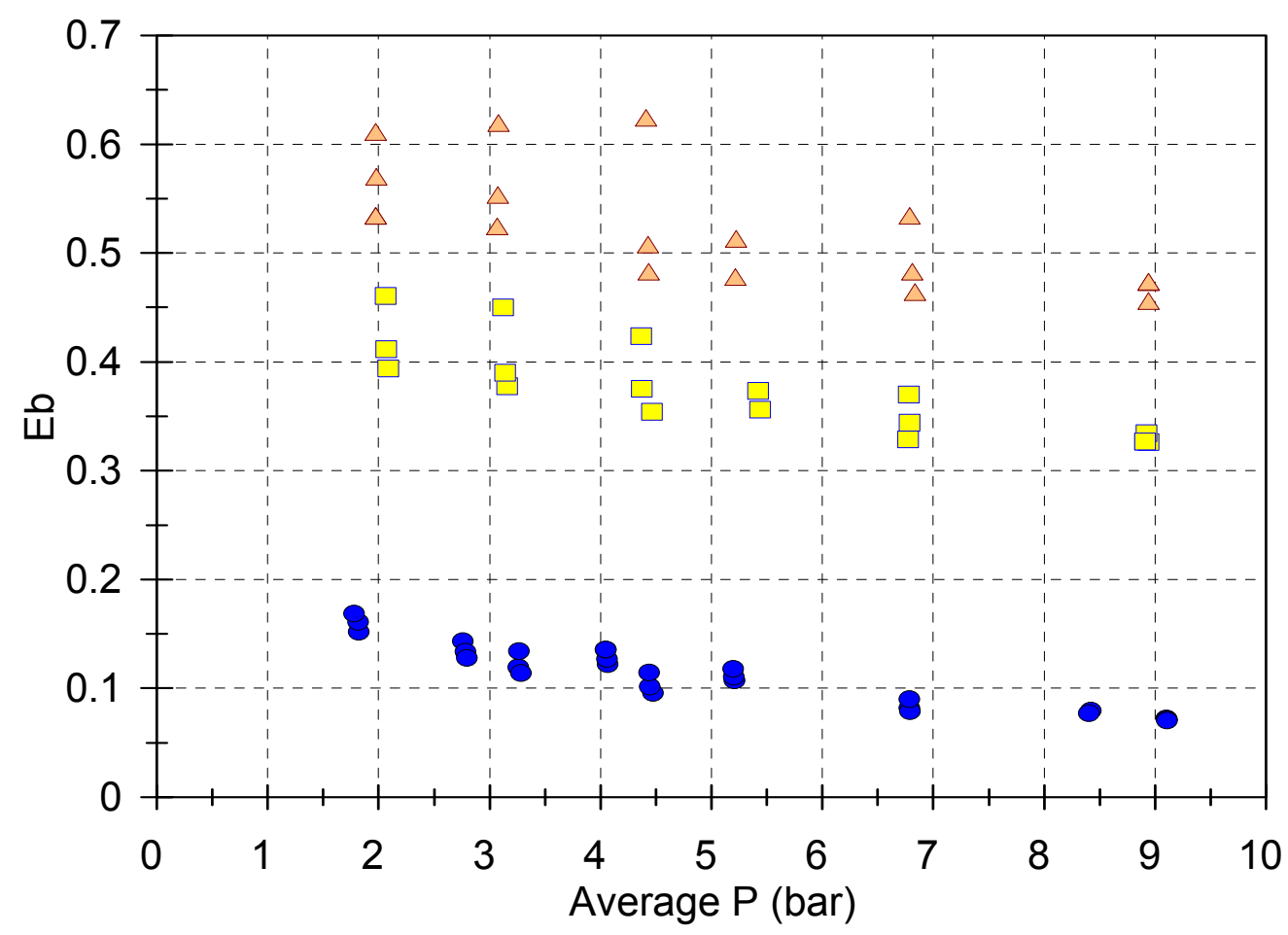

$\triangle 146 \mathrm{C} \quad \square \quad 88 \mathrm{C} \quad 02 \mathrm{C}$

Fig. B.9. Membrane efficiency vs average pressure: Membrane 1230530-89, 25\% $\mathrm{CO}_{2}$ in He.

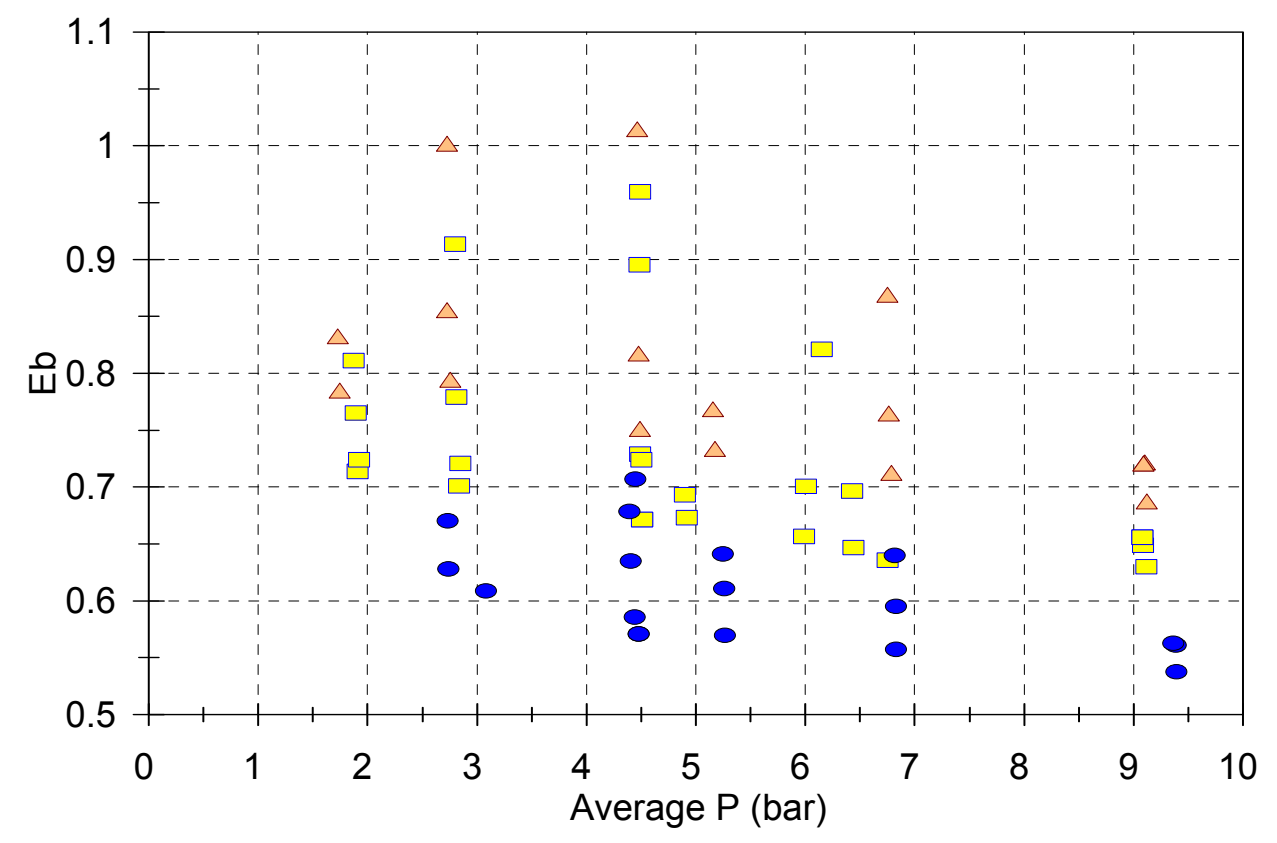

$\triangle 150 \mathrm{C} \square 83 \mathrm{C} \bullet 24 \mathrm{C}$

Fig. B.10. Membrane efficiency vs average pressure: Membrane 1230530-89, 25\% Ar in He. 


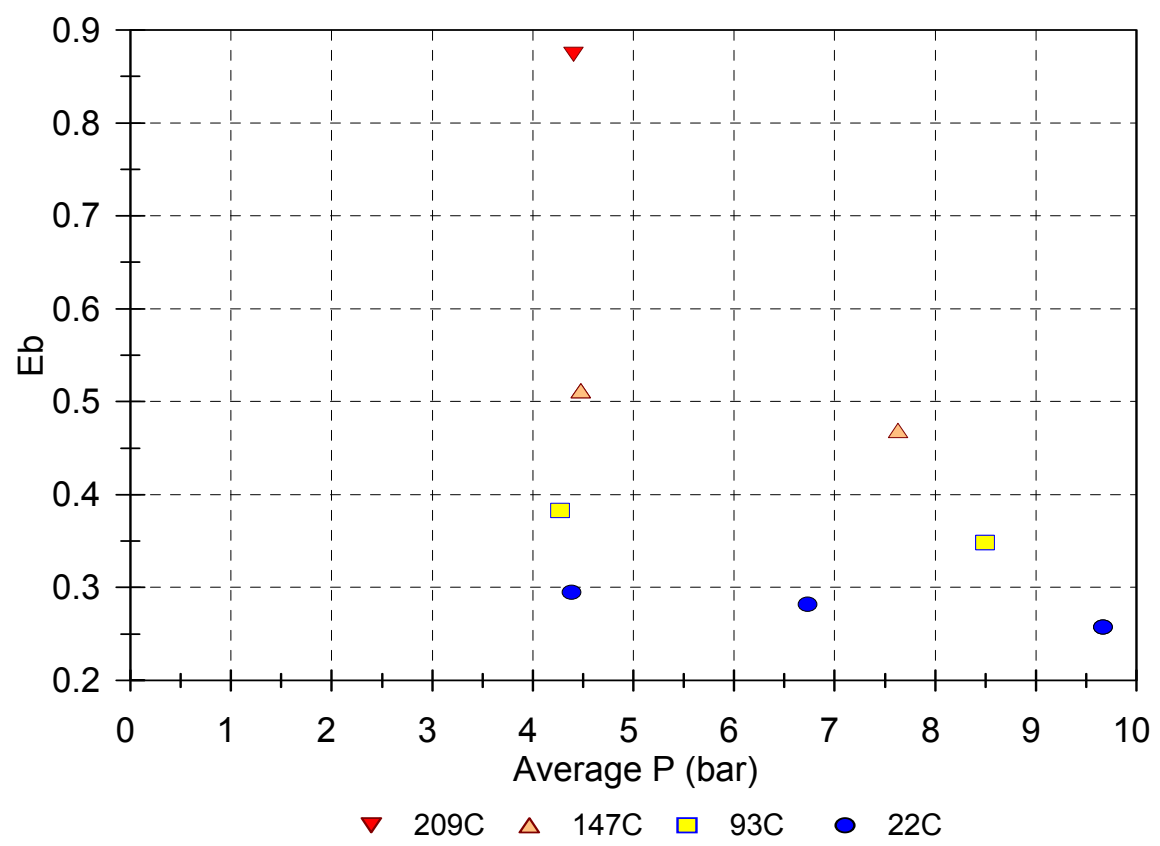

Fig. B.11. Membrane efficiency vs average pressure: Membrane 1230530-108, 25\% $\mathrm{CH}_{4}$ in $\mathrm{H}_{2}$.

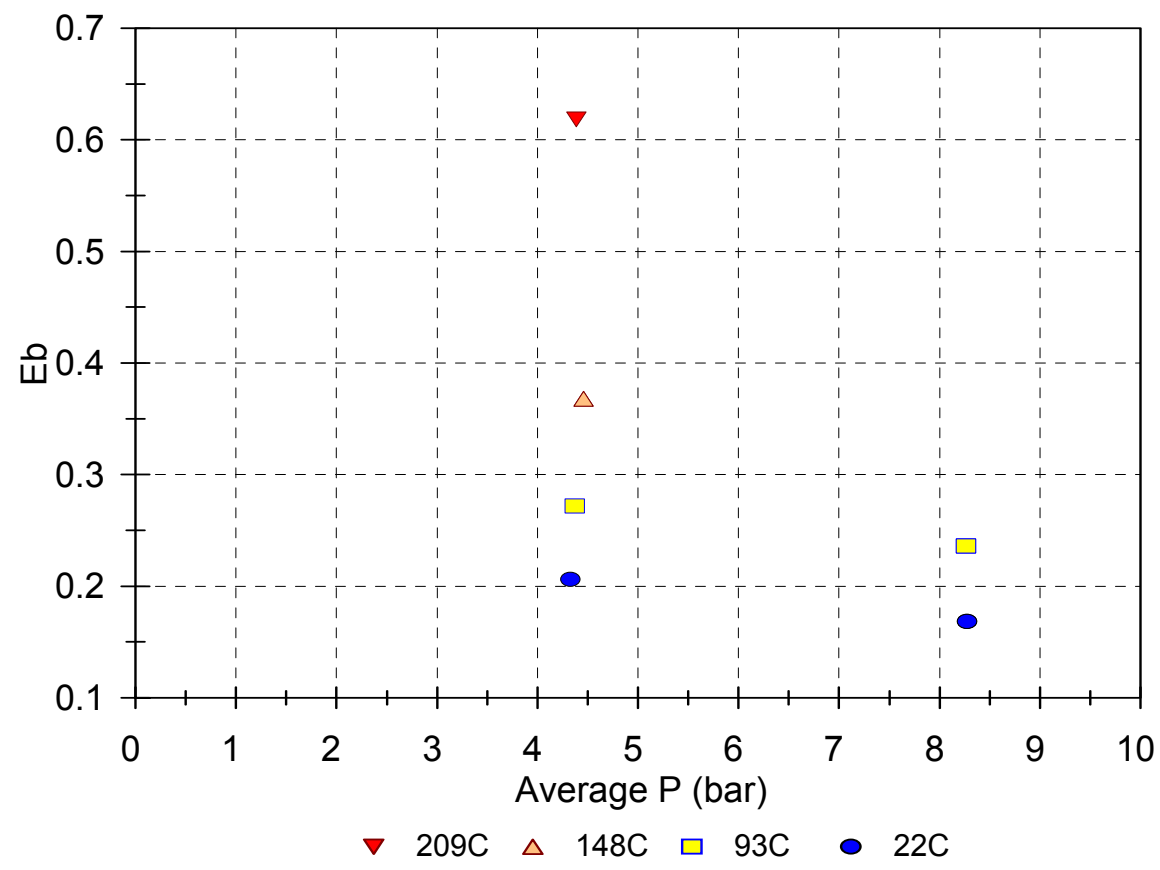

Fig. B.12. Membrane efficiency vs average pressure: Membrane 1230530-108, 25.02\% $\mathrm{C}_{2} \mathrm{H}_{6}$ in $\mathrm{H}_{2}$. 


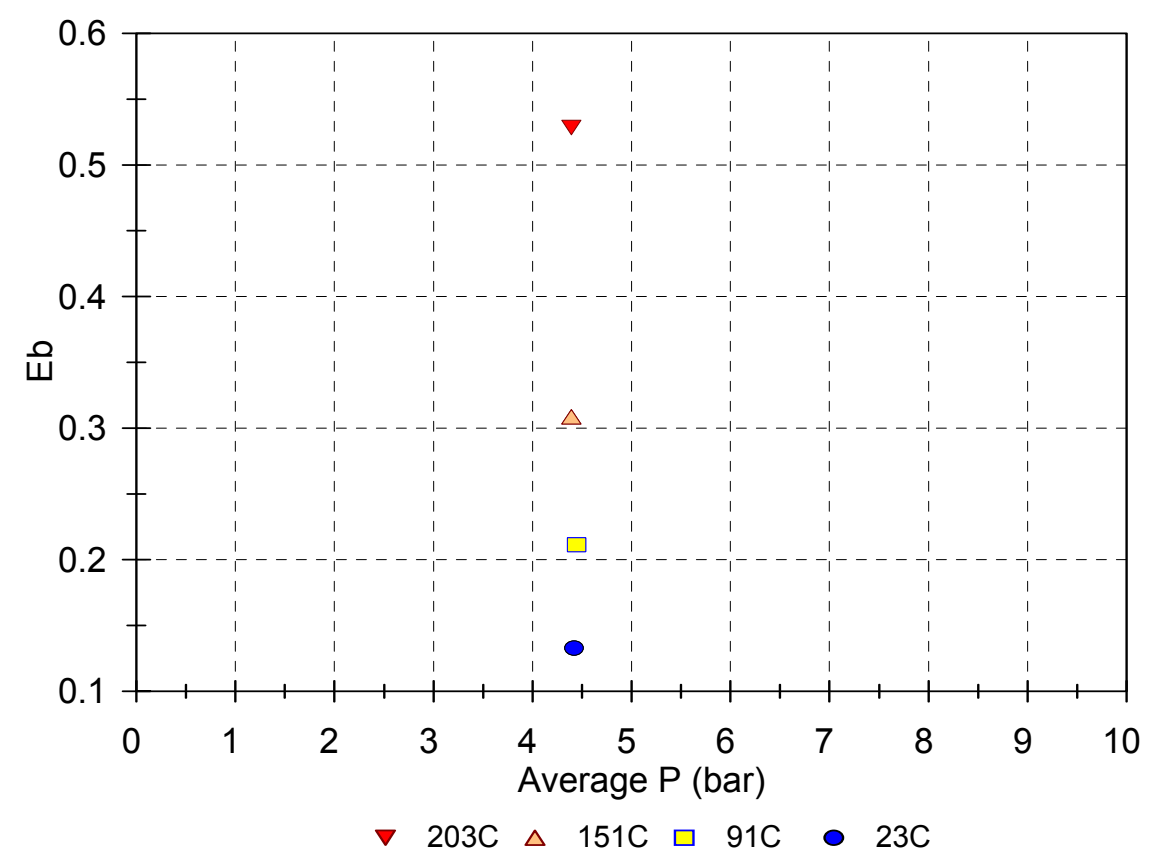

Fig. B.13. Membrane efficiency vs average pressure: Membrane 1230530-108, 24.97\% $\mathrm{C}_{3} \mathrm{H}_{8}$ in $\mathrm{H}_{2}$.

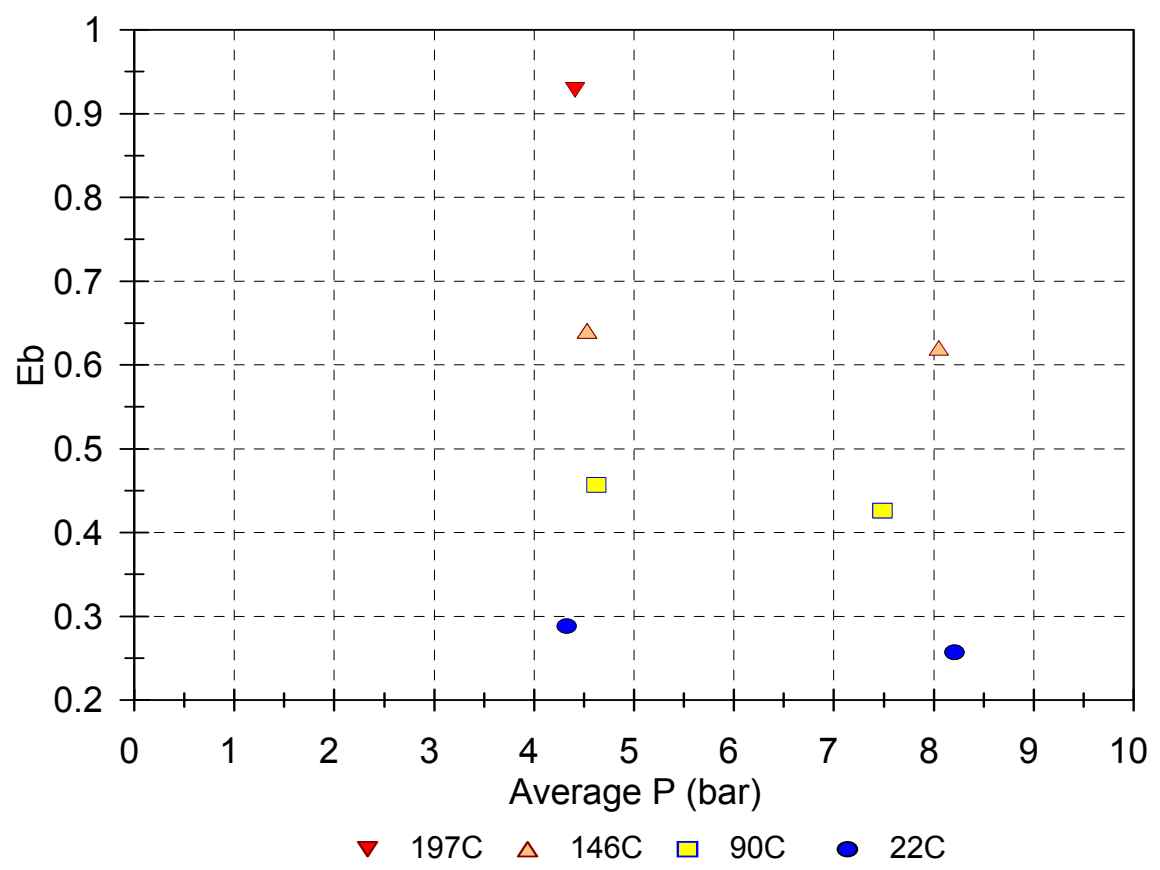

Fig. B.14. Membrane efficiency vs average pressure: Membrane $1230530-108,25 \% \mathrm{CO}_{2}$ in $\mathrm{He}$. 


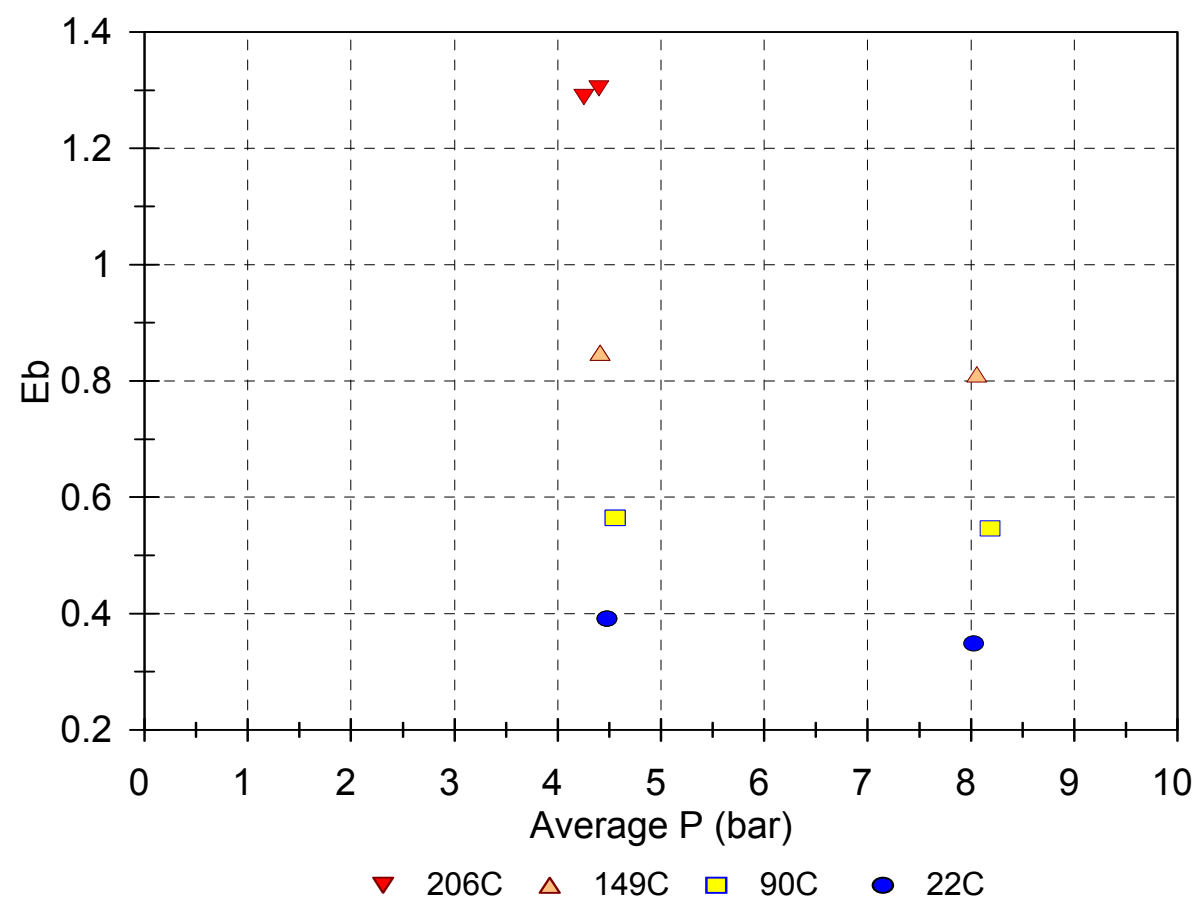

Fig. B.15. Membrane efficiency vs average pressure: Membrane 1230530-108, $25 \%$ Ar in He. 

ORNL/TM-2003/139

\section{INTERNAL DISTRIBUTION}

1. K. D. Adcock

2. T.R. Armstrong

3. B.L. Bischoff

4. G.D. Del Cul

5. D.E. Fain

6. C.W. Forsberg

7. R. G. Gilliland

8. D. J. Hill

9. A. S. Icenhour

10. R. R. Judkins
11 J. B. Knauer

12. L. K. Mansur

13. S. C. Marschman

14. B. B. Marshall

15. L. E. Powell

16. L. M. Toth

17-27. L. D. Trowbridge

28. D. F. Williams

29. Central Research Library

30. ORNL Laboratory Records-RC

\section{EXTERNAL DISTRIBUTION}

31. K. Sterling, NPTO/DOE 1 West $3^{\text {rd }}$ St., Tulsa, OK 74103

32. F. D. Sutterfield, NPTO/DOE, 1 West $3^{\text {rd }}$ St., Tulsa OK 74103

33. R. G. Shong, Chevron Texaco, 3901 Briarpark, Houston, TX 77042

34. E. W. Corcoran, ExxonMobil, 1545 Rt. 22E, Annandale, NJ 08801

35. J. E. Johnson, ExxonMobil, 1545 Rt. 22E, Annandale, NJ 08801

36. T. J. Mazanec, BP Amoco Chemicals, 150 W. Warrenville Rd., P.O. Box 3011, MC H-5, Napierville, IL 60566-7011

37. R. Paul, ConocoPhillips, 131AL Phillips R\&D, Bartlesville, OK 74004 